WALDEN

UNIVERSITY

A higher degree. $A$ higher purpose.

Walden University

ScholarWorks

Walden Dissertations and Doctoral Studies

Walden Dissertations and Doctoral Studies

Collection

2015

\title{
Southeastern United States' Parental Perspectives to Promote Adolescent Sleep Health
}

Steven Mark Tompa

Walden University

Follow this and additional works at: https://scholarworks.waldenu.edu/dissertations

Part of the Higher Education Administration Commons, Higher Education and Teaching Commons, and the Medicine and Health Sciences Commons

This Dissertation is brought to you for free and open access by the Walden Dissertations and Doctoral Studies Collection at ScholarWorks. It has been accepted for inclusion in Walden Dissertations and Doctoral Studies by an authorized administrator of ScholarWorks. For more information, please contact ScholarWorks@waldenu.edu. 


\title{
Walden University
}

\author{
College of Health Sciences
}

This is to certify that the doctoral dissertation by

\author{
Steven Mark Tompa
}

has been found to be complete and satisfactory in all respects, and that any and all revisions required by the review committee have been made.

\section{Review Committee}

Dr. Earla White, Committee Chairperson, Health Services Faculty Dr. Jennifer Oliphant, Committee Member, Health Services Faculty Dr. Suzanne Richins, University Reviewer, Health Services Faculty

Chief Academic Officer

Eric Riedel, Ph.D.

Walden University

2015 


\begin{abstract}
Southeastern United States' Parental Perspectives to Promote Adolescent Sleep Health by

Steven Mark Tompa
\end{abstract}

MA, West Virginia University, 2002

BA, West Virginia University, 1993

\author{
Dissertation Submitted in Partial Fulfillment \\ of the Requirements for the Degree of \\ Doctor of Philosophy \\ Health Services
}

Walden University

November 2015 


\begin{abstract}
Many U.S. adolescents suffer from sleep disorders. Although poor sleep habits may contribute to health issues, less is known about how parental perspectives influence sleep health in adolescents. The purpose of this descriptive phenomenological study was to address a knowledge gap in understanding parental views to promote better sleep habits in adolescents. The blended theoretical framework included the theories of caring science, social learning, advocacy paradigm, and repair and restoration of sleep. Twenty parents in the Southeastern United States participated in open-ended interviews. Research questions were designed to elicit parental perspectives about recognizing unhealthy sleep habits, improving daily sleep health routines, and identifying conditions that led to consultation with health professionals. Colaizzi's data analysis strategy demonstrated thematic parental reports of declines in attitudes, behaviors, and performances as factors for recognizing unhealthy sleep habits; consistent and routine schedules as options for promoting improved sleep habits; and irregular sleep or health problems as reasons for consultation with health professionals. Recommendations for future research include exploring other geographical locations and investigating school bus schedules interfering with early morning sleep loss. To affect positive social change, dissemination of this study's findings to health practitioners may influence enhanced provider-patient communications and ultimately contribute to improved sleep habits among adolescents. Additionally, this study's findings may inform health care administrators with strategies to develop effective parent and provider education programs while reducing unnecessary health services' utilization and resulting costs for adolescent health.
\end{abstract}


Southeastern United States' Parental Perspectives to Promote Adolescent Sleep Health by

Steven Mark Tompa

MA, West Virginia University, 2002

BA, West Virginia University, 1993

\author{
Dissertation Submitted in Partial Fulfillment \\ of the Requirements for the Degree of \\ Doctor of Philosophy \\ Health Services
}

Walden University

November 2015 


\section{Dedication}

I dedicate my dissertation to the following organizations: American Association of Sleep Technologists, American Board of Sleep Medicine, Board of Polysomnographic Technologists, Centers for Disease Control and Prevention, Children's Sleep Charity, Sleep Research Society, National Healthy Sleep Awareness Project, Society for Adolescent Health and Medicine, United Nations International Children's Emergency Fund, U.S. Department of Health and Human Services, Virginia Academy of Sleep Medicine, and Virginia Board of Medicine. I thank each of these organizations for their expertise in their domain of sleep medicine and their dedication to advocacy for adolescent health saving lives, improving overall health, and making the world better for adolescents. 


\section{Acknowledgments}

Successfully completing a dissertation, undoubtedly, generates a need for the doctoral student to acknowledge their deepest gratitude to all who provided support during each step of the arduous journey. I am forever grateful to Dr. Earla White, with her background in health informatics and high expectations as my doctoral chair. I also wish to acknowledge my committee member, Dr. Jennifer Oliphant, for your background in adolescent health and believing in me from the beginning of my doctoral studies. I am appreciative to Dr. Carol Lieberman for her initial guidance as my chair. I also wish to thank my university research reviewer Dr. Suzanne Richins, my research coordinator and program director interim Dr. Tammy Root, and my program director Dr. Stephen Bowman for their commitment in overseeing this capstone intensive research.

I experienced a superb introduction to the science of sleep from instructors Joe and Candace Anderson and Debbie Akers with Priority Health Education. I am grateful to medical director Dr. Tom Bond and sleep manager Marci Fiske for providing my initial clinic experience at Riverside Neurology and Sleep Specialists. I am further grateful to medical director Dr. Vandana Dhawan and sleep technical director Mary Jane Kenrick for my continued clinical growth at Bayview Pulmonary Medicine and Sleep Specialists.

During all of this, I was blessed with love from my wonderful parents Emily and Steve, my brother Tony, and my aunts Martha and Patsy. In addition, I am thankful to Rob Asbury for his constant motivation and encouragement to include cardio, jogging, and exercise in my daily routine. His words of motivation are, "running makes the heart strong, the brain focused, allows the body to sleep well, and promotes healthy life." 


\section{Table of Contents}

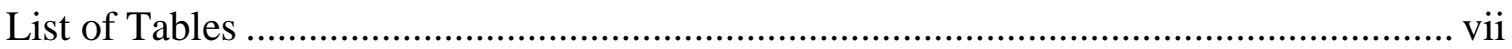

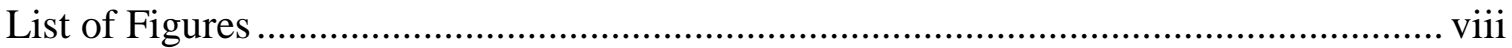

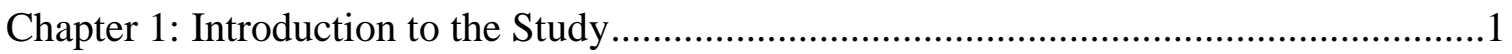

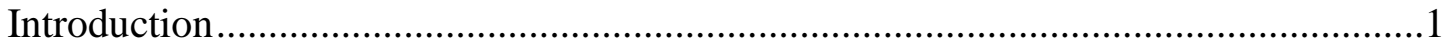

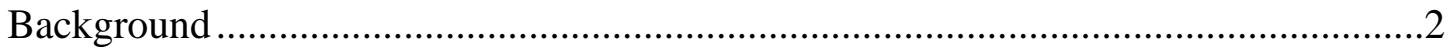

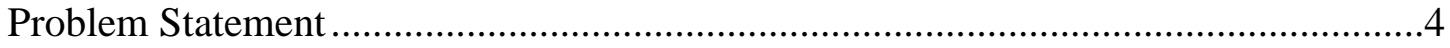

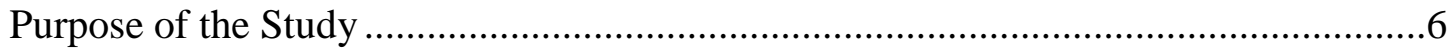

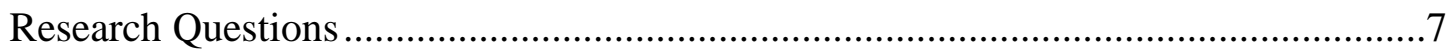

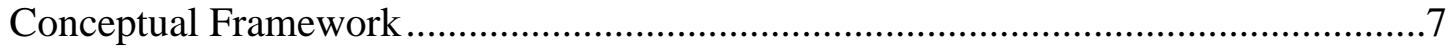

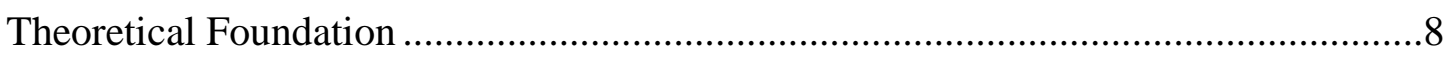

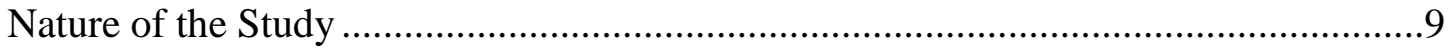

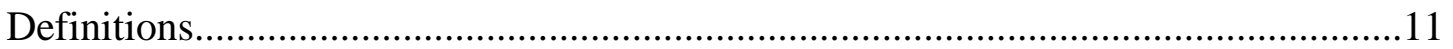

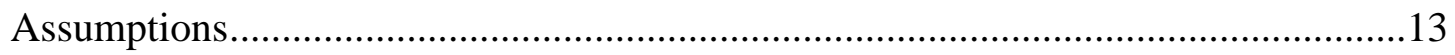

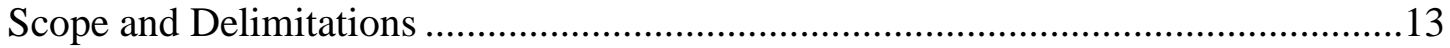

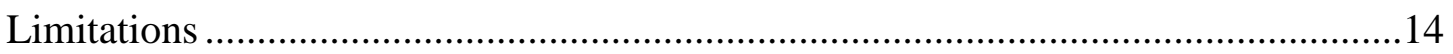

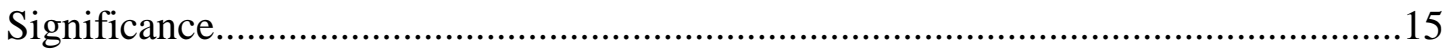

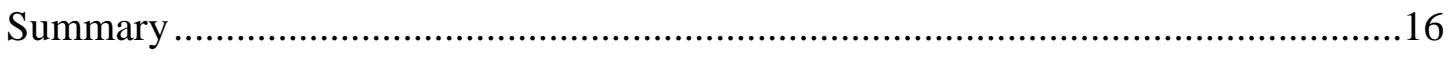

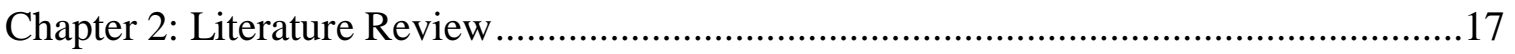

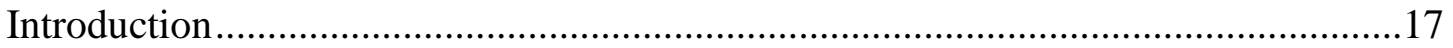

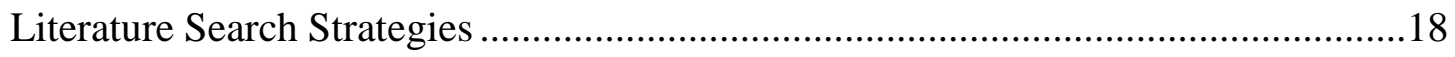




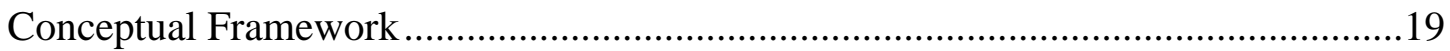

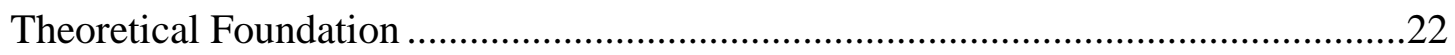

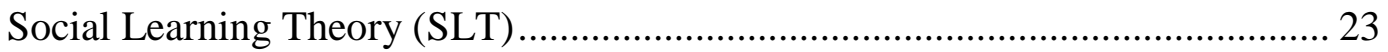

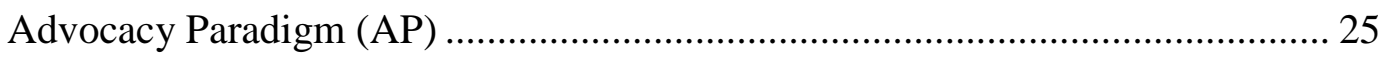

Repair and Restoration Theory of Sleep (RRTS) ……….................................. 27

Theory of Caring Science (TCS) .................................................................. 29

Prominent Research Concepts ...............................................................................31

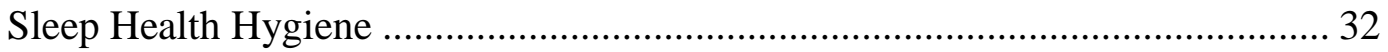

Adolescent Sleep Statistics ........................................................................... 33

Understanding the Importance of Adolescent Sleep Health ................................. 34

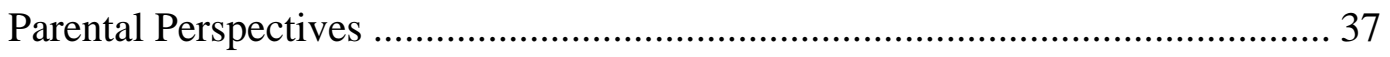

Parental Promotion and Influence...................................................................... 39

Parental Recognition, Knowledge, and Understanding ...................................... 40

Effects and Consequences of Inadequate Sleep ................................................... 42

Health Professional Influence ......................................................................... 43

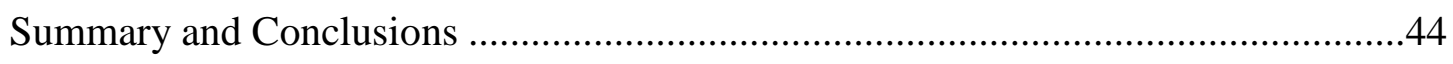

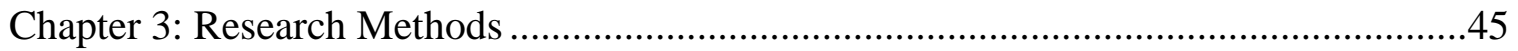

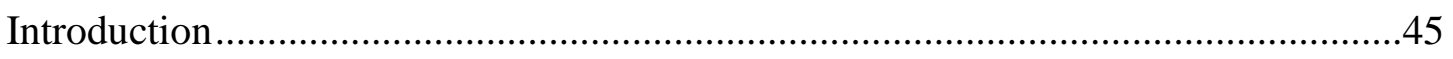

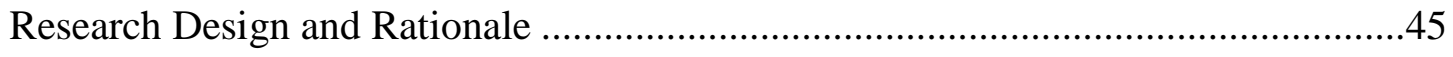

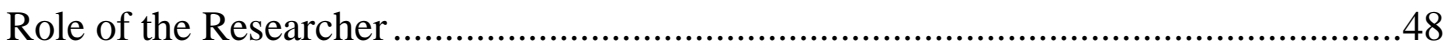

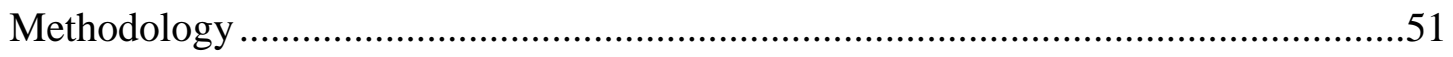




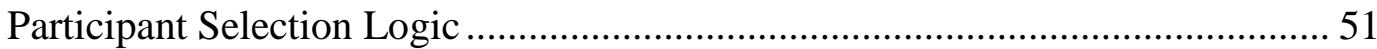

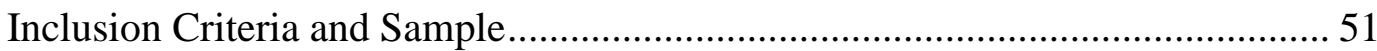

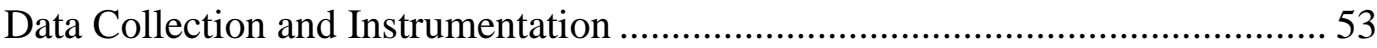

Procedures for Pilot Study ............................................................................ 54

Procedures for Recruitment, Participation, and Data Collection .......................... 55

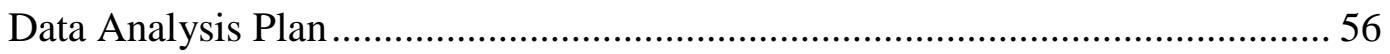

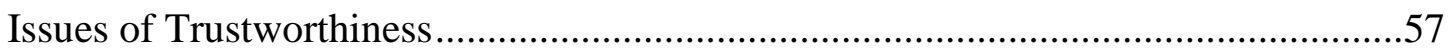

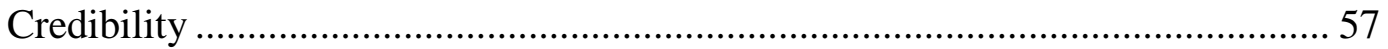

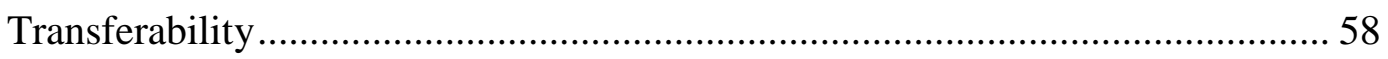

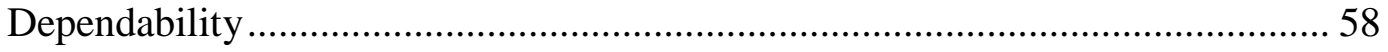

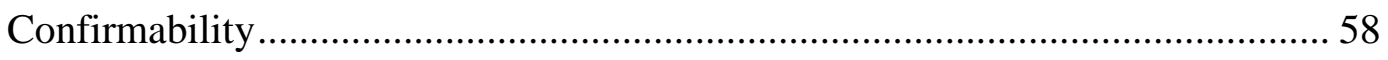

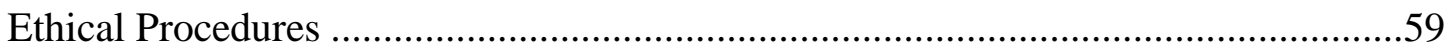

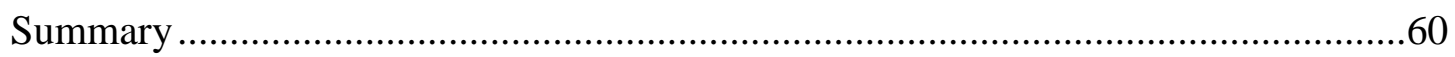

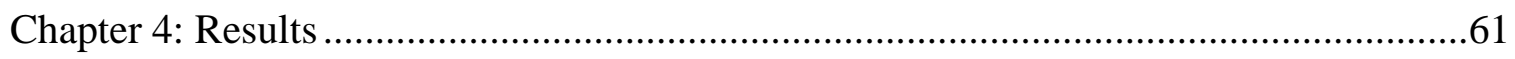

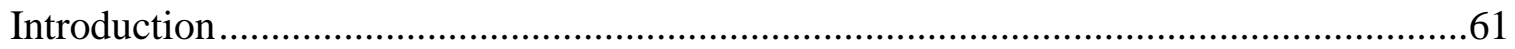

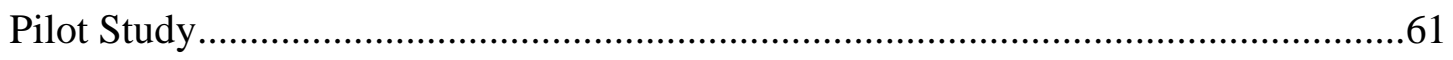

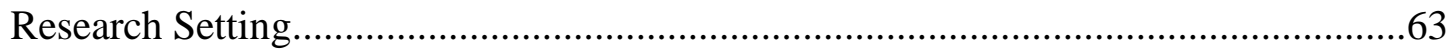

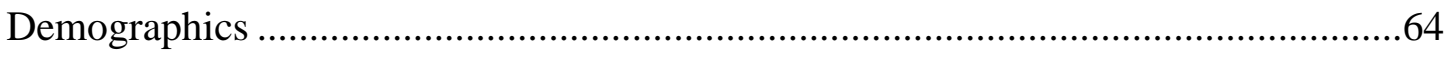

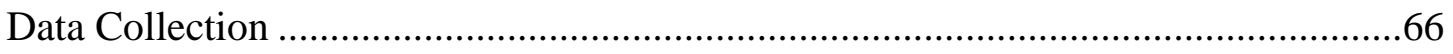

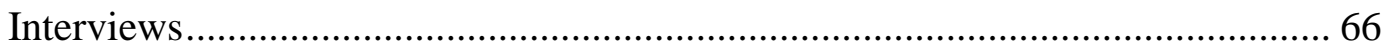

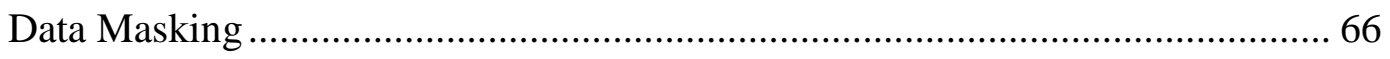


Profiles

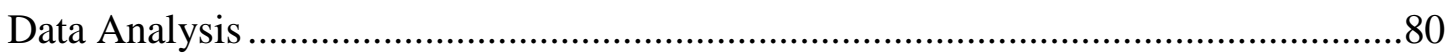

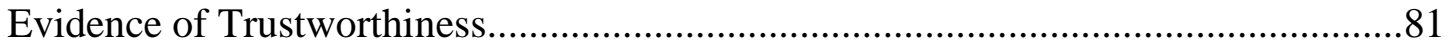

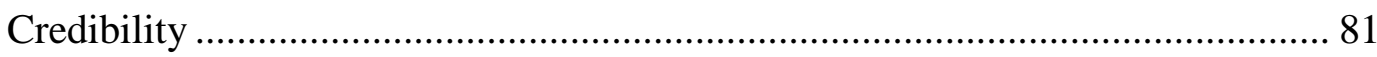

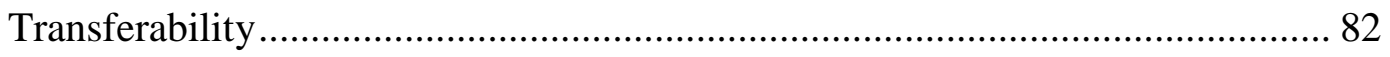

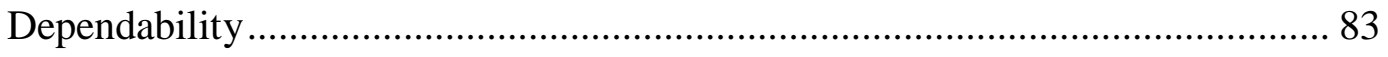

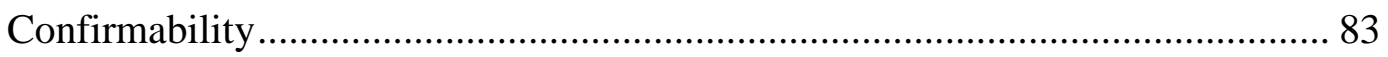

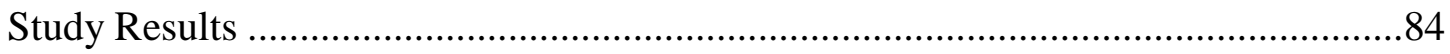

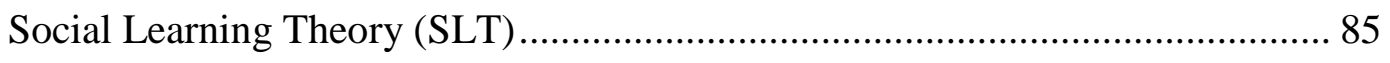

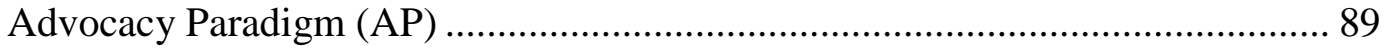

Repair and Restoration Theory of Sleep (RRTS) …………………………....... 93

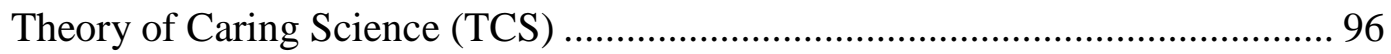

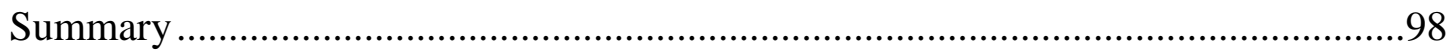

Chapter 5: Discussion, Conclusions, and Recommendations ........................................100

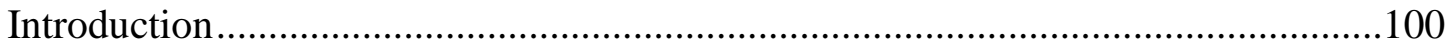

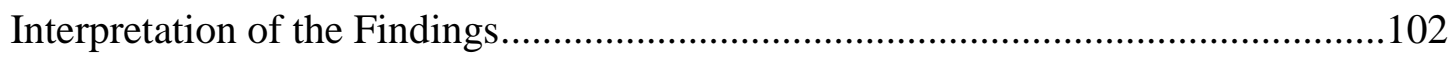

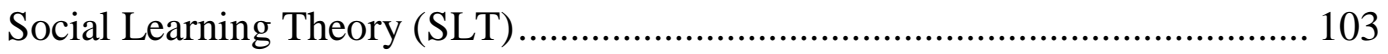

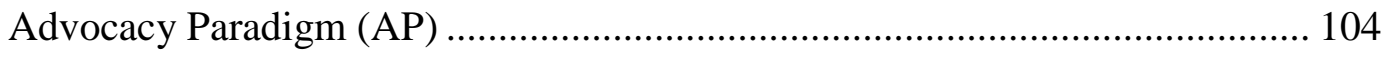

Repair and Restoration Theory of Sleep (RRTS) …………………….............. 105

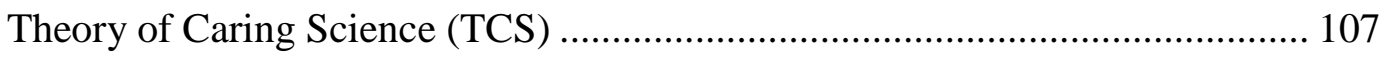

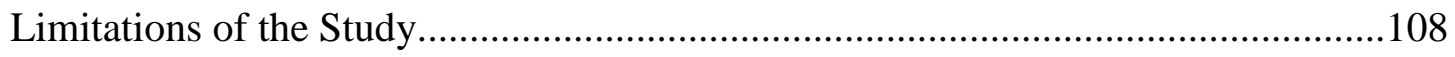


Recommendations

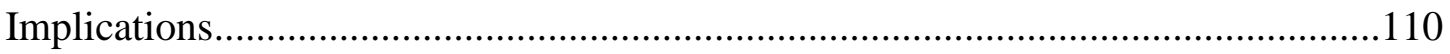

Potential Impact for Positive Social Change ................................................ 110

Methodological, Theoretical, and/or Empirical Implications ......................... 111

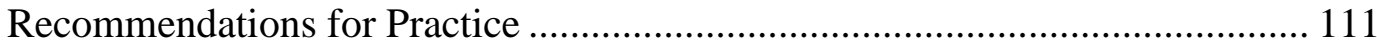

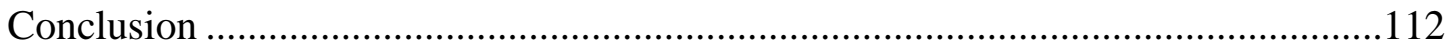

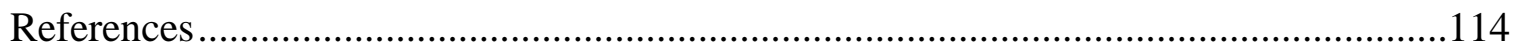

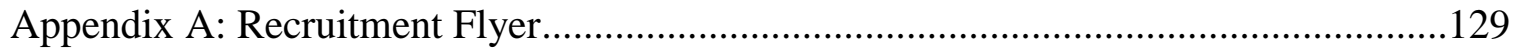

Appendix B: Informed Consent Letter ............................................................ 130

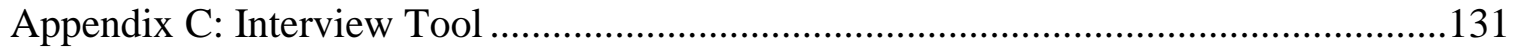

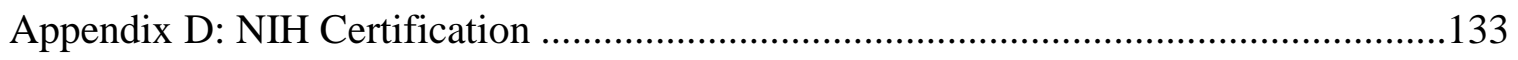

Appendix E: Free Parental Counseling Resource List..............................................134

Appendix F: IQ1/Parental Strategies Most Effective for Adolescent Sleep Health ........136

Appendix G: IQ2/Parental Difficulties for Adolescent Sleep Health ............................137

Appendix H: IQ3/Adolescent Behaviors Related to Sleep Health ...............................138

Appendix I: IQ4/Parental Perceptions of Social Learning and Adolescent Sleep..........139

Appendix J: IQ5/Parental Knowledge to Promote Better Adolescent Sleep ...................140

Appendix K: IQ6/Daily Routines Resulted From Unhealthy Adolescent Sleep .............141

Appendix L: IQ7/Parental Recommendations to Promote Adolescent Sleep .................142

Appendix M: IQ8/Parental Recommendations to Advocate Adolescent Sleep...............143

Appendix N: IQ9/Reasons Noted by Parents to Consult Health Professionals ...............144 
Appendix O: IQ10/Parental Recognition of Poor Adolescent Sleep

Appendix P: IQ11/Outcomes From Health Professionals

Appendix Q: IQ12/Parental Views of Adolescent Sleep Repair and Restoration

Appendix R: IQ13/Parental Views for Caring and Adolescent Sleep

Appendix S: Parent Quotes Related to SLT

Appendix T: Parent Quotes Related to AP

Appendix U: Parent Quotes Related to RRTS

Appendix V: Parent Quotes Related to TCS

Appendix W: Parent Quotes Related to School Transportation

Appendix X: Alignment Matrix of Findings 160 


\section{List of Tables}

Table 1. Purpose of Theoretical Foundations to the Study ......................................... 23

Table 2. Alignment of Interview Questions With Research Questions and Theories .......54

Table 3. Purpose of Colaizzi's Strategy to the Data Analysis.......................................56

Table 4. Characteristics of the Participants....................................65

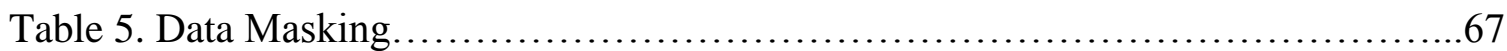

Table 6. Key Findings From the Study......................................... 112 


\section{List of Figures}

Figure 1. Purpose of conceptual framework to the study......................... 20

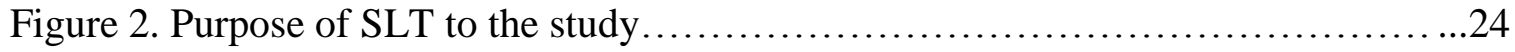

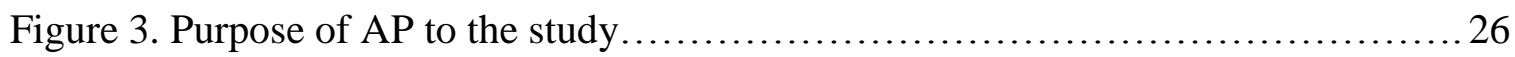

Figure 4. Purpose of RRTS to sleep stages and time..............................27

Figure 5. Purpose of RRTS to sleep cycles....................................... 28

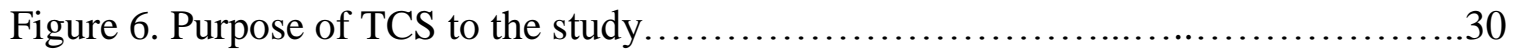

Figure 7. Demographic setting of the research...................................63

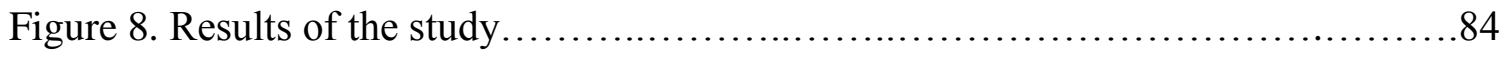

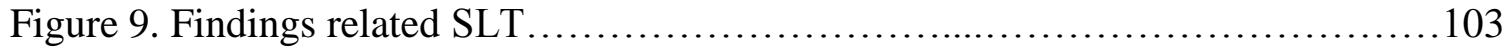

Figure 10. Findings related to AP ........................................... 105

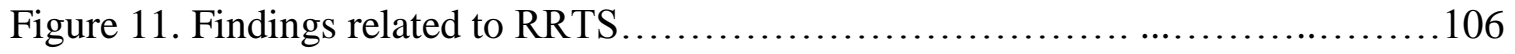

Figure 12. Findings related to TCS........................................... 108 
Chapter 1: Introduction to the Study

\section{Introduction}

Parental perspectives might assist health professionals to promote better sleep habits for adolescents and improve overall adolescent health. Approximately 25 million U.S. adolescents have been diagnosed with sleep problems from 2006 to 2015 (National Sleep Foundation [NSF], 2015). Adolescent sleep disorders have contributed to increased health services requirements as well as budget control challenges for health care administrators (Tripuraneni, Paruthi, Armbrecht, \& Mitchell, 2013). Sleep problems among adolescents may contribute to obesity, high blood pressure, heart problems, and other health care disparities (Crowley, Acebo, \& Carskadon, 2014). On average, adolescents require 8-10 hours of sleep each night for optimal mental and physical restoration (Lee-Chiong, 2008). To address this impending health services problem and to foster health sleep habits, the NSF (2015) has been developing recommendations for adolescent improved sleep habits. Researchers also have suggested that parental perspectives may provide insights to advance scientific knowledge and understanding of adolescent sleep deprivation, while furthering research insights to improve adolescent health and overall well-being (Costanzo \& Woody, 1984). While parental perspectives have been identified as a key strategy for improving adolescent health, little research has been conducted specifically in the area of adolescent sleep health (NSF, 2015).

Therefore, my study was designed to help address this research gap and contribute to the 
body of knowledge in this area by exploring how parental perspectives may promote adolescent sleep health.

Parental perspectives and insights may ultimately contribute to the development of effective solutions to improve adolescent sleep health and influence health care administrators to maximize resources, control expenses, and decrease insurance billing. It is also possible that, through this research, practitioners may expedite treatment techniques and encourage preventative measures for health care relative to adolescent sleep health. Given these possible benefits, understanding parental perspectives as it pertains to their experiences with adolescent sleep problems is an important contribution to this research domain.

In this chapter, I provide the background, problem statement, purpose, research questions, framework, nature of the study, and definitions. I then, provide assumptions, scope, delimitations, limitations, and the significance of this study. I conclude this chapter with a summary. In Chapter 2, I provide an exhaustive literature review of prominent themes and concepts related to adolescent sleep health.

\section{Background}

Literature on adolescent sleep health originated from scientific practices and principles of sleep disorders developed by Dement, who was coined as father of sleep medicine (Kryger, Dement, \& Roth, 2011). Dement's approach was predominately pathological and diagnostic oriented (Dement \& Vaughan, 1999). Based on Dement's foundational work, sleep medicine research has become one of the fastest growing 
subspecialties within the health care industry (Kryger et al., 2011). Although there has been growth within this domain, the body of research has not kept pace in the area of understanding parental perspectives on adolescent sleep health (NSF, 2015).

Parental perspectives have been found to influence adolescent behavior and may ultimately improve adolescent lifestyles (Hart, Herriot, Bishop, \& Truby, 2013). Wiggins and Freeman (2014) found that when adolescent sleep efficiency, time, patterns, and awakenings were recorded by parents, they became educated on the process, and ultimately, their advocacy as well as involvement, increased (Wiggins \& Freeman, 2014). Sleep health disorders are as medically significant as other health disorders such as heart disease, lung cancer, diabetes, and HIV pathologies (Parsons, VanOra, Missildine, Purcell, \& Gomez, 2014). These findings supported the need to investigate parental perspectives to promote adolescent sleep health.

Parental counseling has also been found to increase awareness and involvement with processes that foster improved sleep habits among adolescents (Albert, 2009). Other researchers have investigated the value of integrating interpretive research methods within the exposition of sleep medicine and health care for adolescents (Fulton \& Hayes, 2012). Many sleep researchers have focused on adolescent sleep behaviors, but less on how perceptions of sleep may advance an understanding of this science (Noland, Price, Dake, \& Telljohann, 2009; Paiva \& Matos, 2011). These findings supported exploring parental viewpoints to advoacate for adolescent sleep health. 
Although the field of sleep medicine has progressed in terms of understanding the underlying physiology and anatomy of sleep disturbance and related adolescent behaviors, the current literature did not provide an in-depth understanding of parental perspectives as a means of promoting adolescent sleep health (Andersen, Dore-Stites, Gleit, Lopez, \& Fredericks, 2014). Of the literature about this field of sleep disorders, researchers do not understand parental insights and how these perspectives might influence behavior changes (i.e., change in nutrition, fitness, and other health habits) as a means to contribute to improved adolescent lifestyles (Hart et al., 2013). Consequently, a need existed for a descriptive phenomenological qualitative study to address the research gap of not understanding how parental perceptions may promote sleep restoration and contribute to healthy lifestyles and overall well-being of adolescents.

\section{Problem Statement}

Health professionals may not fully understand how parental perspectives may promote adolescent sleep health. This lack of knowledge may have contributed to medically significant sleep health disorders and less than optimal well-being in the affected population of adolescents (Paiva \& Matos, 2011; Worcester, 2011). The U.S. Department of Health and Human Service (HHS) conducted outreach at the state and community levels in an effort to improve the overall health of adolescents as well as adults (as cited in Worcester, 2011). Sleep health standards have been relevant for restoration and healthy lifestyles including improved sports performance, academic achievement, and resultant career success, later in life (Zhu et al., 2013). Parental 
perceptions have proven to be a significant influence within the adolescent health disciplines, specifically for healthy eating and physical activity at home (Andersen et al., 2014). These findings supported examining the lived experiences of parents to better promote adolescent sleep health.

Improving adolescent health and well-being has been a complex endeavor that has required the collaborative efforts of health services and health care administration, parents, families, schools, pediatricians, clinics, health care agencies, community youth organizations, media, employers, government agencies, and sleep specialists (NSF, 2015). Sleeplessness has created $\$ 16$ billion in annual health care expenses and $\$ 50$ billion in lost productivity (National Institute of Health Journal [NIHJ], 2014). These findings supported investigating parental perspectives to promote adolescent sleep health to disseminate to health professionals to possibly save on health expenses.

Parental promotions toward healthy eating and physical activity within the home environment significantly benefit adolescents' sports performance and physical activity (O'Dea, 2013). When parents are involved in their adolescent's academic activities and engaged in positively influencing their adolescent's rest and nutrition habits, these factors significantly improve academic achievement and future career success (DePlanta, 2010). Parental perceptions and care promote better physical activity and healthy eating habits among adolescents (Burusic \& Sakic, 2013). Parental involvement may promote improved adolescent sleep health and overall well-being, and therefore, warranted the current study. 


\section{Purpose of the Study}

The purpose of this study was to understand parental perspectives held on adolescent sleep health using a descriptive phenomenological qualitative approach. The descriptive approach enabled me to obtain deep, rich, exhaustive, details specific to the phenomenon of parental perspectives as it relates to their adolescent's sleep habits (Shosha, 2012). Prior researchers have predominately focused on the importance of sleep health to restore the human body and foster healing and rejuvenation (Lee-Chiong, 2008).

Litte research, however, has been conducted on understanding the role that parental perceptions play in care and the advancement of positive sleep habits of adolescents. Therefore, the goal of my study was to understand how the experiences of these caregivers might influence positive sleep health of their adolescents. It is possible that by gaining these insights, various treatment options may be offered to rectify adolescent sleep disorders, including those influenced by parental perspectives as an early intervention (Orzech, 2013; Paiva \& Matos, 2011).

The concepts and phenomenon of interests for this study was the parental perspectives and their possible influence on adolescent sleep health to improve adolescent health and overall well-being. To understand this phenomenon, three research questions were identified as the primary focus of this study. 


\section{Research Questions}

Three descriptive phenomenological qualitative research questions were derived from the problem statement and purpose of this study to explore parental perspectives to promote adolescent sleep health.

RQ1: What strategies do parents use to recognize potential unhealthy sleep habits in adolescents?

RQ2: What knowledge do parents obtain to promote better daily behaviors for sleep health habits in adolescents?

RQ3: Which conditions and behaviors do parents consult health professionals for sleep problems in adolescents?

These research questions were further deconstructed in further chapters to align with specific interview questions related to seminal theories, prominent themes, and key concepts.

\section{Conceptual Framework}

I constructed a conceptual framework comprised of a blended theoretical foundation blended from the social learning theory (SLT), advocacy paradigm (AP), repair and restoration theory of sleep (RRTS), and the theory of caring science (TCS) to understand the phenomenon of parental perspectives on adolescent sleep health. The combined framework of multiple propositions was necessary to examine this research problem, holistically and thoroughly. The conceptual lens for this study included parental viewpoints, observations, communication, behaviors, and influence toward sleep health 
standards among adolescents. Further, I explored logical connections among parental viewpoints in sports performance, academic achievement, nutrition, and other attributes. Chapter 2 provides a more thorough explanation of prominent research themes and key concepts.

\section{Theoretical Foundation}

The blended theoretical foundation identified for this descriptive phenomenological qualitative study was framed upon a combination of four propositions that embodied numerous investigations and scientific discoveries within health services on how phenomena occur. First, Bandura (1977) originated the SLT and established that adolescent habits are learned cognitively from parents, peers, and teachers by social context, observation, instruction, and reinforcement with rewards and punishments. Second, Nightingale (1893) claimed that better health habits are essential care strategies relevant within nursing and health service professions (as cited in Selanders \& Crane, 2012). Third, Oswald (1966) suggested the RRTS and identified sleep to be imperative for the revitalization and restoration of the human body and brain for physical and mental functions (Burns \& Dobson, 1984). Fourth, Watson (1979a) created the TCS that values, beliefs, practices, healing techniques, and restoration measures are vital as a concession within childcare, health, education, and human service professions and fields. After blending these theories, I explored the following concepts derived from the aforementioned theories: parental values, beliefs, practices, influence on healing 
techniques and restoration measures, how parents perceive cognitively influencing their adolescent, and how parents perceive promoting better health habits.

These concepts helped to form constructs related to these four theories and provided boundaries for this descriptive phenomenological qualitative study. This framework and approach also helped me to address my study's research questions. Specifically, the SLT provided the rationale for parental involvement with adolescent social learning. The AP correlated with the concept that parents have influence to promote health habits to adolescents. The RRTS justified that adolescents need sleep for restoration. Lastly, the TCS was based upon the concept of care and overlapped with the combined SLT, AP, and RRTS for a foundation of understanding parental perspectives to promote adolescent sleep health. More detailed explanations of these theoretical propositions are provided in Chapter 2.

\section{Nature of the Study}

I developed a descriptive, phenomenological, qualitative research study using Colaizzi's methodology as a data analysis process. The rationale for using this methodology was driven by my need to understand a phenomenon and obtain deep and rich descriptions provided by parents of adolescents. A quantitative design is used for studies with measurable variables (Bleijenbergh, Korzilius, \& Verschuren, 2011). I selected a qualitative research design with open-ended interviews to answer this study's research questions as recommended to obtain in-depth information pertaining to participants' experiences and viewpoints as recommended by Turner (2010). 
Moreover, phenomenology is a philosophy and a research method for exploration and understanding of shared perspectives and the core essence of a phenomenon experienced by a homogenous group of individuals (van Manen, 2007). I used semistructured, open-ended interview questions for data collection. Using this interview guide, I was able to garner an understanding of the essence of parental perspectives. Further, I obtained an exhaustive description of their lived experiences related to their role in influencing their adolescent's sleep habits.

I used Colaizzi’s strategy of seven steps to analyze data obtained from interviews. This process has proven to be successful when conducting studies related to health care, human behavior, and health experiences (Moustakas, 1994). In addition, qualitative researchers tend to employ a framework that enables them to investigate a problem with roles assigned to data collection and analysis (Web Center for Social Research Methods, 2006). To manage the data, I used NVivo qualitative data analysis software for organizing the collection of interviews, questionnaires, and surveys. These data were aligned into themes and trends for synthesis and interpretation.

Phenomenological scholars support the development of rich, thick descriptions resulting from in-depth participant responses (Turner, 2010). Therefore, open-ended interview question formats have been effective when seeking to obtain in-depth perspectives, experiences, and viewpoints from participants (Turner, 2010). The methodology that I used replicated previous descriptive phenomenological qualitative studies. These scholars also used open-ended interviews for similar lines of inquiry 
related to (O'Dea, 2013), academic achievement (DePlantya, 2010), and healthy eating habits (Burusic \& Sakic, 2013). Concise definitions of key terms that are both prominent and specific to this field of research were provided in the next section.

\section{Definitions}

Adolescents: For the purpose of this study, adolescents are teenagers undergoing puberty to adulthood and are between the ages of 13 to 18 (Worcester, 2011).

Adolescent sleep health: For the purpose of this research study, adolescent sleep health referred to sleep habits of adolescents which affect mental and physical restoration necessary for growth of the human body (Lee-Chiong, 2008).

Advocacy paradigm (AP): The theory introduced by Nightengale in 1893 as the supposition to promote better health habits are essential care strategies relevant within nursing and health service professions (as cited in Selanders \& Crane, 2012).

Parental perspectives: The manner in which parents think or understand their adolescents sleep habits and other factors attributing to their daily habits. Perceptions may vary among parents as different situations may be perceived differently with various meanings assigned to the interpretation (Mason, 2010).

Polysomnography: The diagnostic, biophysiological recording of brain activity, eye movements, muscle activation, heart rhythm, respiratory airflow, pulse, and leg movements during sleep (Lee-Chiong, 2008).

Rapid eye movement (REM): The sleep phase characterized by random movement of the eyes, low muscle tone throughout the body, and dreaming (lee-Chiong, 2008). 
Repair and restoration theory of sleep (RRTS): The theory developed by Oswald in 1966 that identified sleep to be imperative for revitalization and restoration of the human body and brain for physical and mental functions (Oswald, 1966).

Sleep disorders: The conditions preventing individuals from sleeping and may result in excessive daytime somnolence (sleepiness or drowsiness), fatigue, and dysfunction (NSF, 2015).

Sleep medicine: The field of health care dedicated to sleep habits and disorder (Lee-Chiong, 2008).

Sleep stages: The sleep stages occur for repair and restoration of the human body during the night sleep cycle, including Stage 1, Stage 2, Stage 3, and REM with lower stages necessary for physical restoration and the REM stage necessary for mental restoration (Lee-Chiong, 2008).

Slow-wave sleep (SWS): The deep sleep phase often referred as Stage 3 and characterized by delta waves needed for growth specifically for adolescents during puberty (Lee-Chiong, 2008).

Social learning theory (SLT): The theory originated by Bandura in 1977 that established adolescent habits are learned cognitively from parents, peers, and teachers by social context, observation, instruction, and reinforcement with rewards and punishments (Bandura, 1977).

Theory of caring science (TCS): The theory developed by Watson in 1979 that values, beliefs, practices, healing techniques, and restoration measures are vital as a 
concession within childcare, health, education, and human service professions and fields (Watson, 1979a).

\section{Assumptions}

Strategies were employed from Rubin and Rubin's (2012) responsive interview model for managing assumptions and to better understand the data through recommended strategies on design, planning, and asking qualitative interview questions. Additionally, several other factors were assumed critical to the meaningfulness of this descriptive, phenomenological qualitative study. This first assumption was the parent participants were honest regarding their perceptions to promote adolescent sleep health. Honest, forthright, and candid interview responses dealing with lived experiences are significant, as asserted by Patton, when conducting a phenomenological study (as cited by Mason, 2010). The second assumption was that parent participants did not withhold information about adolescent habits in fear of being accused as negligent for not properly monitoring their adolescent's behaviors. Third, convenience-based sampling technique from a local setting did not provide a homogenous sample of significant data. These assumptions were necessary so that I could properly mitigate any possibilities of them occurring through remediation of establishing a rapport and ensured that parents understood that there was no penalty associated with negligent behavior or other reasons.

\section{Scope and Delimitations}

The scope of my study was concerned with only understanding parental perspectives and how their influences might promote adolescent sleep health (NSF, 
2015). This understanding was vital in gaining insights specific to how their influence might contribute to the process of repair and restoration of sleep as it relates to the human body (Paiva \& Matos, 2011). The scope of this descriptive, phenomenological qualitative study was targeted for potential transferability and dissemination of one to two page result summaries to clinics, schools, parents, pediatricians, health agencies, high school health courses, health care administrators, and sleep medicine journals as contributing research for social change among adolescent teen sleep health problems.

I delimited my study by involving parents of adolescents within the Southeastern region of the United States using convenience-based sampling without restriction to age or ethnic group. I did not include groups such as nonparental caregivers or foster parents. I limited participant interviews to a sample of 20 parents, proportionally stretched over the Southeastern United States region. This delimitation was appropriate because the sample size of no more than 20 participants would enhance the validity of the study, based on information obtained from Crouch and McKenzie (2006).

\section{Limitations}

Limitations pertaining to the design of this study included time, financial resources, and administrative management (for obtaining a representative sample of parents with adolescents on various spectrums of sleep habits). In addition, the convenience-based sample of 20 parents possibly did not consistently represent the broad spectrum of perceptions held by parents, globally. Additionally, the outcomes and addressing the collection of data were subject to the bias of the researcher (Mehra, 2002). 
For reasonable measures to address limitations, I adhered to the parameters identified within the scope of this study.

\section{Significance}

This descriptive, phenomenological qualitative research study may provide contributions to advance knowledge, practices, and policies, which may lead to positive social change implications within health services, health care administration, and sleep medicine. In general, the global population lacks awareness of sleep health standards (NSF, 2015). Parental perspectives of adolescent sleep health may enhance an understanding specific to adolescent health, puberty, growth, and development (Worcester, 2011). In addition to sleep positively influencing disorder practices, correlated problems with heart problems, lung diseases, neurology factors, obesity, high blood pressure, and various other health comorbidities and disparities may be improved (Costanzo \& Woody, 1984).

When parents are informed and aware of issues regarding health, they are better equipped for informed parental decision making, vital for the care of their adolescents (Worcester, 2011). Low awareness of sleep health hygiene standards among the general population, health care professionals, and policy makers necessitates a well-coordinated strategy to improve sleep-related health (NSF, 2015). The relevance of this study was aligned with the goals of HHS and their goals and objectives for improving adolescent sleep health. I focused my research on perceptions, attitudes, and knowledge of parents toward recognizing adolescent sleep problems. Potential implications for positive social 
change may include providing information specific to parental care and perceptions of adolescent sleep habits that may influence health care administrators' ability to save money, reduce time spent for diagnosis, and expedite treatment techniques.

\section{Summary}

This chapter provided an introduction to the problem related to parental perceptions of adolescent sleep problems. Secondly, the problem statement was clarified and substantiated with the research purpose. I introduced the research questions supported by my study's conceptual framework. I provided clarity of the theories used and provided the nature of this phenomenological study. I then provided the assumptions, scope, delimitations, limitations and the significance of this study.

The field of sleep medicine has grown since the seminal research of Dement, who identified the linkage between sleep and overall health. In this descriptive, phenomenological qualitative study I concentrated on parental care and perceptions of adolescent sleep habits. The findings from this study may inform health care administrators on ways to save money, reduce time, and expedite treatment techniques. The SLT, AP, RRTS, and TCS framed the groundwork for the study. Viewpoints of parents historically contributed to better nutrition, fitness, and other health facets; however, gaps in research exist with promoting adolescent sleep health.

In Chapter 2, I provide a literature review on various research conclusions on sleep with an alignment with the impact on adolescent behaviors and health. I emphasize 
the gaps within this research area and conclude that parent perspectives are the mechanisms to promote better behaviors for sleep patterns.

Chapter 2: Literature Review

\section{Introduction}

Health professionals might not fully understand how parental perspectives may promote adolescent sleep health. The purpose of this study was better understand parental perspectives on adolescent sleep health using a descriptive, phenomenological approach. Sleep medicine has expanded within the health services domain, emerging and keeping pace with its counterparts, neurology, psychology, pulmonology, and otolaryngology (Lee-Chiong, 2008). This field of inquiry, however, has lagged in understanding parents' role in sleep science. Health professionals may not fully understand how parental perspectives may promote adolescent sleep health. Consequently, this lack of knowledge

may have contributed to medically significant sleep health disorders and less than optimal well-being in the affected population of adolescents (Paiva \& Matos, 2011; Worcester, 2011).

Sleep medicine became a scientific field when Dement developed methods to conduct polysomnography testing during sleep of eye and brain activity and discovery of various sleep stages including SWS and REM for repair and restoration in 1953 (Berry \& Wagner, 2014). The American Board of Sleep Medicine (ABSM) identified sleep medicine as a specialty of medicine in 2007 , with sleep clinics deployed in most medical centers of the United States (as cited in Lee-Chiong, 2008). This need for clinics is 
partially based on the United States having approximately 25 million adolescents diagnosed with sleep disorders (NSF, 2015). Adolescent sleep disorders have attributed to increased health services and associated budgets by health care administrators (Tripuraneni et al., 2013). These findings supported the need to explore the lived experiences of parents to promote adolescent sleep health.

Health professionals may not fully understand parental perspectives to promote adolescent sleep health. Consequently, this lack of knowledge may have contributed to medically significant sleep health disorders and less than optimal well-being in the affected population of adolescents (Paiva \& Matos, 2011; Worcester, 2011). In Chapter 2, I provide the literature review specific to this problem. First, I describe the literature search strategies, followed by this study's conceptual framework. I then provide prominent research concepts and ended the chapter with a summary.

\section{Literature Search Strategies}

I used several key terms as search criteria during this literature review including, parents, parental, attitudes, perceptions, involvement, adolescents, teenagers, sleep, quality, health, and sleep hygiene. The literature review included journal articles, books, and dissertations primarily ranging from 2010 to 2015; the exceptions were seminal literature. All sources were obtained from Walden's library via Academic Search Complete, CINHAL Plus, Google Scholar, MEDLINE, ProQuest Central, and Science Direct databases. The sources varied from primary research, qualitative methods, and 
quantitative methods. I also used websites including the American Board of Sleep Medicine, National Sleep Foundation, and Children's Sleep Charity.

Many studies have been conducted on adolescent sleep disorders; however, I found little research on parental perspectives to promote sleep health among adolescents. Hence, the findings obtained from this study may help address this literature gap and provide a means for dissemination among health services and health care administration, parents, families, schools, pediatricians, clinics, health care agencies, and other organizations to possibly save time with diagnosis, reduce cost, and improve lives of adolescents.

\section{Conceptual Framework}

The conceptual framework provided a foundation for this study. The rationale for selecting four theories enabled me to examine the research problem thoroughly and holistically. Seminal researchers have used conceptual frameworks with descriptive, phenomenological, qualitative studies to investigate perceptions, viewpoints, beliefs, meanings, attributes, values, and symbols that are difficult or impossible to quantify mathematically (Armour, Rivaux, \& Bell, 2009; Goldberg \& Allen, 2015). This type of framework enables researchers to explore and understand the perspectives of people (Armour et al., 2009).

Conceptual frameworks are generally presented in research studies in tabular, narrative, or graphical format to convey the key factors, concepts, or relationships (Miles, 
Huberman, \& Saldana, 2014). Consistent with this approach, I provided a diagram depicting how this study's conceptual framework was organized (Figure 1).

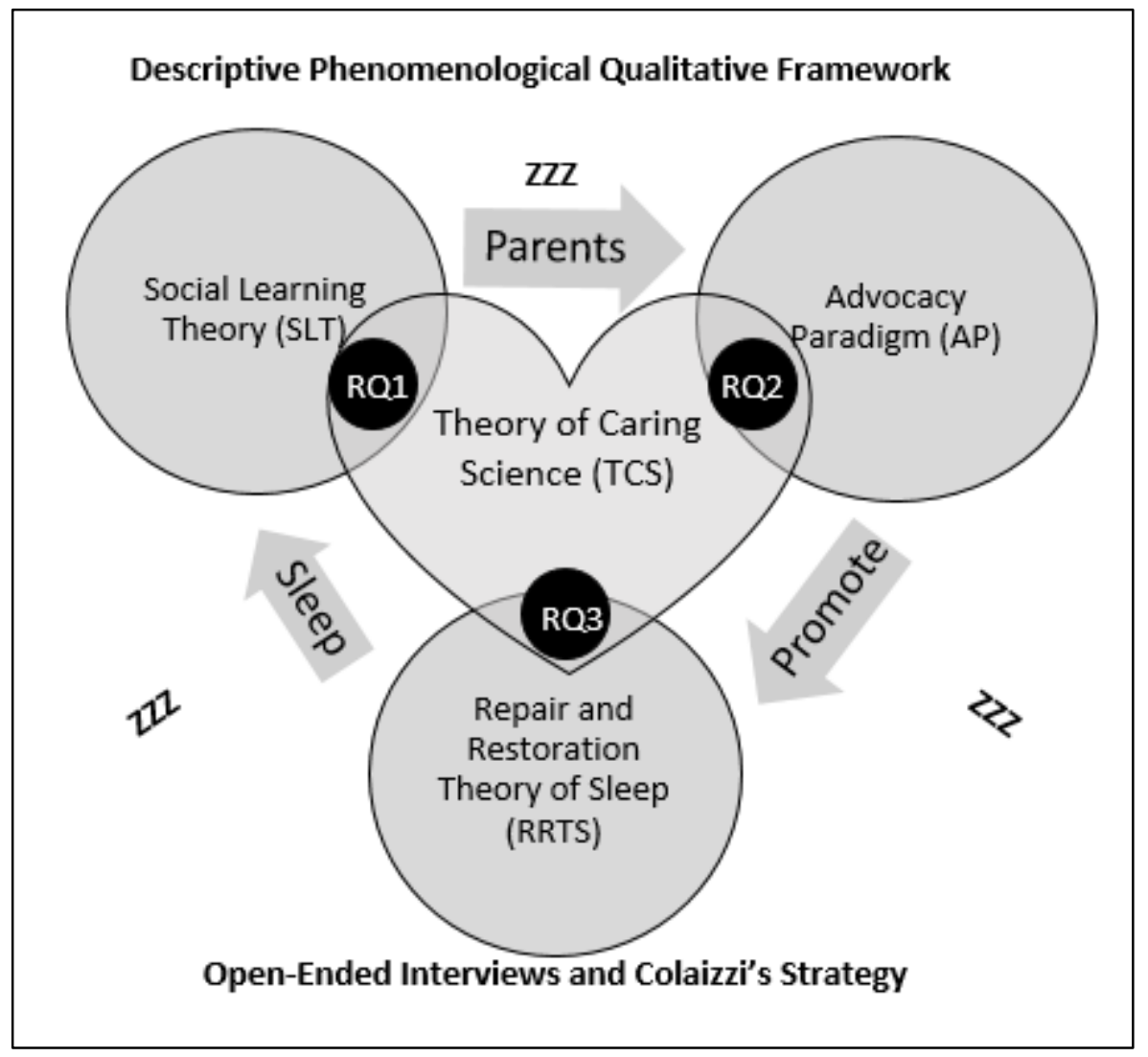

Figure 1. Purpose of conceptual framework to the study

As I illustrated in Figure 1, the contextual lens involved a descriptive, phenomenological, qualitative study that used open-ended interviews for data collection and employed Colaizzi's strategy for data analysis. In the top left corner, I represented SLT annotated in a circle aligned with, and intersecting with, the first research question (RQ1) that is related to the concept parents. In the top right corner, I denoted AP annotated in a circle aligned with and intersecting with the second research question (RQ2) that pertains to the concept promote. In the bottom middle, I depicted the RRTS 
annotated in a circle aligned and intersecting with the third research question (RQ3) that deals with adolescent sleep health. Lastly in the center of the diagram, I illustrated the TCS as a heart that overlaps and intersects with each of the three circles, symbolic of the alignment of care to each of the three research questions (RQ1, RQ2, and RQ3) to promote better sleep health denoted in the diagram as ZZZ.

Descriptive, phenomenological, qualitative studies using a contextual lens in conjunction with open-ended interviews have been applied with success in previous research. Key theorists have noted phenomenological styles, specifically using Colaizzi's strategy to analyze interviews, yield success with studies related to health care, human behavior, and health experiences (Moustakas, 1994). The seven steps of the data analysis and Colaizzi's strategy is detailed in Chapter 3. As an example, Australian researchers used in-depth qualitative interviews among parents to investigate and obtain more comprehensive insight toward prevention strategies for the nature of alcohol usage among adolescents and the harm it causes to others (Manton, MacLean, Laslett, \& Room, 2014). In addition, Chibber, Biggs, Roberts, and Foster (2014) investigated parental perspectives using open-ended interviews to conclude reasons for abortions among teenage girls and found them to be related to potential support they may or may not receive from the partner or parents. Specifically, McGarry et al. (2015) used Colaizzi’s strategy with in-depth interviews among 21 parents with adolescents who suffered burn injury and found that health care professions were able to optimize the holistic clinical approaches and improved protocols within clinics as a result. Consequently, this same 
contextual lens was applied in this study for the purpose of investigating parental perceptions of adolescent sleep health among the Southeastern region of the United States.

\section{Theoretical Foundation}

This study's blended theoretical foundation provided the basis for the systematic exploration of the constructs related to this study's research problem and phenomenon as recommended in previous research (Anfara, 2010). In this study, I investigated parental perspectives to promote adolescent sleep health. As introduced in Chapter 1, the theoretical foundations identified for this descriptive, phenomenological, qualitative study were combined within a conceptual framework. Theoretical foundations are typically presented in research studies in tabular, narrative, or graphical format to convey the key factors, concepts, or relationships (Miles et al., 2014). Therefore, in this section, I provide a tabulated overview of the theories, a descriptive narrative of the concepts, and a graphical depiction of each of the constructs that were explored.

Each theory offered seminal background from numerous investigations and scientific discoveries within health services. The blended theoretical framework included the theories of caring science, social learning, AP, and repair and restoration of sleep. To clarify how the theories related to the foundation of this study, I listed in Table 1 the four theories in alignment with their origin along with their relation to research questions and constructs. 
Table 1

Purpose of Theoretical Foundations to the Study

\begin{tabular}{llll}
\hline Theoretical foundation & Origin & Research question(s) & Construct \\
& & & \\
\hline SLT & Bandura (1977) & RQ1 & Parents \\
AP & Nightingale (1893) & RQ2 & Promote \\
RRTS & Oswald (1966) & RQ3 & Sleep \\
TCS & Watson (1979) & RQ1, RQ2, RQ3 & Caring \\
\hline
\end{tabular}

I listed in Table 1 the four theoretical foundations that were blended to form the conceptual framework of this descriptive, phenomenological, qualitative study and supported my research questions. More specifically, when consolidated, these concepts comprised parental perceptions, recognition, perception, and understanding adolescent sleep health for promoting daily behaviors, health concerns, and disparities among adolescents.

\section{Social Learning Theory (SLT)}

In the SLT, Bandura (1977) established that parents, teachers, and society positively influence children through social contexts of observation, learning, monitoring, and interacting. The concepts of the SLT have been applied in previous studies across the world to promote parental perspectives among adolescents with improvements with nutrition and physical activity (Anzman-Frasca et al., 2014); physical abuse, depression, and substance usage (Snyder \& Smith, 2015); counseling and academia (Marshall, Nelson, Goessling, Chipman, \& Charles, 2015); alcohol reduction (Strunin et al., 2015); and sexual education and awareness (Alekseeva, Krasnopolskaya, \& Skokova, 2015). The first component of the blended theoretical foundation was the SLT. 
In Figure 2, I depicted the four social learning concepts of interaction, observation, influence, and monitoring. Further, I represented in the figure the alignment of RQ1 to parents' perspectives of their role with their children. I illustrated the SLT within a plus symbol as connotation for positive social change toward adolescent sleep health denoted as ZZZ.

ZZZ

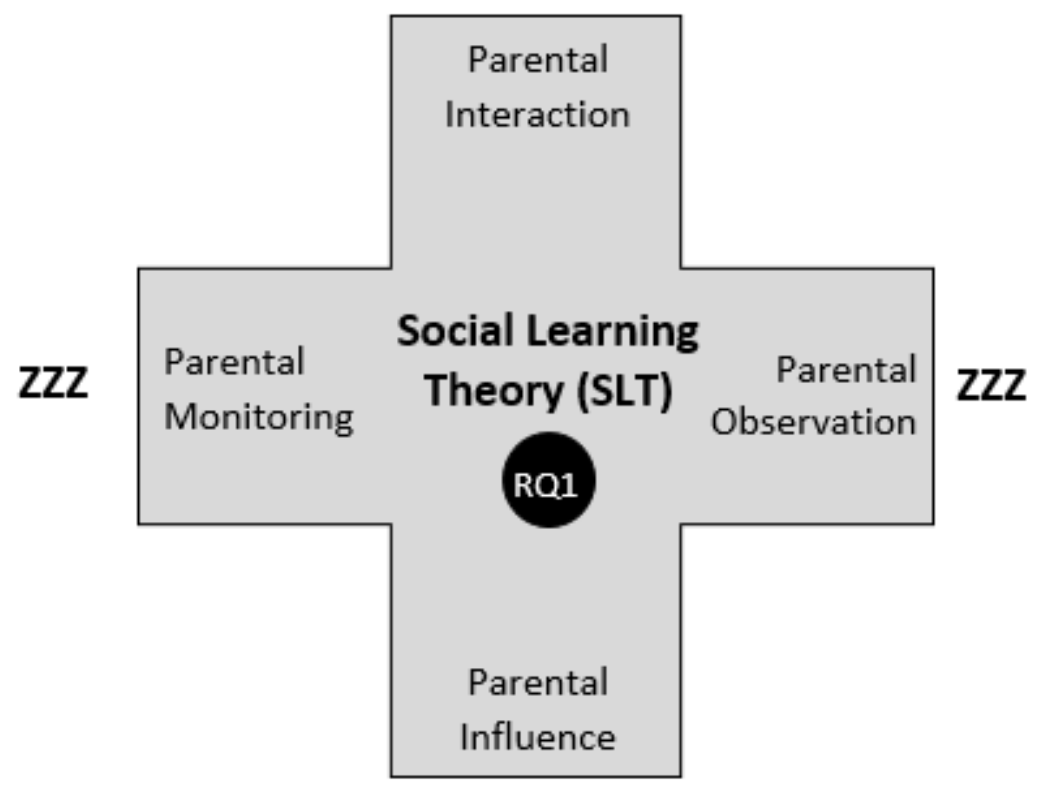

ZZZ

Figure 2. Purpose of the SLT to the study

Consequently, the SLT provided a rationalization for the selection of the sampling of parents to investigate for improved sleep habits among adolescents. Although the aforementioned studies used SLT to examine parental perspectives, I found no study on adolescent sleep deprivation through the lens of TCS, SLT, AP, RRTS theories. In my 
study, I used SLT in alignment with RQ1 to examine parental perspectives in terms of interaction, observation, influence, and monitoring.

\section{Advocacy Paradigm (AP)}

AP was founded by Nightingale in 1893 and outlined core concepts of promoting, educating, informing, and communicating (Steefel, 2010). Nightingale promoted better health habits as essential care strategies relevant within nursing and health service professions (Selanders \& Crane, 2012). Nightingale fostered a greater awareness for advocacy resulting in improved patient care among individuals, groups, and others within the health care profession. Nightingale also promoted the use of strategies for advocacy, education, and awareness that continued well into the $21^{\text {st }}$ century (as cited in Free, 1994).

AP was applied in previous adolescent health research studies to promote health habits, educate adolescents, inform patients, and communicate ideas for better health outcomes with general health and well-being (Resnick, Harris, \& Blum, 2013). Additionally, it was used to understand transition trends from adolescent to adult care with treatment of chronic conditions (Whitehouse, Brodie, \& Towns, 2013). Finally, AP was used for communication with sexual health and reproduction (Wilkins, 2014).

In Figure 3, I denoted how RQ2 was aligned with the main tenants of the AP. I represented how the tenants promote, communicate, inform, and educate promote adolescent sleep health. I illustrated AP within a plus symbol as connotation for positive social change toward adolescent sleep health denoted as ZZZ. 


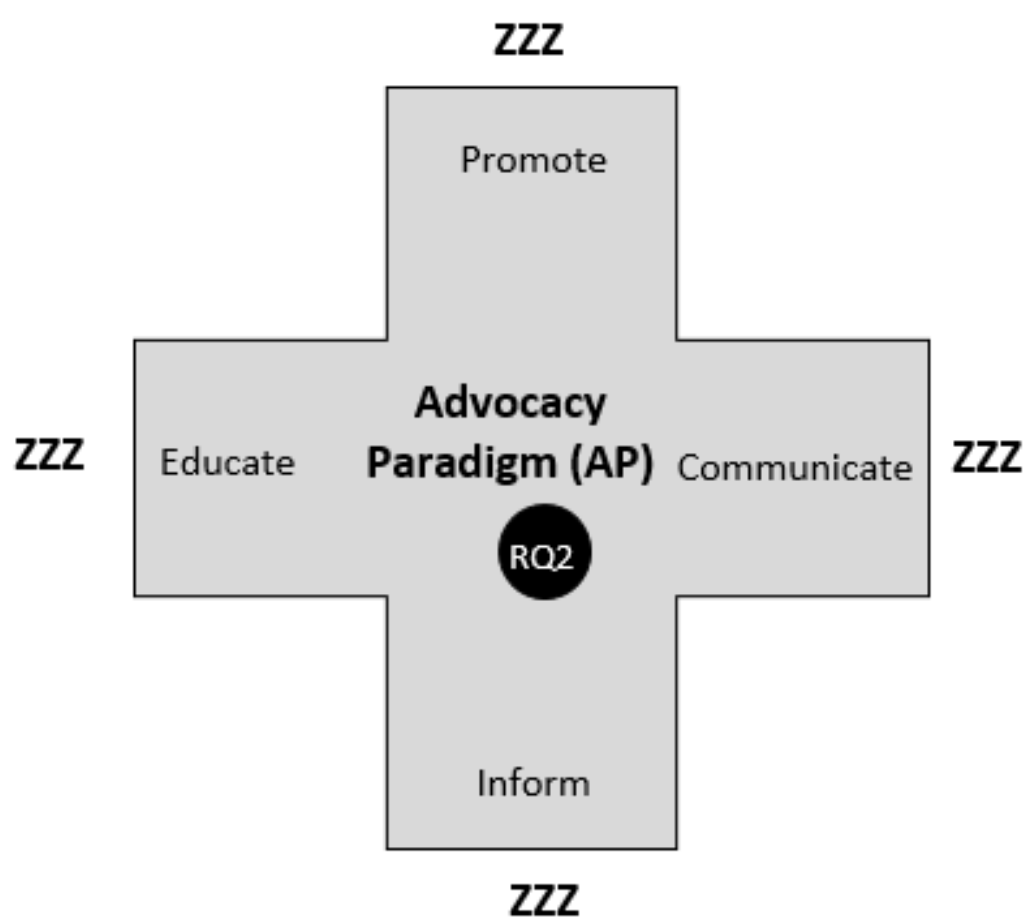

Figure 3. Purpose of AP to the study

Consequently, I used these four core concepts of AP in my study to analyze how parents view their role with advocacy in becoming educated to influence better health outcomes during the adolescent stage and understand how parental ideas and what role they play in sleep health habits. Although the aforementioned studies used AP to examine parental promoting, I found no study on adolescent sleep deprivation through the lens of TCS, SLT, AP, RRTS theories. In my study, I used AP in alignment with RQ2 to explore parental promoting in terms of educating, promoting, communicating, and informing. 


\section{Repair and Restoration Theory of Sleep (RRTS)}

Oswald (1966) originally suggested that RRTS was imperative in fostering revitalization and restoration of the human body and brain for mental and physical functions. Adolescents require approximately 8-10 hours of daily sleep for this restoration to occur and to also maintain the required level of rest to achieve healthy lifestyles (Lee-Chiong, 2008). Oswald (1966) suggested the necessity for sleep stages and duration of hours.

In Figure 4, I created a diagram that illustrated how sleep is comprised of three stages and REM based upon the repair and restoration model by Oswald (1966) for sleep stages and time. In the diagram, I illustrated the normal repetition patterns of sleep stages and REM over various times throughout the night.

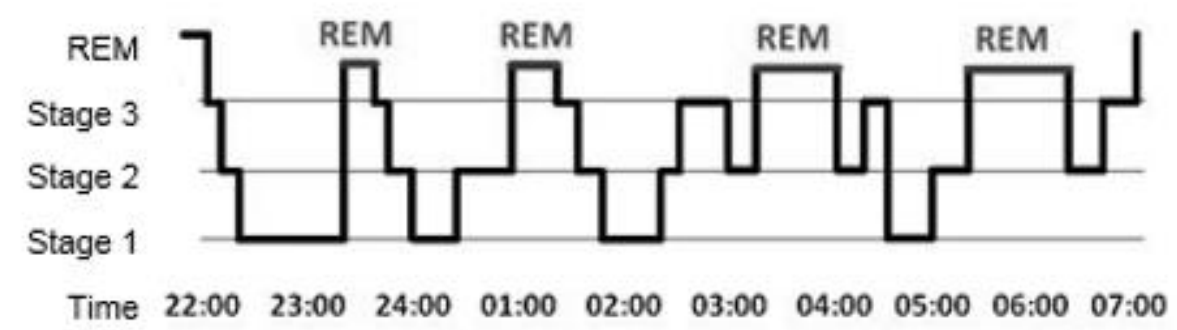

Figure 4. Purpose of RRTS to sleep stages and time

Additional research endeavors by Home (1988) detailed the importance of understanding SWS for normal physical growth of the body and REM for cognitive mental revitalization (Kryger et al., 2011). Adolescents require more SWS for body growth during the puberty and tender growing years (Lee-Chiong, 2008). The RRTS established predictions including: (a) increased REM is necessary for mental growth and 
reorganization; (b) increased overall sleep is necessary for growth of the human body especially during repair and growth stages; (c) more timespans for catchup is necessary from incidences of sleep deprivation; (d) mental and physiological consequences are resulted from poor habits including deficits and sleep deprivation (Kryger et al., 2011).

To illustrate the aforementioned process, I created a model as shown in Figure 5, which conveyed the various stages of sleep during a 90-120 minute cycle. In the diagram, I illustrated a normal 90-120 minute cycle of sleep beginning with the transitional stage 1 , then stable stage 2 , then SWS, and finally REM.

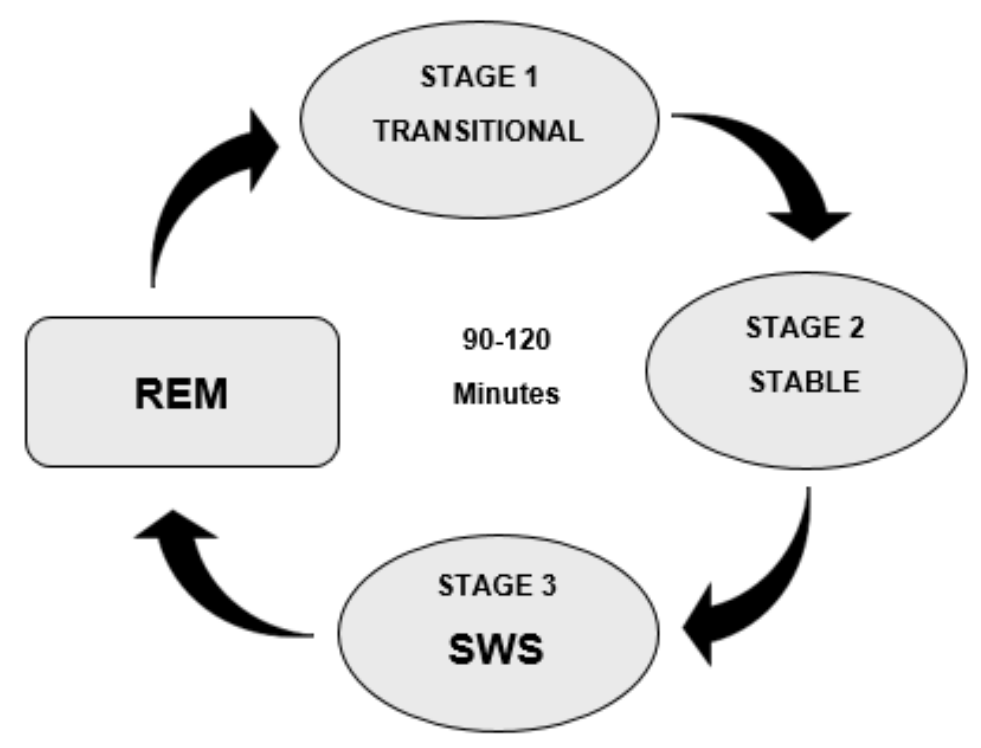

Figure 5. Purpose of RRTS to sleep cycles

The RRTS was referenced as seminal theory framework in other adolescent health studies. For example, quantitative researchers in Michigan investigated the RRTS among adolescents and concluded poor sleep attributes to increased stress and appetite (Michels et al., 2015). Researchers in metropolitan Melbourne, Australia, conducted a cross- 
sectional, population-based study that examined the RRTS among adolescents to determine linkage between poor sleep with memory difficulties and learning disabilities (Cho et al., 2015). In addition, researchers at the Cincinnati Children's Hospital Medical Center explored the RRTS to conclude adequate sleep habits are essential as the building blocks of healthy development among adolescents for neurodevelopment (Delgado, Stawn, \& Pedapati, 2014). Finally, I used the concepts from the RRTS in this specific study in alignment with the third research questions (RQ3) to explore adolescent sleep health from the viewpoints of parents.

\section{Theory of Caring Science (TCS)}

The TCS was comprised of techniques that contribute to healing and health through a multiple faceted approach. As introduced in the background section in Chapter 1, sleep medicine has become one of the fastest growing fields in health services vital for both mental and physical restoration necessary for the care of the human body (LeeChiong, 2008). Watson's (1979a) TCS suggested that values, beliefs, practices, healing techniques, and restoration measures are vital as a concession among childcare, health, education, and human service professionals.

The 10 core concepts important to the TCS model included: (a) embrace parental values; (b) honor family; (c) nurture practices; (d) foster trusting with parent-child relationships; (e) promote health; (f) used scientific strategies for caring; $(\mathrm{g})$ teach adolescents in ways they understand; (h) promote restoration with respect to human dignity; (i) consider physical, mental, and spiritual needs for health care; and (j) allow the 
miracle of healing (Watson, 1979b). Each of these concepts were used to provide an understanding of how parents might consider their roles in adolescent sleep health.

In Figure 6, I illustrated the purpose of how these 10 caring science core concepts from the TCS. These core concepts of value, honor, nurture, trust, health, care, teach, restore, needs, and heal provided the anchor for this descriptive phenomenological qualitative study and were aligned with all three research questions (RQ1, RQ2, and RQ3). I illustrated the TCS within a 10 pointed starburst symbol as connotation for positive social change toward adolescent sleep health denoted as ZZZ.

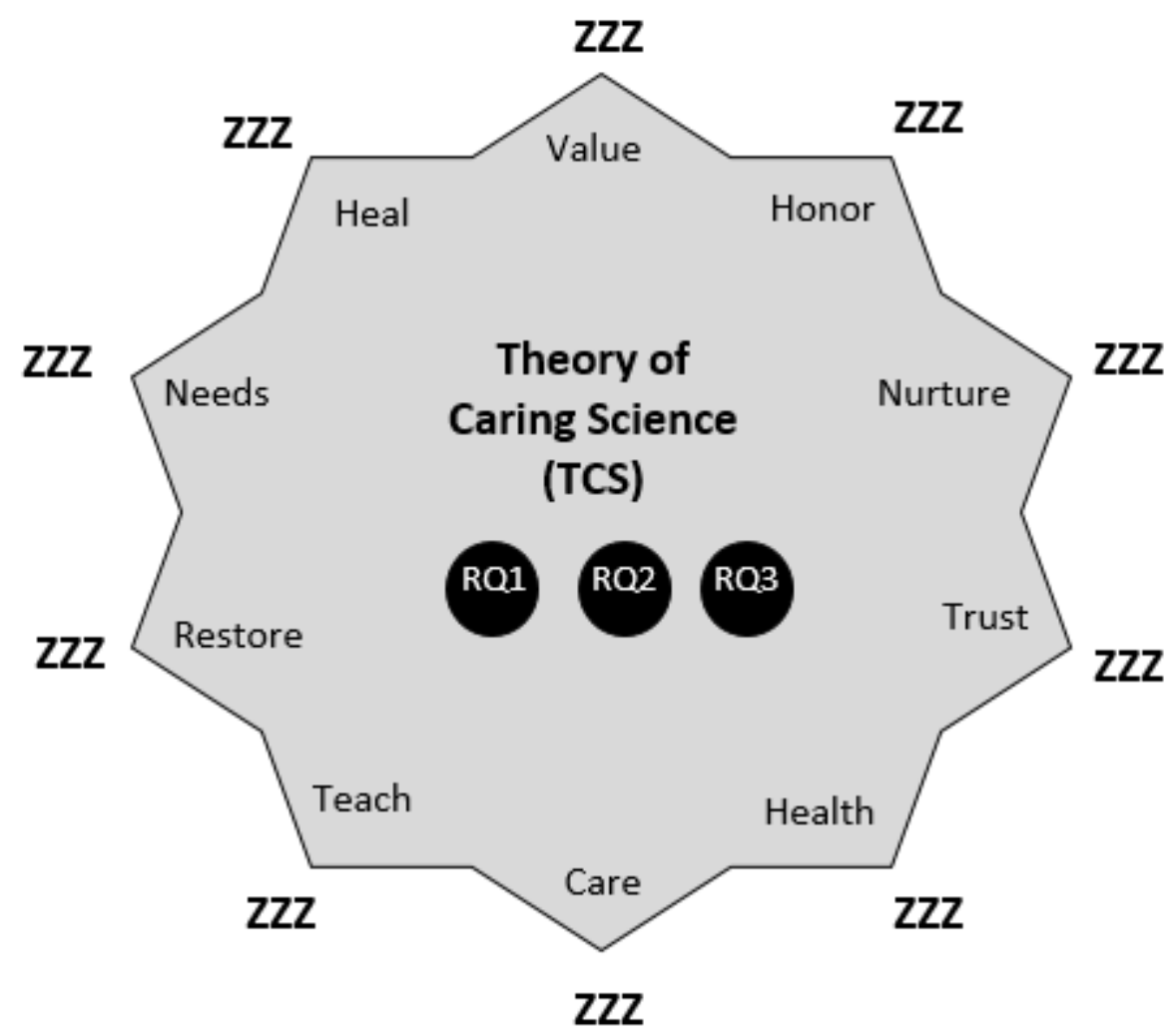

Figure 6. Purpose of TCS to the study 
The TCS was applied in previous adolescent health studies as the seminal theory and anchor of associated research. For example, researchers from England, France, and Greece used caring science to investigate physical activity among parental caring toward male football players, who were age 10-14. These investigators examined the relationship between health behaviors and football success, and concluded that greater success was positively associated with active lifestyles (Hoye et al., 2013). The aforementioned mentioned study supported my aim to understand parental perspectives through the lens of caring science. In another study, scientists in Finland concluded parental coaching improved diets and reduced sexual, alcohol, smoking and drug addictions in adolescents (Watson, Adair, \& Humphris, 2012). Further, researchers in Michigan concluded parental interventions improved automobile driving and safety awareness in adolescent males (Pradhan et al., 2014). The foundation of caring science aligned with all three research questions (RQ1, RQ2, and RQ3) in this study and was used to investigate parental behaviors and perceptions that may contribute to promoting positive sleep health standards to adolescents.

\section{Prominent Research Concepts}

In this section, I reviewed literature related to several key concepts and principles, which included sleep health hygiene, adolescent sleep statistics, adolescent health, parental perspectives, parental promoting and influence, parental recognition, parental knowledge and understanding, effects and consequences of inadequate sleep, health professional influence, and sleep problem reduction efforts. 


\section{Sleep Health Hygiene}

Medical professionals have identified sleep health hygiene factors to include: (a) maintaining a consistent routine for sleep with a regular bedtime and wake time; (b) avoiding forced sleep; (c) regular exercise; (d) utilizing the bed for only sleeping; (e) avoiding alcohol, nicotine, or caffeine before bed; (f) eating a well-balanced diet with proper times for breakfast, lunch, dinner, and snacks to avoid hunger during the night time; (g) maintaining a proper dark, quiet, and appropriate environment in the bedroom; (h) dealing with worries before bedtime; and (i) avoiding all electronic usage in bed (Thoropy, 2011). With the emergence of electronic devices, the percentage of adolescents following these sleep health hygiene factors has become worse (Lamberg, 2014). These findings supported the need to explore parental opinions for sleep health hygiene among adolescents.

American adolescents suffered with poor sleep hygiene because of video gaming, telephone use, computer use, evening light, Internet use, tobacco use, negative family environment, and non-parental involvement ad noted by meta-analysis of 41 studies conducted by Bartel, Gradisar, and Williamson (2014). Sleep medicine experts reported that few adolescents follow proper sleep health hygiene rules to obtain the required time of sleep for repair and restoration (Lamberg, 2014). Along similar lines, sleep researchers reported that adolescents require 8-10 hours of sleep per night (Lee-Chiong, 2008). Notwithstanding, in a poll taken by the NSF in 2006, researchers determined that less than $20 \%$ of adolescents obtain necessary sleep requirements on school nights (NSF, 
2015). These statistics justified the need to examine parental viewpoints toward adolescent sleep health.

From a broader perspective, researchers from the Midlands region of the United Kingdom in 2010 concluded music, movies, computers, video games, and technology impact adolescents with prolonged sleep onset, frequent awaking through the night, nightmares, and sleep walking (Arora, Broglia, Thomas, \& Taheri, 2014). Within the literature reviewed, sleep health hygiene was a common trend yet the gap existed specifically to understand how parental perspectives promote better sleep patterns, and behaviors specific to technology usage patterns.

\section{Adolescent Sleep Statistics}

Based on national statistics from a Princeton University poll in 2011, 68.9\% adolescents did not obtain sufficient sleep on school nights (McKnight-Eilya et al., 2011). Further, $6 \%$ of 10th graders and 3\% of 12th graders in Fairfax, Virginia, obtained the recommended amounts of adequate sleep according to study results by Lambert (2014). In addition, $40 \%$ of adolescents experienced sleep disorders and $86 \%$ of adolescents with special needs suffered from sleep disorders according to additions study results by Lambert (2014). Other researchers have found that sleep deprivation and poor sleep routines were associated with obesity, cognitive ability, academic failure, and family problems (CSC, 2014). In general, sleep has been reported by scholars as vital to the human body, just like food and drink, and provided higher successes with health disparities remedied by the use of some medications (CSC, 2014). 
Health risk behaviors were found prevalent among two-thirds of the American adolescent population as concluded by McKnight-Eilya et al. (2011). Sleep was noted to be important during adolescent years for brain maturation, as indicated from research findings by Maume (2013). The average sleep timeframe, for most humans, averaged 9 hours, according to studies conducted by Michalos (2014). Consistent with these findings, data from the NSF included information regarding how only $20 \%$ of adolescents attained 9 hours of sleep per night with 50\% reporting less than 8 hours on school nights (NSF, 2015). Research, however, prevailed adolescents did not obtain adequate sleep specifically during the school week ( $\mathrm{Zu}$ et al., 2013). Approximately $66 \%$ of adoelscents identified as severly sleep-deprived due to only receiveding an average of 5-6 hours of sleep each night, based upone data from a study conducted by Lamberg (2014). Within the literature that was reviewed, significant percentages of issues related to sleep patterns yet the gap existed for parental interventions might promote improved sleep habits among adolescents.

\section{Understanding the Importance of Adolescent Sleep Health}

Data from the Centers for Disease Control and Prevention [CDC] (2013) included information about how sleep health was critical to adolescent overall well-being and may help to reduce other health related ailments. As a result from insufficient sleep, the adolescent population was found to be at a greater risk for car accidents, depression, diabetes, heart disease, high blood pressure, obesity, risk-taking behaviors, and suicidal ideation, according to pediatric specialist, Dr. Judith Owens, from Children's National 
Health System in Washington (as cited in Lamberg, 2014). Over 10 million adolescents in the United States have been diagnosed with health related problems stemming from sleep disorders, and $13 \%$ of the cases involved the use of prescription medication, according to data released by the CDC (2013). Adolescents with poor sleep quality and a lack of deeper stages of sleep were more likely to suffer hypertension and obesity, according to Hannon et al. (2014). In addition, intervention studies were needed to determine if improved sleep quality would lower blood pressure (Hannon et al., 2014). Lack of sleep and obesity were determined to be factors associated with food intake, lower energy, and hormones such as leptin and ghrelin that regulate the appetite (Hannon et al., 2014). In a different study, inconclusive findings left open questions on whether or not television viewing, computer usage, and Internet surfing also influenced and impacted adolescent health (Bayon, Leger, Gomez-Merino, Vecchierini, \& Chennaoui, 2014).

With over a decade of research, scholars have established possible associations between sleep duration and adolescent obesity, yet further research is warranted (Thind et al., 2014). When using various ages and waves of adolescents, short sleep durations accompanied with increased television watching and electronic activities were found to be possible risk factors for obesity according to Magee, Caputi, and Iverson (2014). Sleep patterns were determined to be associated with physical activity, dietary habits, and weight management as discovered by Kabadayi (2013). In addition, sleep duration predicted the cardio metabolic risk factors for obese adolescents regardless of physical 
activity, anthropometry, or adiposity as discovered by Iglay Reger et al. (2014). Further research was needed for the determination of reducing health issues according to Iglay Reger et al. (2014). Sleep deprivation in adolescents attributed to dietary activity and physical behaviors related to balance, energy, and metabolism, yet questions existed as to whether a modern environment or lifestyle were also factors according to Penev (2014). Examining this problem further, adolescent health and quality of sleep were possible correlations between high blood pressure, hemoglobin levels, and cardiovascular disease as concluded by Berentzen et al. (2014). Higher quality of sleep was determined to shorten times with illness such as the flu, the common cold, strep throat, gastroenteritis, and other infectious diseases among adolescents, [specifically, during weeks with adequate sleep in comparison with weeks without adequate sleep] as discovered by Orzech, Acebo, Seifer, Barker, and Carskadon (2014). In contrast, the CDC (2013) reported one-third (18 million) of adolescents with proper sleep habits had perfect school attendance and no reported illnesses or injuries. Sleep was determined a health imperative just like eating, breathing, physical activity, or medication as concluded by Lamberg (2014). Based on relevant and importance data from the CDC (2013), 1.2 million adolescents (2\%) could not receive medical attention due to low income and 2.1 million adolescents (3\%) experienced delayed treatment due to worry of the associated expenses. The literature reviewed noted overwhelming adolescent health impacts, yet a gap existed with parental perspectives for improved sleep among adolescents for possible reduction of adolescent health issues. 


\section{Parental Perspectives}

There are a number of research studies that supported the idea that parental perspectives are potentially related to adolescent sleep health. Parental perspectives were found to influence behavior changes and improve adolescent lifestyles, according to Hart et al. (2013). A three day study using Wrist actigraphy monitoring and sleep diary documentation among 26 adolescent children ages 13-18 concluded correlations between sleep efficiency, time, patterns, and awakenings by Wiggins and Freeman (2014). Further research was deemed necessary surrounding the sleep routines of adolescents in relations to improved education and advocacy among their parents according to Wiggings and Freeman (2014). Using an alternative approach to parent perspectives, 293 adolescents used sleep diaries for seven days, capturing data specific to their own psychological function along with rating their parent sleep habits and styles (Branda, Grberb, Hatzingerc, Becka, \& Holsboer-Trachslera, 2009). The overall findings revealed that sleep health and disorders are as medically significant and important as other health factors such as the concern for heart disease, lung cancer, diabetes, HIV status, and various other medical related matters in a study conducted by Parsons et al. (2014).

Although the influences of parents may affect adolescent psychological functioning and sleep, data has not been obtained for parental perspectives toward sleep habits among adolescents (Short et al., 2011). Adolescents required sufficient sleep to function adequately daily, yet there is a lack of consolidated evidence for parental involvement for adolescent sleep interventions (Bartel et al., 2014). Sleep habits among 
adolescents differ when environmental stress factors and parental interventions are measured or taken into account (Branda et al., 2009). Parental interventions, with setbedtimes, provided opportunities to improve daily activities and nightly sleep routines among adolescents in a study conducted by Short et al. (2011). More research was determined necessary as to whether parental sleep interventions could improve sleep habits among adolescents who suffer from sleep disorders as well as adolescents who are healthy after further investigation by Wiggins and Freeman (2014). Correlation existed between adolescent and parent sleep patterns with similarities to enable treatment and counseling of sleep disorders for both parents and adolescents as determined in studies by Branda et al. (2009). Supporting the concept of the importance of parental engagement, this type of support was indicative for ensuring scheduled bedtimes and physical activity as beneficial activities (Bartel et al., 2014). Each of these studies supports the concept that parental perspectives are essential in promoting sleep health hygiene among adolescents.

As evident in this review, scholars have conducted studies dealing with parental perspectives toward diseases and health issues and have concluded both negative and positive consequences of education and awareness. Some of the negative consequences included a lack of promoting disclosure of disease status and education toward adolescents for fear of rejection, loss of affection, and violence (Parsons et al., 2014); to feelings of pity, worry regarding health, troubles for adolescents during their youth, and worry by family (Kallem, Renner, Ghebremichael, \& Paintsil, 2011); to giving the child 
an untroubled childhood (Kennedy et al., 2010); and due to self-blame or worry (Persson \& Richards, 2010). On the positive side, parents who disclose their health status to their children and proceed with education, awareness, and treatment of health disorders may experience an immense sense of relief, gain more knowledge to proceed with methods to improve the overall health issues, make plans for other necessary treatments, and consequently save time and money for other health disparities (Rwemisisi, Wolff, Coutinho, Grosskurth, \& Whitworth, 2009).

\section{Parental Promotion and Influence}

Parents play a critical role in promoting and influencing healthy sleep habits among adolescents based on data from the NSF (2015). Parental promotion and influence were hypothesized to have significant impacts on sleep patterns, television-viewing, dietary habits, and body measurements among adolescents with obesity from research conducted by interviewers of parents in a North-East England town (Jones, Pollard, Summerbell, \& Ball, 2014). Parental promoting, motivation, positive role modeling, involvement of child in decisions, and investing time were factors determined to promote healthier lifestyles among adolescent in another global study by Pocock, Trivedi, Wills, Bunn, \& Magnusson (2010). Parental demoralization and support at home influenced and benefited improved health habits as concluded from three studies in the Northeastern school districts by Okado, Bierman, and Welsh (2014). Parents' intervention strategies promoted abstinence from drinking, premarital sex, drugs, communication, and positive 
influences among peers as discovered from a study conducted among Newark teenagers by Ross, Baird, and Porter (2014).

Parental involvement influenced adolescent health, dietary intake, daily behaviors, education pursuits, and income status later in life as revealed from a study conducted by Mantziki et al. (2014). Similarly, weight management among teens provided greater benefit using family-focused approaches that used healthy diet and exercise (Santa Maria et al., 2014). Researchers concluded parents noted higher rates of sleep disturbances and periodic limb movement during sleep routines of adolescent with liver transplants (Andersen et al., 2014). Within the literature, a gap existed for specific parental strategies to promote and influence better sleep habits for adolescents.

\section{Parental Recognition, Knowledge, and Understanding}

Parental recognition, knowledge, and understanding about adolescent sleep were explored in a study conducted by Malow et al. (2013). The study focused on children with autism spectrum disorder (ASD) and concluded that parent-based sleep education sessions, directly helped improve delays with sleep onset latency (Jones, et. al, 2014). Parents may or may not actually know how to engage in proper sleep hygiene health habits as concluded by Malow et al. (2013). Parent knowledge improved adolescent nutrition and dietetics utilizing qualitative methods among 25 parents divided in 5 focus groups as discovered by Hart et al. (2013). Furthermore, healthy nutrition was determined as challenge perceived by parents to assimilate dietary guidelines through empowerment or motivation as a means to tackle weight issues as explored by Hart et al. (2013). 
Parental education was determined to be successful for better knowledge and understanding with involvement in the promotion of health practices at both home and school to advocate long-term health and well-being among adolescents in a qualitative study conducted in New Zealand among 26 teachers' interview responses by Clelland, Cushman, and Hawkins (2013). Parent's needs, knowledge, and guidance was deemed significant to understanding various health risks among adolescents in home-based studies among elementary schools in the United States by Moreover, Dickinson, Hayes, Jackson, Ennett, and Lawson (2014) replicating the qualitative data collection method among 25 parents versus the 26 teachers in New Zealand by Clelland, Cushman, and Hawkins (2013).

The importance of parental acceptance and influence specific to their role in fostering sleep health was conveyed based on sleep diary research among 385 adolescents in South Australia (Short et al., 2011). Data from this study included information about how only $17.5 \%$ of the participants reported that their bedtimes were scheduled by their parents, which could potentially heightened their risk for depression, mortality, and accidental injuries (Short et al., 2011). Adolescents who retired to sleep after midnight had $24 \%$ more chance for depression and $20 \%$ were at risk for suicide ideation according to result by Dubik (2010) with a sample of 15,659 American adolescents, to examine the importance of parental knowledge and understanding of sleep schedules. Within the literature, I have found no research that holistically, examined the essences of parental 
perspectives through the lens of sleep health and hygiene promotions with TCS, SLT, and AP theories. Thus the gap remained parental views to promote adolescent sleep health.

\section{Effects and Consequences of Inadequate Sleep}

The causes of inadequate sleep can be behavioral, environmental, or biological (Michalos, 2014). In addition, adolescents may also incur issues with academic progress due to inadequate sleep (Albert, 2009). Data from the National Youth Risk Association included information about how high school students, in the United States, poor sleep habits were linked with more possibilities of cigarette smoking, marijuana usage, sexual activity, suicide incidents, depression feelings, and physical aggression (McKnight-Eilya et al., 2011). Poor sleep hygiene appeared to be a protective factor impacted immensely by a homes' environmental factors with more association on the usage of electronic devices, caffeine, tobacco, and alcohol, thus contributing to poor daily performance at school based on research from data from Bartel et al. (2014). His study obtained data from parents to feasibly address poor sleep habits among adolescents (Bartel et al., 2014).

Various scientists at the University of North Texas analyzed sleep patterns among adolescents utilizing a cross-section design and concluded that adolescents with insufficient sleep frequently reverted to alcohol, drugs, and medications to help with sleeping and staying awake according to Taylor and Adam (2010), Researchers at the Cincinnati Children's Hospital Medical Center, Division of Behavioral Medicine and Clinical Psychology, National Institutes of Health Neuropsychology Program, and University of Cincinnati College of Medicine focused on data collected from children and 
adolescents and concluded that inadequate sleep impacts cognitive, behavior, and functional development (Beebe, 2011). Consequently, data from this study concerning parental perspectives to promote sleep health hygiene was shown to influence a number of adverse consequences among adolescent health.

\section{Health Professional Influence}

Improving adolescent health and well-being is a complex endeavor that requires the influence and collaborative efforts among health service providers, health care administrators, parents, family members, school staff, pediatricians, clinicians, health care agencies, community youth organizations, media, employers, government agencies, and sleep specialists, based on data from the CDC (2013). The field of sleep medicine continues to unveil discoveries that may contribute to a greater understanding of how its role affects the overall health and well-being among adolescents (Lee-Chiong, 2008). According to data from the CDC (2013), over 75\% of adolescents in America visited their family doctor or clinic within six-month time intervals. Consequently, over 8.8 million adolescents (12\%) in America visited the emergency room within the last year and 4.2 million adolescents (6\%) visited more than twice, based on data released by the CDC (2013). Sleeplessness created $\$ 16$ billion in annual health care expenses and $\$ 50$ billion is lost from a lack of productivity as compiled from data from NIHJ (2014). Consequently, the gap in the literature continued as parental dynamics that may enhance better sleep habits in adolescents. 


\section{Summary and Conclusions}

In summary, the major themes in the literature consisted of sleep health hygiene, adolescent health, parental perspectives, recognition, knowledge, understanding, effects of inadequate sleep, and health professional influence. Research studies were presented that demonstrated the magnitude of significant issues related to sleep disorders affecting 25 million American adolescents, based on data from the NSF (2015). These findings also conveyed that adolescent sleep disorders attributed to increased health services and budget control by health care administrators (Tripuraneni et al., 2013). The research, however, failed to provide an understanding of how parental perspectives are promoting sleep health hygiene among adolescents.

This Chapter 2 highlighted various research conclusions on sleep with a correlation to the impact on adolescent behaviors and health. The literature review dwelled into prominent research concepts involving adolescent sleep health hygiene, statistics, importance, parental perspectives, promotion, influence, recognition, knowledge, effects, consequences, and health professional influence. In addition, gaps within research indicated a common theme with parent perspectives for strategies to promote better behaviors for sleep patterns. In the next Chapter, I provided research methods and described this study's proposed research design and rationale. I described my role as the researcher, discussed the methodology, issues of trustworthiness, and ethical procedures. 
Chapter 3: Research Methods

\section{Introduction}

Health professionals may not fully understand how parental perspectives may promote adolescent sleep health. The purpose of this study was to understand parental perspectives held on adolescent sleep health. This chapter provides an understanding of how the problem and purpose of this study was addressed through methodology. In this chapter, I provide the research methods and design. Specifically, I address the research design strategy and rationale. I then cover my role as the researcher. In the methods section, I cover the participant sample and inclusion criteria. Next, I cover the data collection and data analysis, followed by the areas of trustworthiness, readability, transferability, dependability, confirmability, and ethical procedures. I end this chapter by summarizing the current chapter and foreshadowing the research design and rational in Chapter 4.

\section{Research Design and Rationale}

Phenomenology's hallmark has included providing the researcher with the ability to glean the core essence of phenomena under study from research participants who have a shared experience (Zenobia, Yuen-ling, \& Wai-tong, 2013). Although variations of phenomenological approaches existed, I used descriptive phenomenology because, according to Zenobia et al. (2013), it is fitting when little is known about an area of research. This type of method enables researchers to understand the lived experiences and how the phenomena of study is perceived and experienced by the participants as their 
realities (Penner \& McClement, 2008). It is the lived experiences as well as the parents' interpretation of these experiences that may bring an understanding of their realities as aligned with their role in influencing their adolescent's sleep health. The research questions were

RQ1: What strategies do parents use to recognize potential unhealthy sleep habits in adolescents?

RQ2: What knowledge do parents obtain to promote better daily behaviors for sleep health habits in adolescents?

RQ3: Which conditions and behaviors do parents consult health professionals for sleep problems in adolescents?

As the central focus of my study, I explored parental perspectives to promote adolescent sleep health. The central phenomena included viewpoints, communication, behaviors, and perceptions of parents. Health professionals may not fully understand parental perspectives to promote adolescent sleep health and, consequently, this lack of knowledge may contribute to medically significant sleep health disorders (Paiva \& Matos, 2011) and less than optimal well-being in the affected population of adolescents (Worcester, 2011). Consistent sleep has been found to be essential for repair and restoration of the human body (Paiva \& Matos, 2011). The state and communities must understand the barriers of achieving sleep health to improve overall health of adolescents and adults (Worcester, 2011). Sleep health standards are relevant for restoration and healthy lifestyles including improved sports performance, academic achievement, and 
career success later in life (Zhu et al., 2013). Parental perceptions may prove significant to the adolescent health discipline, specifically for promoting healthy eating and physical activity at home (Andersen et al., 2014).

The research tradition identified for my study was descriptive, phenomenological, and qualitative, applying Colaizzi's strategy for data analysis of answers obtained from using open-ended interviews. This tradition originates from the field of philosophy, noted by Husserl, who revealed that understanding individuals' lived experiences is derived by allowing emergent ideas through qualitative inquiry (as cited in Zenobia et al., 2013). The rationale for choosing descriptive, phenomenological, qualitative research methods over other phenomenological approaches and methods was that this approach supported my goal of ascertaining perceptions, viewpoints, beliefs, meanings, attributes, meanings, values, and symbolism that are difficult or impossible to quantify mathematically. Moreover, according to Zenobia et al. (2013), phenomenology is a philosophy-based research method for the exploration and understanding perspectives of people.

Phenomenological styles, specifically Colaizzi’s strategy, may be used to analyze interviews and have proven successful with studies related to health care, human behavior, and health experiences (Moustakas, 1994). In addition, qualitative studies guide the purpose, methods, data collection, and analysis process (Web Center for Social Research Methods, 2006). Through the use of the phenomenological method, the development of rich, thick descriptions of in-depth responses can be achieved by the researcher (Turner, 2010). Therefore, I used open-ended interview question formats that 
were purposive to obtain these rich and thick qualitative in-depth perspectives based on the experiences and viewpoints from the participants (Turner, 2010). Finally, Colaizzi's strategy proved to be successful for McGarry et al. (2015) who interviewed 21 parents whose children suffered from burns; McGarry et al. revealed that health care professions were better equipped to optimize holistic clinical approaches and protocols within clinic settings. Based on the aforementioned justifications, I believed that the descriptive, phenomenological, qualitative research tradition using Colaizzi's data analysis strategy and open-ended interview questions was best suited to help address this study's research questions.

\section{Role of the Researcher}

My role as the researcher involved data collection and analysis for a pilot study involving two participants and the main study using 20 participants. As a researcher, I did not have any existing personal or professional relationships with the parental participants including supervisory or instructor relationships that could impose power differentials over the participants.

I managed biases primarily through organizing data in brackets, clusters, themes, and trends. Bracketing, according to Zenobia et al. (2013), should be used to ensure that biases are managed at the outset of the study and used throughout the data analysis process. Organizing data into brackets clusters, themes, and trends includes acknowledging judgmental or subjective preconceived ideas and putting these ideas aside 
so that personal experiences do not interfere with the emergent themes that may be identified in the data (Zenobia et al., 2013).

Unlike the hermeneutic approach where my ideas could be incorporated during the analysis to help discern the meaning of the data, with the descriptive approach, I refrained from doing so. Therefore, I bracketed my biases by setting aside my ideas and allowed the true lived experiences of participants to emerge through data analysis. I managed this process using a self-reflection journal, where I recorded my thoughts and ideas. I was then able to reflect on my analysis more thoroughly to ensure that no biases were present.

My role as a researcher was to also ensure trustworthiness and credibility. I used triangulation for data collection in comparison to current research studies to, as recommended by Golafshani (2003), to assure trustworthiness of the descriptive phenomenological qualitative data. Second, as a researcher, I compared and verified my field notes and audio recordings captured during the interviews to the coded data as suggested by Armour et al. (2009) and Taylor and Gibbs (2010). Third, I maintained a self-reflection journal during the data collection and analysis process. Further, to ensure credibility, I conducted a pilot using two individuals. This helped to validate my research approach as well as to substantiate that my interview questions had face validity. These results were used to confirm that my questions addressed the research questions and achieved what they purported to do (Golasfshani, 2003). I also used member checking and follow-up with participants in cases when interview data proved to be questionable 
and I required further clarification. I ensured that the request for follow up was included in the informed consent process.

To ensure the protection of human subjects, I completed the National Institute of Health's human research subject training (Appendix D). At the outset, however, I did not anticipate that my research would bring about any ethical dilemmas specific to my interview questions. These questions were not intrusive in nature, and I did not anticipate that they would generate an emotional response from participants. In the event any parental participant would have experienced emotional issues from the interviews as a result of feeling negligent for his or her adolescent's sleep health, a reference list was available, as provided in Appendix E. This list was a source for free parental counseling by telephone, Internet, or face-to-face. Additionally, I did not anticipate any ethical issues concerning coercion based on this study's interview settings. As the interviewer, I did not conduct data collection from my work environment. This eliminated the risk of participants thinking that they must take part in the study do to a work related obligation. Therefore, interviews occurred in a mutual agreed upon environment that was feasible for the participants.

Per Walden University's Institutional Review Board (IRB), thank you gifts to research participants may be issued no more than $\$ 5$ value (personal communication, September 11, 2014). As a thank you to the participants of this study, I provided teddy bears (valued at $\$ 1$ ) to the parent participants to give to their children with personalized notes thanking the parents for their time and efforts to contribute to social change by 
promoting adolescent sleep health. Finally, additional details on trustworthiness and ethical procedures were provided later in this Chapter 3.

\section{Methodology}

\section{Participant Selection Logic}

The population identified for this study was parents among the Southeastern region of the United States. My sample included parents with adolescents between the ages of 13-18. This sample was justified and significant for delving into the missing gap in literature to understand the views of parents and to advocate for social change for healthier adolescent lifestyles. The sampling strategy and data collection criteria was targeted for a sample of 20 parents that used convenience-based sampling selected across the Southeastern region of the United States using semistructured, open-ended interview questions. Convenience based sampling was rationalized as the best approach to accomplishing the goals of this study. As stated in the limitations section of Chapter 2, the possible drawback of convenience-based sampling was that the data collection may not represent the viewpoint of the entire particiapnt population (Mason, 2010). Phenonmenology studies, however, are specific to a group of individuals who have experienced the same phenomena of research inquiry.

\section{Inclusion Criteria and Sample}

The inclusion criteria for participant selection was based upon parents among the Southeastern region of the United States with adolescents (ages 13-18) who speak English and were willing to agree to the informed consent (Appendix B). The number of 
participants was 20 parents. The rationale for the sample size was that descriptive, phenomenological, qualitative studies should include sample sizes with no more than 20 participants to enhance the validity of the study (Crouch \& McKenzie, 2006). Further, smaller sample sizes for qualitative studies are less time consuming, more practical, and alleviate repetitive and superfluous data (Mason, 2010). Attentiveness is essential and critical by the researcher during the interview process and collection of data (Turner, 2010). Thus, the data collection approach and key research questions targeted a population of 20 parents using convenience-based sampling selected across the Southeastern region of the United States using interview questions.

Once Walden University IRB approval number 03-17-15-0313916 with expiration date 03-16-2015 was granted, I employed procedures outlined in my IRB application to identify, contact, and recruit parental participants for this study. I used a recruitment flyer and a process known as snowball sampling. My flyer was provided to individuals who may know others who met the inclusion criteria for this study (Appendix A). Each participant was asked to complete informed consent (Appendix B), and interview protocol (Appendix C). A sample size of 20 parents that stretched over the Southeastern region of the United States was used for this study as recommended by Turner (2010) as being the appropriate size to reach data saturation. My study was within the scope and standards to assure I reached saturation as suggested by Mason (2010). 


\section{Data Collection and Instrumentation}

The primary instrument for this research was me as the researcher and the semistructured interview tool (Appendix C). Upon Walden University IRB approval, I began participant recruitment. I solicited research participants using recruitment flyers (Appendix A) distributed by convenience-based sampling techniques. I used Internetbased social media sites to advertise this study, once permission was obtained from site administrators. Additionally, I solicited within my community located in the Southeastern region of the United States. I used public bulletin boards such as libraries, grocery stores, community recreational facilities, and other public locations.

The participants were required to provide informed consent (Appendix B). I conducted all of the interviews by telephone using an audio recorder because most of the participants were reluctant or not comfortable to use Skype or other video recording, as initially planned. I transcribed these interviews and placed them in NVivo qualitative data analysis software for review and data management. I subsequently fashioned thematic data into a report for the participant to review (member checking) and confirmed the accuracy of the information collected. I used field notes and employed strategies during the interview process to serve as a contingency, should the recorder or associated technology fail. This process enabled me to collect rich, detailed data using a systematic process, as posited by Turner (2010). The interviews were comprised of multiple parts to ensure that I established a rapport with participants. This was important so that I would have the best chance of eliciting their full disclosure of their experiences. 
Additionally, by creating an interview protocol with introduction, interview instructions, ice-breaker, list of probing questions, pauses for data recording, and concluding thank you statement, I believe that I accomplished the goals of my research (Appendix C). In addition to interview questions, I created a list of open-ended probing questions that were based on models of other successful phenomenological studies (McGarry et al., 2015; Rice, 2014). My list of questions were reviewed and validated by subject matter experts (pediatridicans and sleep medicine experts) whose professional experience aligned with the scope and content of this study.

In Table 2, I provide a rationale for the purpose of each interview question in alignment to the research questions and theories associated with this descriptive, phenomenological, qualitative study investigating parental perspectives to promote adolescent sleep health.

Table 2

Alignment of Interview Questions With Research Questions and Theories

\begin{tabular}{ccc}
\hline Interview questions & Research questions & Theories \\
\hline $1-4$ & RQ1 & SLT \\
$5-8$ & RQ2 & AP \\
$9-12$ & RQ3 & RRTS \\
$1-13$ & RQ1, RQ2, RQ3 & TCS \\
\hline
\end{tabular}

\section{Procedures for Pilot Study}

My pilot study consisted of two research participants to pretest the interpretation of the interview questions. The rationale for using only two parental participants was in accordance with Simon's (2011) recommendation of achieving $20 \%$ of the research 
sample as the appropriate pilot strategy. The pilot study was conducted separately and results were not included in the main study or reported in the dissertation. The pilot study enabled me to work out any flaws with the interview questions before I interviewed the main participants.

Procedures for pilot participants also included recruitment flyers (Appendix A), informed consent (Appendix B), and interview tool (Appendix C). The same data collection and analysis procedures, as identified for the main study, were used for the pilot and main study. No major issues arose from the pilot study. If any major issues had arisen during the pilot study that required modification of the interview tool, IRB would have been contacted to request approval for any deemed modifications. I stopped reviewing here due to time constraints. Please go through the rest of the chapter and look for the patterns I pointed out to you. I will now look at Chapter 4.

\section{Procedures for Recruitment, Participation, and Data Collection}

I collected data from the parental participant interviews utilizing conveniencebased sampling among the Southeastern region of the United States after IRB approval number 03-17-15-0313916 with expiration date 03-16-2016 was granted. The interviews were conducted by telephone, using an audio recorder. As indicated earlier, participants were either reluctant or not comfortable to use Skype or other video recording. The recordings were transcribed into a report for the participant to review and confirm accuracy of information collected. I continued to promote recruitment using flyers until obtaining 20 participants proportionally spread over the Southeastern population of the 
United States. At any time during the interviews, participants were willingly able withdraw if they did not wish to proceed. If this would have occurred, I would have solicited replacement participant(s). Arrangements were made with the participants in the event any follow-up interviews would have been necessary.

\section{Data Analysis Plan}

In Table 3, I list how I replicated each of the seven steps from the Colaizzi's strategy for data analysis for this study.

Table 3

Purpose of Colaizzi's Strategy to the Data Analysis

\begin{tabular}{|c|c|c|}
\hline Step & Action & Data analysis process \\
\hline 1 & Transcribe & $\begin{array}{l}\text { Transcribe parental interviews dialog into detailed report } \\
\text { loaded in NVivo qualitative data analysis software }\end{array}$ \\
\hline 2 & Extract & $\begin{array}{l}\text { Extract significant statements from parental transcripts and } \\
\text { analyze within reports }\end{array}$ \\
\hline 3 & Interpret & $\begin{array}{l}\text { Interpret meanings of parental responses from the extracted } \\
\text { significant statements }\end{array}$ \\
\hline 4 & Categorize & $\begin{array}{l}\text { Categorize and sort parental interpretations into clusters and } \\
\text { themes }\end{array}$ \\
\hline 5 & Narrate & $\begin{array}{l}\text { Narrate parental perceptions within exhausted report with } \\
\text { descriptions }\end{array}$ \\
\hline 6 & Conceptualize & $\begin{array}{l}\text { Conceptualize the fundamental findings of each parental } \\
\text { response }\end{array}$ \\
\hline 7 & Validate & Validate the interpretation with the parents \\
\hline
\end{tabular}

As listed in Table 3, I replicated Colaizzi's strategy and used the following seven steps: (a) transcribe and review each parent interview transcript thoroughly to obtain content; (b) extract significant statements from the parents pertinent to research questions, such as descriptions of how a parent feels about the sleep habits of their adolescents; (c) interpret and formulate meanings from direct quotes of the parents for 
accurate data reflection; (d) categorize the meanings of responses from the parents through data analysis of themes and clusters; (e) narrate the results into a comprehensive report; (f) conceptualize the fundamental findings of each response; and lastly, (g) validate the interpretation with the parents (Speziale and Carpenter, 2007).

NVivo software was used for data analysis enabling organized collection of interviews into themes and trends for synthesis and understanding of the primary phenomena and core essence of the participant's lived experiences. No discrepant cases were found.

\section{Issues of Trustworthiness}

\section{Credibility}

As asserted by Patton, trustworthiness can be achieved with the development of sound, ethical research without threats that jeopardize the quality of a study or research participants (as cited in Mason, 2010). I completed trustworthiness training and am certified from the National Institute of Health Office of Extramural Research to protect human research participants (Appendix D). I maintained credibility by following the IRB approved data collection process and through professionalism and business-like conduct with study participants. I allowed for 45-60 minutes during each interview to ensure that I was able to extract thick, rich, detailed descriptions based on participant responses (Mason, 2010). I limited sampling to 20 participants as Mason (2010) asserted that the point of saturation is when no relevant or new information occurs. After the interview, I 
provided each participant with a transcription of their interview to verify if the information was correct.

\section{Transferability}

Within this study, I established transferability protocols to the degree that other researchers may be able to generalize more studies to investigate parental perspective to promote adolescent sleep health among other regions, perhaps the Northwestern region of the United States. In addition, I established possible dissemination of one to two page result summaries for transferability to health services, health care administrators, parents, families, schools, pediatricians, and sleep medicine journals with examples of parental viewpoints to promote better sleep habits or techniques to identify sleep disorders to seek treatment from health professionals.

\section{Dependability}

Dependability was attained through establishing audit trails and using triangulation. By using Colaizzi's methods, I established a protocol that can be replicated by future researchers. Additionally, I have established using NVivo software where I organized the collection of interviews, questionnaires, and surveys into themes and trends for possible synthesis and interpretation. Each of these processes can be replicated using the aforementioned approaches.

\section{Confirmability}

I achieved confirmability and reliability by employing check points and rechecks throughout the study as well as through the use of member checking. Additionally, my 
supervisory committee was responsible for advising me if any issues arose regarding confirmability.

\section{Ethical Procedures}

I followed all identified ethical procedures. Once I received approval of the IRB application, I applied the approval number 03-17-15-0313916 with expiration date 03-162016 to all interview and informed consent documentation. No ethical issues were foreseen for this research study. Agreements to gain access to participants were by recruitment flyers (Appendix A) and an informed consent (Appendix B). I treated all research participants with professionalism and business-like conduct. During the interview process, I was empathetic, used active listening techniques, and established a rapport with participants. I protected the identity and confidentiality of the participants by masking their names, using participant number, unique numeric identifier, and pseudonyms.

I ensured that all participants understood that taking part in the interviews was voluntary and would last between 45-60 minutes. The interviews were audio recorded. After the interview, I transcribed them into a written report for review by the participant and confirmation of accuracy of information collected. At any time during the interview, the research participant may have withdrawn if uncomfortable with the content of the interview process.

The confidentiality of the research results were assured as only I, as the researcher, and my Walden University dissertation supervisory committee had complete 
access to the descriptive phenomenological qualitative data. No associated risks were identified for participation in this study. In the event any parental participant experienced emotional issues from the interviews as a result of feeling neglect for adolescent sleep health, a reference list was available in in Appendix E as a source for free parental counseling by telephone, Internet, or face-to-face. I stored written interview information in a locked and secure place. Electronic information was password protected. Each of these artifacts will remain in storage for duration of 5 years (Personal Communication. September 11, 2014).

Finally, I ensured that interviews did not occur on my work premise. Interviews took place from home or mutual environment feasible for both the researcher and the participant. Per Walden University IRB, thank you gifts to research participants may be issued no more than $\$ 5$ value (Personal Communication, September 11, 2014). As thank you to the participants of this study, the researcher gave teddy bears (valued at \$1) to the parent participants to give to their child with personalized note thanking the parents for their time and efforts to contribute to social change by promoting adolescent sleep health.

\section{Summary}

In this chapter, I provided the research design and rationale, role of the researcher, methodology, participant selection logic, instrumentation, pilot study procedures, recruitment, participation, data collection, data analysis, issues of trustworthiness, and ethical procedures. In Chapter 4, I provided summaries of the demographics, data collection, data analysis, evidence of trustworthiness, and study results. 
Chapter 4: Results

\section{Introduction}

The purpose of this descriptive, phenomenological, qualitative research study was to investigate the problems of adolescent sleep health with a focus of understanding perspectives and views of parents among the Southeastern region of the United States. The research questions (RQ) were the following:

RQ1: What strategies do parents use to recognize potential unhealthy sleep habits in adolescents?

RQ2: What knowledge do parents obtain to promote better daily behaviors for sleep health habits in adolescents?

RQ3: Which conditions and behaviors do parents consult health professionals for sleep problems in adolescents?

In this chapter, I provide an overview of the key results of parental perspectives that led to the conclusions in Chapter 5. In this chapter, I describe the pilot study, research setting, demographics, data collection, data analysis, evidence of trustworthiness, and final results. Then, in the next chapter, I provide final discussions, conclusions, and recommendations.

\section{Pilot Study}

I conducted a pilot study in March 2015. As asserted by Simon (2011), pilot studies are used to work out any flaws prior to proceeding to the main study. I conducted a pilot study to test interview questions before I interviewed the main participants. As 
Simon recommended, I used parental participants because $20 \%$ of aggregate pool of participants from the main study should be pilot tested. The pilot study was conducted separately, and the results were not reported in the dissertation. Two participants were initially recruited for the pilot study using recruitment flyers (Appendix A), informed consent (Appendix B), and interview tool (Appendix C). One of the pilot participants withdrew during the interview with emotional issues that involved a lack of support from her boyfriend and mother to raise her daughter. I offered her counseling telephone numbers from the free parental counseling resource list (Appendix E). She refused the counseling numbers and stated she needed to resolve the issues with her boyfriend and mother. In lieu of this individual withdrawing, I recruited a replacement pilot participant. The pilot study was successful and enabled me to move forward with the main study without any changes to the original proposal. The recruitment flyers and informed consent procedures were successful tools to generate participants. Prior to conducting the pilot study, I consulted a subject matter expert and determined the phenomenological interview questions were aligned with the research questions for valid responses. The pilot interviews averaged 45-60 minutes and led to 20-25 pages of thick, rich, descriptive information. No changes were necessary for the instrumentation or data analysis strategies. The same data collection and analysis procedures were used for the pilot participants as the main participants. If any major issues had arisen during the pilot study that required modification of the interview tool, IRB would have been contacted to request approval for any deemed modifications. 


\section{Research Setting}

I conducted research for this a descriptive, phenomenological, qualitative study in April 2015 by private recorded telephone interviews with parents from 13 states in the Southeastern region of the United States including Alabama, Arkansas, Florida, Georgia, Kentucky, Louisiana, Maryland, Mississippi, North Carolina, South Carolina, Tennessee, West Virginia, and Virginia. In Figure 7, I illustrated with star symbols as indicators of the origins of recruitment of the 20 parental participants proportionally spread over the 13 states of the Southeastern region of the United States.

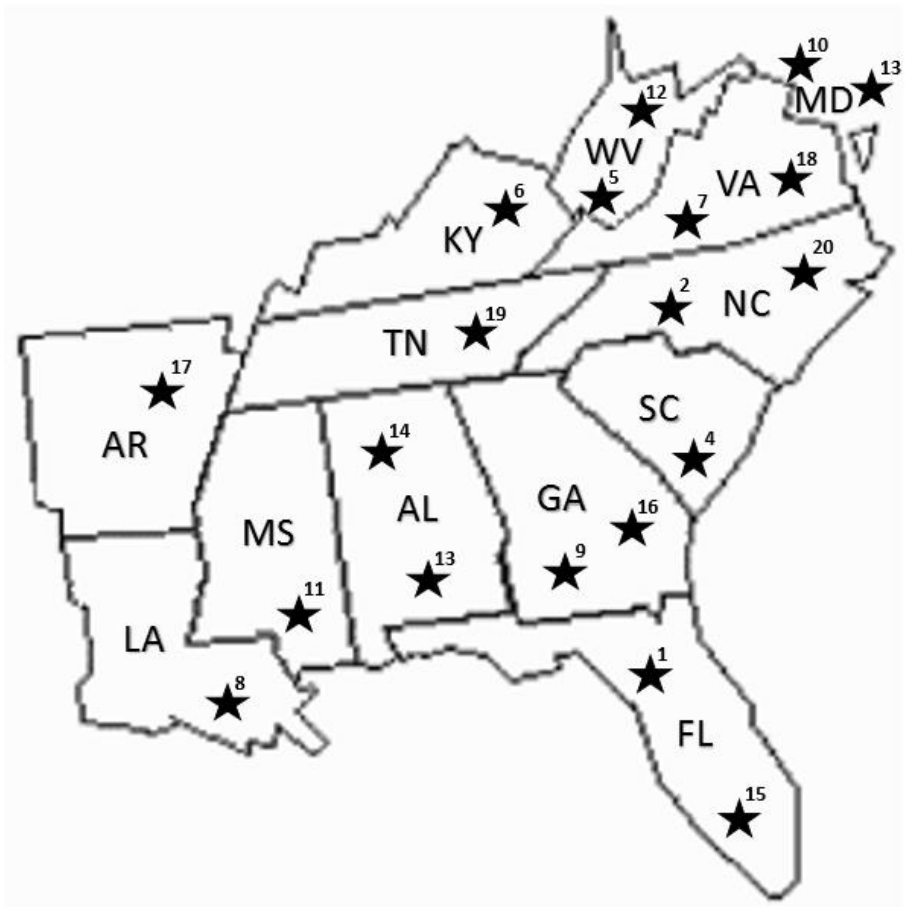

Figure 7. Demographic setting of the research

At the time of the study, some of the participants expressed personal concerns related to being video recorded. I originally planned to use Skype or video recording. The majority of the parental participants who were recruited preferred telephone recording 
and were either not comfortable or reluctant to be video recorded. To assure no issues or discrepancies would occur within the results of the study, I conducted all of the interviews consistently over the phone.

For interview scheduling purposes and organization of the telephone interviews with the parents, I retained a log documenting dates, times, and contact information with only the first name to preserve confidentiality. No other personal or organizational conditions influenced participants at the time of the study that may have influenced the interpretation of the study results. None of the main participants withdrew from the study. Several of the participants, however, needed to reschedule their initial interview appointment for another date and time due to unexpected temporary sickness or workrelated obligations.

\section{Demographics}

The demographics and characteristics of the 20 parent participants among the Southeastern region of the United States relevant to the study included their state, race, marital status, number of adolescent children, occupation, spouse occupation, and income class. Each of these characteristics is listed in Table 4. 
Table 4

Characteristics of the Participants

\begin{tabular}{|c|c|c|c|c|c|c|c|}
\hline$\#$ & State & Race & Status & Children & $\begin{array}{l}\text { Participant } \\
\text { Occupation }\end{array}$ & $\begin{array}{l}\text { Spouse } \\
\text { Occupation }\end{array}$ & $\begin{array}{l}\text { Income } \\
\text { Class }\end{array}$ \\
\hline 1 & FL & White & Married & 2 & $\begin{array}{l}\text { Social } \\
\text { Worker }\end{array}$ & $\begin{array}{l}\text { Graphic } \\
\text { Artist }\end{array}$ & Middle \\
\hline 2 & $\mathrm{NC}$ & Black & Married & 2 & Professor & Policeman & Middle \\
\hline 3 & $\mathrm{AL}$ & Black & Married & 4 & $\begin{array}{l}\text { Child } \\
\text { Development }\end{array}$ & Air Force & Middle \\
\hline 4 & $\mathrm{SC}$ & Black & Married & 3 & $\begin{array}{l}\text { Medical } \\
\text { Professional }\end{array}$ & $\begin{array}{l}\text { Property } \\
\text { Inspector }\end{array}$ & High \\
\hline 5 & WV & White & Married & 1 & Real Estate & Engineer & Middle \\
\hline 6 & KY & White & Married & 2 & $\begin{array}{l}\text { College } \\
\text { Administrator }\end{array}$ & $\begin{array}{l}\text { Corporate } \\
\text { Administrator }\end{array}$ & Middle \\
\hline 7 & VA & White & Single & 2 & Cook & $\mathrm{n} / \mathrm{a}$ & Middle \\
\hline 8 & LA & White & Married & 2 & Physician & Professor & High \\
\hline 9 & GA & White & Married & 5 & Government & Army & High \\
\hline 10 & MD & Black & Married & 2 & Government & $\begin{array}{l}\text { Law } \\
\text { Enforcement }\end{array}$ & High \\
\hline 11 & MS & White & Divorced & 2 & Medical & $\mathrm{n} / \mathrm{a}$ & Middle \\
\hline 12 & WV & White & Divorced & 2 & $\begin{array}{l}\text { Marketing } \\
\text { Director }\end{array}$ & Teacher & Middle \\
\hline 13 & MD & White & Married & 3 & Teacher & Engineer & High \\
\hline 14 & $\mathrm{AL}$ & Black & Divorced & 2 & $\begin{array}{l}\text { Nursing } \\
\text { Assistant }\end{array}$ & $\begin{array}{l}\text { Automotive } \\
\text { Detailer }\end{array}$ & Low \\
\hline 15 & FL & White & Divorced & 2 & Professor & $\mathrm{n} / \mathrm{a}$ & Middle \\
\hline 16 & GA & Black & Married & 6 & Photographer & Photographer & Middle \\
\hline 17 & AR & White & Married & 2 & $\begin{array}{l}\text { Parole } \\
\text { Officer }\end{array}$ & Attorney & Middle \\
\hline 18 & VA & White & Divorced & 2 & $\begin{array}{l}\text { Military } \\
\text { Officer }\end{array}$ & $\mathrm{n} / \mathrm{a}$ & Middle \\
\hline 19 & TN & Hispanic & Married & 3 & $\begin{array}{l}\text { Public Policy } \\
\text { Administrator }\end{array}$ & $\begin{array}{l}\text { HVAC } \\
\text { Technician }\end{array}$ & Middle \\
\hline 20 & $\mathrm{NC}$ & White & Married & 4 & Medical & Engineer & Middle \\
\hline
\end{tabular}




\section{Data Collection}

\section{Interviews}

I collected data from 20 parents by 45 to 60 minute, private, recorded telephone interviews among 13 states in the Southeastern region of the United States including Alabama, Arkansas, Florida, Georgia, Kentucky, Louisiana, Maryland, Mississippi, North Carolina, South Carolina, Tennessee, West Virginia, and Virginia. I used the interview tool in Appendix C comprised of interview questions, validated by subject matter experts, pediatricians, and sleep medicine experts whose professional experience aligned with the scope and content of this study.

\section{Data Masking}

For reporting the results, I protected the identity and confidentiality of the participants by masking their names with the use of participant numbers, unique numeric identifiers, and pseudonyms. I audio recorded and saved telephone interviews files on my laptop computer with secured passwords to ensure privacy, and I used unique numeric identifiers constructed from the participant number, date, and time of the interview. As the researcher, I concluded that numbers were too impersonal to report results; thus, I honored the participants with star and constellation names. These pseudonyms were randomly assigned with the assumption that stars are not gender specific, and the pseudonyms are used when applicable hereinafter in this dissertation when referring to participants. In Table 5, I provided the unique numeric identifiers, parent roles, pseudonyms, and ages. 
Table 5

\section{Data Masking}

\begin{tabular}{|c|c|c|c|c|c|}
\hline \# & $\begin{array}{l}\text { Unique Numeric } \\
\text { Identifier }\end{array}$ & $\begin{array}{l}\text { Parent } \\
\text { Role }\end{array}$ & $\begin{array}{l}\text { Pseudonym } \\
\text { Parent/Age }\end{array}$ & $\begin{array}{l}\text { Pseudonym } \\
\text { Son/Age }\end{array}$ & $\begin{array}{l}\text { Pseudonym } \\
\text { Daughter/Age }\end{array}$ \\
\hline 1 & $01-033115-1400$ & Mom & Shashni/45 & $\begin{array}{l}\text { Lanx/18 } \\
\text { Sirius/13 }\end{array}$ & N/A \\
\hline 2 & $02-033115-1700$ & Mom & Andromeda/48 & Ksora/18 & Marfik/26 \\
\hline 3 & $03-033115-1850$ & Mom & Denebola/43 & $\begin{array}{l}\mathrm{Jih} / 22 \\
\mathrm{Dabih} / 9\end{array}$ & $\begin{array}{l}\text { Dheneb/17 } \\
\text { Dnoces/11 }\end{array}$ \\
\hline 4 & 04-033115-1945 & Mom & Talitha/33 & Jomam/6 & $\begin{array}{l}\text { Nava/13 } \\
\text { Asterion/11 }\end{array}$ \\
\hline 5 & $05-040715-1630$ & Mom & Kirithiga/46 & Jcynosura/17 & N/A \\
\hline 6 & 06-040715-1800 & Mom & Kiriya/38 & $\begin{array}{l}\text { Gacrux/15 } \\
\text { Edasich/10 }\end{array}$ & N/A \\
\hline 7 & $07-040815-1700$ & Mom & Alya/36 & Castor/11 & Vindemiatrix/15 \\
\hline 8 & $08-041215-1420$ & Dad & Ashwin/49 & $\begin{array}{l}\text { Beid/17 } \\
\text { Kuma/13 }\end{array}$ & N/A \\
\hline 9 & $09-041315-1100$ & Mom & Mrudani/45 & $\begin{array}{l}\text { Menkent/20 } \\
\text { Zaniah/16 } \\
\text { Tabit/16 }\end{array}$ & $\begin{array}{l}\text { Terebellum/21 } \\
\text { Sadalsuud/18 }\end{array}$ \\
\hline 10 & $10-041315-1230$ & Dad & Jabbah/48 & N/A & $\begin{array}{l}\text { Taygeta/17 } \\
\text { Capella/15 }\end{array}$ \\
\hline 11 & $11-041315-1400$ & Dad & Kawkab/36 & N/A & $\begin{array}{l}\text { Electra/15 } \\
\text { Hamal/13 }\end{array}$ \\
\hline 12 & $12-041315-1800$ & Dad & Belros/41 & Iwast/9 & Pleione/14 \\
\hline 13 & $13-041415-1730$ & Mom & Mugana/50 & Edasich/16 & $\begin{array}{l}\text { Juchba/17 } \\
\text { Minelava/14 }\end{array}$ \\
\hline 14 & $14-041515-0930$ & Mom & Deneb/40 & Matar/17 & Scheat/23 \\
\hline 15 & $15-041615-0930$ & Mom & Mughilsri/45 & Lasuperba/15 & Lrumium/14 \\
\hline 16 & $16-041915-1650$ & Dad & Latrell/40 & $\begin{array}{l}\text { Decrux/20 } \\
\text { Baham/15 } \\
\text { Lesath/4 }\end{array}$ & $\begin{array}{l}\text { Jhydrobius/19 } \\
\text { Iwezn/4 } \\
\text { Adhatera/1 }\end{array}$ \\
\hline 17 & $17-042015-1215$ & Mom & Azmitha/56 & $\begin{array}{l}\text { Sabik/20 } \\
\text { Sadr/16 }\end{array}$ & N/A \\
\hline 18 & $18-042015-1600$ & Mom & Izar/42 & Magrez/14 & Muscida/22 \\
\hline 19 & $19-042015-1715$ & Mom & Lyra/43 & $\begin{array}{l}\text { Jegor/19 } \\
\text { Menchib/13 }\end{array}$ & Diadem/22 \\
\hline 20 & $20-042115-1400$ & Mom & Shashvina/32 & $\begin{array}{l}\text { Kastra/13 } \\
\text { Lucida/12 } \\
\text { Menkent/8 }\end{array}$ & Canopus/5 \\
\hline
\end{tabular}




\section{Profiles}

During data collection, profile information of the parents and their adolescent children emerged during the interview process. The profiles are provided below in narrative format with a background and context for later discussion. Any variations or unusual circumstances pertaining to the participants are included in the profiles. In the profiles below, I summarized the parent participant number, unique identifier, and pseudonym in accordance to information reported by each parent participant including his or her age, self-identified role, number of adolescent children, city and state, household income status, occupation, and information about the adolescent children such as medical conditions, medications, academia, sports, hobbies, or extracurricular activities.

Participant 1, \#01-033115-1400, Shashni, was a 45-year-old mom of two children at the time of data collection. She identified as a White married woman residing in Destin, Florida. She reported household income as middle class with her occupation as a social worker and her husband as a graphic artist. Shashni described her role as a mom of 18-year-old son Lanx in high school as a senior and 13-year-old Sirius in the eighth grade. Shashni explained that Lanx is in the culinary vocational curriculum and works part time in the evenings and nights at a fine dining restaurant. She noted her youngest son Sirius does not work but has allergies and has been diagnosed with attention deficit hyperactivity disorder (ADHD), taking Benadryl which causes memory loss, Zyrtec, Adderall, and sometimes, melatonin as some of the medications affect his sleep. Shashni 
indicated that Lanx played sports in grade school until he had an ankle injury, and Sirus plays softball and kick ball. She added that both boys like to surf, swim, and fish.

Participant 2, \#02-033115-1700, Andromeda, was a 48-year-old mom of two children at the time of data collection. She identified as a Black married woman residing in Waxhaw, North Carolina. She reported household income as middle class with her occupation as a professor and her husband as a policeman. Andromeda described her role as a mom of 26-year-old daughter, Marfik, and 18-year-old son, Ksora, in high school as a senior. Andromeda explained that her daughter, Marfik, now works as a teacher and that her son, Ksora, is a senior in high school preparing for college next year. She clarified that while in school Marfik, worked at a day care center and Ksora worked at a grocery store. Andromeda added that her daughter, Marfik, was often a sleep walker as a child, but she did not disclose any medications taken by either of her children. Andromeda indicated that both children are active with sports, but did not disclose specific activities.

Participant 3, \#03-033115-1850, Denebola, was a 43-year-old mom of four children at the time of data collection. She identified as a Black married woman residing in Vestavia, Alabama. She reported household income as middle class with her occupation in child development and her husband in the Air Force. Denebola described her role as a mom of 22-year-old step son, Jih, in college, 17-year-old daughter, Dheneb, in high school as senior, 11-year-old daughter, Dnoces, in sixth grade, and 9-year-old son, Dabih, in fourth grade. Denebola explained that her husband is often out of town in 
Detroit for work. Denebola explained that Dheneb had her tonsils removed in her early teens for snoring. She added that Dnoces and Dabih were diagnosed with autism and sometimes took melatonin to help sleep. Denebola did not disclose if any of her children work or mention any sports her children play.

Participant 4, \#04-03311501945, Talitha, was a 33-year-old mom of three children at the time of data collection. She identified as a Black married woman residing in Sumter, South Carolina, and planning to move in the next several months to Round Rock, TX. She reported a household income as high class with her occupation in the medical field and her husband as a property inspector. Talitha described her role as a mom of 13-year-old daughter, Nava, in eighth grade, 11-year-old daughter, Asterion, in sixth grade, and 6-year-old son, Jomam, in first grade. Talitha explained that Nava and Asterion are in college preparatory courses and are not old enough to work. She noted that Nava has asthma and was diagnosed at 5-months-old with reactive airway disease, and they had to determine her triggers for allergies and asthma flares with an impact on sleep as well as the proper nebulizer treatment and steroid medications. Talitha added that Asterion sometimes has migraines and severe headaches, but did not disclose any medication she or Jomam takes. Talitha indicated that all of her kids play basketball, softball, and volleyball. She added that they also run track, and Jomam plays tee ball too.

Participant 5, \#05-040715-1630, Kirithiga, was a 46-year-old mom of one child at the time of data collection. She identified as a White married woman residing in Montgomery, West Virginia. She reported a household income as middle class with her 
occupation as an office manager in a real estate office and her husband as a mechanical engineer. Kirithiga described her role as a mom of 17-year-old son, Jcynosura, in the 11th grade of high school. Kirithiga explained that Jcynosura recently began working at the local grocery store and will continue working part time during his senior year of high school. Kirithiga noted that Jcynosura was diagnosed with Asperger's syndrome in the autism spectrum. She added that he also has weight issues, experienced night terrors until he was 14-years-old, and was diagnosed with a sleep cycle disorder with irregular sleep patterns sometimes falls asleep in school. She noted that he takes Zoloft and melatonin. Kirithiga added that her husband has sleep apnea and uses continuous positive air pressure (CPAP) treatment. Kirithiga indicated that Jcynosura has little interest in sports, but as a family they often mountain hike, ice skate, ride bikes, play hockey, soccer, tee ball, and other singular activities versus group. I stopped reviewing here due to time constraints. Please go through the rest of your chapter and look for the patterns I pointed out to you. I will now look at Chapter 5.

Participant 6, \#06-040715-1800, Kiriya, was a 38-year-old mom of two children at the time of data collection. She identified as a White married woman residing in Springfield, Kentucky. She reported household income as middle class with her occupation in college administration and her husband in corporate administration. Kiriya described her role as a mom of 15-year-old son Gacrux in tenth grade and 10-year-old son Edasich in fifth grade. Kiriya explained Gacrux was diagnosed at 3-years old with ADHD and had his tonsils removed when he was 4-years-old for excessive snoring 
problems. She added Edasich often has headaches possibly due to his difficulty sleeping at night. She further added both children experienced occasions of sleep walking until 10years-old. Kiriya noted Gacrux takes Adderall and both children take melatonin and various sleep aids. Kiriya indicated both her boys play football, touch ball, basketball, soccer, and run track as well as involved in drama and theater. She added, they attend church every Sunday.

Participant 7, \#07-040815-1700, Alya, was a 36-year-old mom of two children at the time of data collection. She identified as a White single woman residing in Hampton, Virginia. She explained she does not have contact with the fathers of her children. She reported household income as middle class with her occupation as a cook. Alya described her role as a mom of 15-year-old daughter Vindemiatrix in high school as a sophomore and 11-year-old son Castor in sixth grade. She explained Vindemiatrix will be transferring next year to a special school for the performing arts. Alya added Vindemiatrix grinded her teeth while sleeping as a child but has grown out of the habit after 10-years-old. Alya noted her children are not old enough to work and do not have any health issues. Alya indicated Vindemiatrix is involved with dance and church group activities and Cole plays soccer and is in the cub scouts.

Participant 8, \#08-041215-1420, Ashwin, was a 49-year-old dad of two children at the time of data collection. She identified as a White married man residing in New Orleans, Louisiana. He reported household income as high class with his occupation as an internal medicine physician and his partner as a finance and economics professor. 
Ashwin described his role as a dad of 17-year-old son Beid in high school as a senior and 13-year-old son Kuma in eighth grade. Ashwin explained both boys are adopted and attend Catholic private schools. He added neither of his children work. Ashwin noted Beid was diagnosed with ADD and depression and takes Adderall and Zoloft whereas Kuma was diagnosed with ADHD and talks in his sleep and takes Adderall. Ashwin indicated both of his boys are athletic and ride bikes, run cross country, and exercise. He added Beid plays soccer and Kuma plays basketball.

Participant 9, \#09-041315-1100, Mrudani, was a 45-year-old mom of five children at the time of data collection. She identified as a White married woman residing in College Park, Georgia. She reported household income as high class with her occupation in the government and her husband in the army. Mrudani described her role as a mom of 20-year-old son Menkent in college and 16-year-old son Zaniah in high school as a junior who both reside with her. She explained 21-year-old step daughter Terebellum in college, 18-year-old step daughter Sadalsuud in high school as a senior, and 16-yearold stepson Tabit in high school as a junior all reside in Texas with their mother. Mrudani explained both Menkent and Zaniah have asthma, seasonal allergies, and breathing issues and use nebulizer treatment. Mrudani noted all of the children have part-time jobs in grocery stores or at the mall. Mrudani indicated Menkent plays football and the other children are also active in sports too.

Participant 10, \#10-041315-1230, Jabbah, was a 48-year-old dad of two children at the time of data collection. He identified as a Black married man residing in Upper 
Marlboro, Maryland. He reported household income as high class with his occupation in the government and his wife in law enforcement. Jabbah described his role as a dad of 17-year-old daughter Taygeta in high school as a senior and pre-nursing vocational school and 15-year-old daughter Capella in high school as a sophomore. Jabbah explained the girls sometimes talk in their sleep but do not have any health issues or take medications on a regular basis. Jabbah noted his oldest daughter Taygeta works as a manager for a fast food restaurant after school but Capella does not work yet. Jabbah indicated his daughters are actively involved in dance, ballet, debate, book clubs, and volley ball.

Participant 11, \#11-041315-1400, Kawkab, was a 36-year-old dad of two children at the time of data collection. He identified as a White divorced man residing in Tylertown, Mississippi. He explained he does not have contact with the mother of his children. He reported his household income middle class with his occupation in the medical field. Kawkab described his role as a dad of 15-year-old daughter Electra and 13year-old daughter Hamal. He explained both girls occasionally talk during their sleep and Electra was has weight issues and was diagnosed with sleep apnea and type II diabetes. Kawkab noted Electra uses CPAP nightly and is participating in a trial program for diabetes treatment at the University of Mississippi. Kawkab indicated both of his daughters play soccer and are in the band.

Participant 12, \#12-041315, Belros, was a 41-year-old dad of two children at the time of data collection. He identified as a White divorced man residing in St. Albans, 
West Virginia. He explained he has split custody of his children and that neither he nor his ex-wife have remarried. He reported their household incomes are middle class with his occupation as a marketing director and his ex-wife as a teacher. Belros described his role as a dad with weekend custody of his 14-year-old daughter Pleione in high school as a freshman in the gifted program and his 9-year-old son Iwast in the fourth grade. Belros explained that he has sleep apnea and wears CPAP at night himself. He added that his children are not old enough to work and reported no health issues except Pleione has occasional anxiety and an appendectomy several years. Belros further added, his children do not take any medications on a regular basis. Belros indicated his son Iwast plays soccer and that Pleione plays softball and sings. He said both of his children are involved with church activities.

Participant 13,\#13-041415-1730, Mugana, was a 50-year-old mom of three children at the time of data collection. She identified as a White married woman residing in Lusby, Maryland. She reported household income as high class with her occupation as a teacher and her husband as an engineer. Mugana described her role as a mom of 17year-old daughter Juchba in high school as a senior, 16-year-old son Edasich in high school as a junior, and 14-year-old daughter Minelava in high school as a freshman. Mugana explained Juchba was diagnosed at birth with respiratory syncytial virus (RSV) at birth with breathing issues later requiring nebulizer and asthma medications. Mugana added Edasich has cancer and has frequent treatments. She noted all three of her children take on occasion melatonin and herbal medications to help sleep. Mugana added her 
oldest daughter Juchba works as a restaurant hostess in the evenings after school and as a recreational leader in the summer months. Mugana indicated her daughters compete at national hockey tournaments and her son competes for state soccer championships.

Participant 14, \#14-041515-0930, Deneb, was a 40-year-old mom of two children at the time of data collection. She identified as a Black divorced woman residing in Selma, Alabama. She explained her ex-husband has custody of the children rotated on holidays. She reported household income as low class with her occupation as a restorative aide in a nursing home and her ex-husband as an automobile detailer. Deneb described her role as a mom of 23-year-old daughter Scheat in college and 17-year-old son Matar in high school as a senior. Deneb explained Scheat often has sinus issues and takes Flonase whereas Matar was diagnosed with ADHD and delayed sleep phase syndrome and takes Adderall, Trazadone, and melatonin. Deneb noted her daughter Scheat is involved in gymnastics, her son Matar is in boy scouts, and both of her children work part-time in a grocery store and deliver newspapers while in school.

Participant 15, \#15-041615-0930, Mughilsri, was a 45-year-old mom of two children at the time of data collection. She identified as a White divorced woman residing in Holiday, Florida. She explained she does not have contact with the father of her children. She reported household income as middle class with her occupation as a professor. Mughilsri described her role as a single mom of 17-year-old son Lasuperba in high school as a junior and 14-year-old daughter Lrumium in high school as a freshman. Mughilsri explained Lasuperba has insomnia, night terrors since 2-years-old, 
occasionally talks in his sleep, and walks in his sleep a couple times per year. Mughilsri further explained Lrumium has sensory processing disorder (SPD), ADHD, morning meltdowns, and bruxism taking Adderall, Zoloft, melatonin, and other sleep aids. Mughilsri indicated her son Lasuperba is in Eagle scouts, golfing, and volunteer traveling work whereas her daughter Lrumium coaches horse shows and is in girl scouts. She added both of her children are involved in paddle boarding and water sports.

Participant 16, \#16-041915-1650, Latrell, was a 40-year-old dad of six children at the time of data collection. He identified as a Black married man residing in Lithonia, Georgia. He reported household income as middle class with his occupation as photographer and his wife also as a photographer. Latrell described his role as a dad of 20-year-old son Decrux in college, 19-year-old daughter Jhydrobius in college, 15-yearold son Baham in high school as a sophomore, 4-year-old daughter Iwezn, 4-year-old son Lesath about to begin kindergarten, and 1-year-old daughter Adhatera. Latrell explained his children do not have any health issues or take any medications on a regular basis. Latrell noted his children do not work yet. Latrell indicated his children are all athletic with Baham the most competitive playing basketball in high school.

Participant 17, \#17-042015-1215, Azmitha, was a 56-year-old mom of two children at the time of data collection. She identified as a White married woman residing in Fort Smith, Arkansas. She reported household income as middle class with her occupation as a parole officer and her husband as an attorney. Azmitha described her role as a mom of 20-year-old son Sabik in college and 16-year-old son Sadr in high school as 
a freshman. Azmitha explained Sabik was diagnosed with respiratory syncytial virus (RSV) and breathing disorders at birth whereas Sadr has bronchial issues and weight issues. She added both suffer from depression, allergies, headaches, stress, and sleep marathons. Azmitha further added her children take Adderall, Xanax, and use nasal inhalers. Azmitha indicated both children play football and basketball.

Participant 18, \#18-042015-1600, Izar, was a 42-year-old mom of two children at the time of data collection. She identified as a White divorced woman residing in Stafford, Virginia. She explained she does not have contact with the father of her children. She reported her household income as middle class with occupation in the military. Izar described her role as a mom of 22-year-old daughter Muscida in college and 14-year-old son Magrez in high school in ninth grade. Izar explained she suffers from insomnia herself and takes melatonin but stated her children do not have this issue. She added her daughter Muscida was diagnosed with bruxism and uses retainer, has temporomandibular joint dysfunction (TMJ), and had tonsil removal surgery for snoring. Izar did not disclose if her children work while in school. Izar indicated her children are active with gymnastics and various other sports.

Participant 19, \#19-042015-1715, Lyra, was a 43-year-old mom of three children at the time of data collection. She identified as a Hispanic married woman residing in LaVergne, Tennessee. She reported her household income as middle class with her occupation in public policy and her husband as a home ventilation and air conditioner technician. Lyra described her role as a mom of 22-year-old daughter Diadem in college, 
19-year-old son Jegor in college, and 13-year-old son Menchib in eighth grade. Lyra explained her daughter Diadem was diagnosed with bruxism at 16-years-old and wears a mouth piece. Lyra noted her family has a history of sleep walking but children do not have this issue nor any other health issues or take any medications on a regular basis. Lyra added her oldest two children Diadem and Jegor work part-time in a restaurant while going to school. Lyra indicated her children are active with basketball and other sports.

Participant 20, \#20-042115-1400, Shashvina, was a 32-year-old mom of four children at the time of data collection. She identified as a White married woman in Archdale, North Carolina. She reported her household income as middle class with her occupation in the medical field and her husband as an engineer. Shashvina described her role as a mom of 13-year-old son Kastra in eighth grade, 12-year-old son Lucida in seventh grade, 8-year old son Menkent in third grade, and 5-year-old daughter Canopus in kindergarten. Shashvina explained her oldest son Kastra suffers from Tourette's syndrome, generalized anxiety disorder, depression, social phobia, suicidal thoughts, insomnia, sleep walking, and enuresis (bed wetting). Shashvina added he sees a therapist and takes mood stabilizers, melatonin, and other medications. She reported her other children do not have any health issues or take any medications on a regular basis. Shashvina added her children are not old enough to work. Shashvina indicated her children are active with football and basketball. 


\section{Data Analysis}

For the data analysis process, I used Colaizzi's strategy as outlined in Table 3 to transcribe, extract, interpret, categorize, narrate, conceptualize, and validate the data collected. In addition, NVivo software and hand coding methods were used for data analysis enabling organized collection of interview into themes and trends for possible synthesis and understanding the primary phenomena and core essence of the participant's lived experiences.

To move inductively from coded united to larger representations of categories and themes, I analyzed the data for this study within the lens of the blended theoretical foundation formulated from the four seminal theories illustrated in the conceptual framework diagram in Figure 1. The framework was designed to investigate how the parental perspective phenomenon may promote improved sleep habits for better health among adolescents. I first bracketed the results from the data collection of this study by constructs aligned with the four theories (SLT, AP, RRTS, and TCS) and further coded by the 13 categories within the interview questions and reported common themes and clusters that emerged during the interviews with the parental participants.

The specific codes, categories, and themes were formulated from the three research questions and 13 interview questions as outlined in the blended theoretical foundation outlined in Table 2. The foundation included:

- Bandura's (1977) SLT was aligned with the first research question (RQ1), first interview question (IQ1), second interview question (IQ2), third interview 
question (IQ3), and fourth interview question (IQ4) that all deal with the construct of social learning.

- Nightingale's (1893) AP was aligned with the second research question (RQ2), fifth interview question (IQ5), sixth interview question (IQ6), seventh interview question (IQ7), and eighth interview question (IQ8) that all pertain to the construct of AP.

- Oswald's (1966) RRTS was aligned with the third research question (RQ3), ninth interview question (IQ9), tenth interview question (IQ10), eleventh interview question (IQ11), and twelfth interview (IQ12) that all deal with the construct of sleep health.

- Watson's (1979) TCS was aligned with all three research questions (RQ1, RQ2, and RQ3) and all interview questions with focus on the thirteenth interview question (IQ13) that deal with the construct of caring science.

\section{Evidence of Trustworthiness}

\section{Credibility}

After completion of data collection, I conducted one last literature review to verify the credibility of the literature gap and to verify recent publications pertaining to parental perspectives to promote adolescent sleep health topic. I did not find any new information on the topic. I assured trustworthiness in this descriptive phenomenological qualitative research without threats that jeopardize the quality or research participants. I applied all trustworthiness training techniques learned from the National Institute of 
Health Office of Extramural Research to protect human research participants (Appendix D). I maintained credibility within the data collection process through professionalism and business-like conduct with the parent participants. As recommended by Patton, contact of approximately 60 minutes was provided to interview each participant to assure thick, rich, detailed responses were collected (as cited in Mason, 2010). Thus, I limited sampling to 20 participants to limit saturation to the point of no relevant or new information. After the interview, I provided participants a transcription of the interview and confirmed information is correct.

\section{Transferability}

Within this study, I established transferability protocols to the degree that other researchers may be able to generalize more studies to investigate parental perspective to promote adolescent sleep health among other regions, perhaps the Northwestern region of the United States. In addition, I established result summary tables for possible dissemination to health services, health care administrators, parents, families, schools, pediatricians, and sleep medicine journals with examples of parental viewpoints to promote better sleep habits or techniques to identify sleep disorders to seek treatment from health professionals. I collected rich, thick, detailed data utilizing open-ended question interview formats to capture in-depth perspectives, experiences, and viewpoints from the participants. 


\section{Dependability}

Dependability was attained through establishing audit trails and using triangulation. The interviews were audio recorded and the data analysis reports were compiled to justify the conclusions. Triangulation was used in the data analysis process with Colaizzi's strategies and NVivo software enabling organized collection of interviews, questionnaires, and surveys into themes and trends for possible synthesis and interpretation.

\section{Confirmability}

Confirmability and reliability was achieved by the researcher with check and rechecks throughout the study as well as through the use of member checking.

Replicating Moustakas (1994), I used the process outlined by Colaizzi's strategy to transcribe, extract, interpret, categorize, narrate conceptualize, and validate contributed to all trustworthiness principles. 


\section{Study Results}

The results of the study, as reported in Figure 8, were organized based upon the alignment of research questions established within the blended theoretical foundation including SLT, AP, RRTS, and TCS. The top results, as illustrated in Figure 8, are reported for each research question and aligned theory.

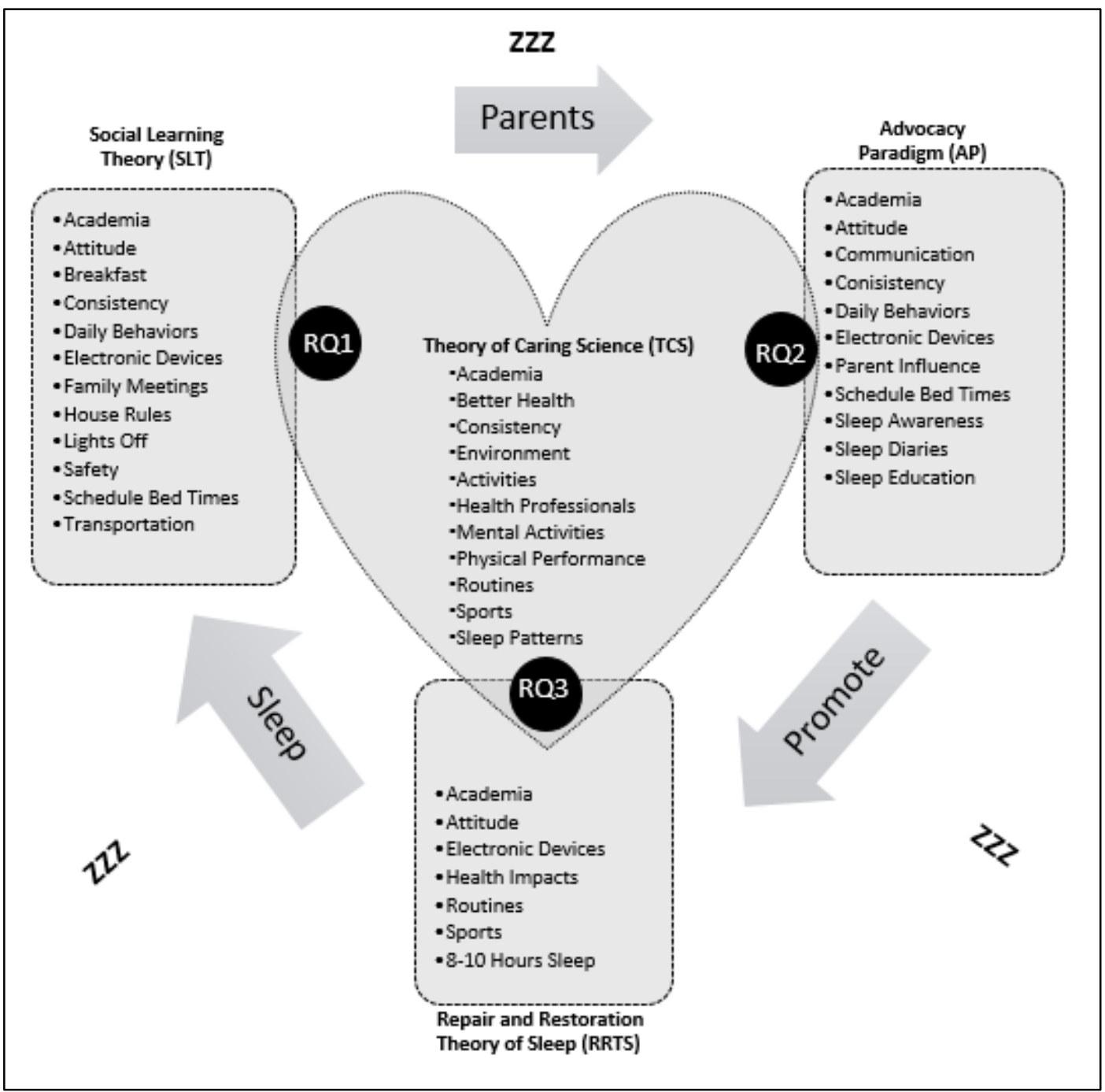

Figure 8. Results of the study 
As denoted in Figure 8, I organized the results in the blended theoretical framework which was originally established in Figure 1. The SLT results related to attitude, breakfast, consistency, daily behaviors, electronic devices, family meetings, house rules, lights off, safety, schedule bed times, and transportation. The AP results related to academia, attitude, communication, consistency, daily behaviors, electronic devices, parental influence, scheduled bed times, sleep awareness, sleep diaries, and sleep education. The RRTS results related to academia, attitude, electronic devices, health impacts, routines, sports, and 8-10 hours of sleep. The TCS science results related to academia, better health, consistency, environment, activities, health professionals, mental activities, physical performance, routines, sports, and sleep patterns.

In the upcoming sections, I expanded upon the results within each blended theoretical framework. Within each section, I clustered the results and reported the top five themes that emerged from each interview question. Furthermore, I provided complete detailed results and quotes from each interview question in tables in the appendices. The tables in the appendices included the common themes and clusters reported by the parents along with the frequency reported by the parent participants.

\section{Social Learning Theory (SLT)}

Bandura's (1977) SLT established that parents, teachers, and society positively influence adolescents through social contexts of observation, learning, monitoring, and interacting. In Figure 2, I depicted how the social learning concepts aligned with RQ1 related to strategies parents use to recognize potential unhealthy sleep habits in 
adolescents. As noted in Table 2, four interview questions (IQ's) were formulated to answer RQ1 to explore strategies (IQ1), difficulties (IQ2), behaviors (IQ3), and social learning (IQ4).

With IQ1 aligned to RQ1, I investigated parental strategies most effective for adolescent sleep health. Parents reported the following top five results:

- $\quad$ schedule bed times for adolescents (15 of 20 [75\%]);

- establish consistent daily routine (9 of 20 [45\%]);

- encourage adolescents to exercise, exhaust themselves, wear down, or wind down before bed (8 of 20 [40\%]);

- plan school transportation in correlation with sleep schedules (7 of 20 [35\%]); and

- $\quad$ read bed time stories to younger adolescents (6 of 20 [30\%]).

A complete listing of all common themes and clusters that emerged related to parental strategies most effective for adolescent sleep health was provided in Appendix F and significant parent quotes were listed in Appendix S.

With IQ2 aligned to RQ1, I examined parental difficulties with adolescent sleep health. Parents reported the following top five results:

- $\quad$ transportation schedules are difficult for adolescents and they miss morning sleep to catch bus, train, metro, or ferry transportation to school (12 of 20 [60\%]);

- electronic devices such as computers, Internet, social media, or television are reasons for difficulty with adolescent sleep habits (10 of 20 [50\%]);

- maintaining consistent bed time schedules (9 of 20 [45\%]); 
- stress, emotions, fear, or anxiety were reasons for sleep difficulties (8 of 20 [40\%]); and

- sleeping at school, or not being focused (7 of 20 [35\%]).

A complete listing of all common themes and clusters that emerged related to parental difficulties with adolescent sleep health was provided in Appendix $G$ and significant parent quotes were listed in Appendix S.

With IQ3 aligned to RQ1, I explored adolescent behaviors related to sleep health. Parents reported the following top five results:

- attitude changes (20 of 20 [100\%]);

- poor performance at school with grades or homework (10 of 20 [50\%]);

- snappy, agitated, short-tempered, crabby, cranky, or moody (9 of 20 [45\%]);

- poor performances with sports or extracurricular activities such as soccer, football, cheer, or dance (7 of 20 [35\%]); and

- watching television or using electronic devices instead of sleeping along with daytime sleepiness and naps (6 of $20[30 \%])$.

A complete listing of all common themes and clusters that emerged related to adolescent behaviors related to sleep health was provided in Appendix $\mathrm{H}$ and significant parent quotes were listed in Appendix S.

For IQ4 aligned with RQ1, I inspected parental perceptions of social learning toward sleep health specifically with interaction, observation, influence, and monitoring. For interaction (IQ4a), parents reported the following top five results: 
- family time and meetings (7 of 20 [35\%]);

- $\quad$ breakfast discussions (7 of 20 [35\%]);

- dinner discussions (6 of $20[30 \%])$;

- family drives (6 of 20 [30\%]); and

- $\quad$ homework and chores (5 of 20 [25\%]).

For observation (IQ4b), parents reported the following top five results:

- observe daily behaviors, attitude, and fatigue (9 of 20 [45\%]);

- observe that adolescents are sleeping and cooperating with the house rules (7 of $20[35 \%])$

- $\quad$ observe sleep habits when sick (6 of 20 [30\%]);

- observe when adolescents need medication such as melatonin or Zoloft (4 of 20 $[20 \%]) ;$ and

- observe adolescents to be alert and not sleepy at day (3 of 20 [15\%]).

For influence (IQ4c), parents reported the following top five results:

- $\quad$ set sleep routines, schedules, and habits when young (10 of 20 [50\%]);

- $\quad$ set guidelines for daily habits (5 of 20 [25\%];

- $\quad$ set parental example and practice same sleep habits as kids (4 of 20 [20\%]);

- enforce no electronic devices or television at bed time (3 of 20 [15\%]); and

- engage with kids to teach health habits overall (2 of 20 [10\%]).

For monitoring (IQ4d), parents reported the following top five results:

- monitor to assure adolescents follow bedtime schedule (10 of 20 [50\%]); 
- $\quad$ monitor to check kids are safe (6 of 20 [30\%]);

- monitor to check kids are sleeping and not pretending (5 of 20 [25\%]);

- monitor to compare sleep patterns versus school and sports performance (3 of 20 [15\%]); and

- monitor to check the lights are off, doors shut, and listen for noises (3 of 20 $[15 \%])$.

A complete listing of all common themes and clusters that emerged related to parental perceptions of social learning toward sleep health specifically with interaction,

observation, influence, and monitoring was provided in Appendix I and significant parent quotes were listed in Appendix S.

\section{Advocacy Paradigm (AP)}

Nightingale's (1893) AP outlined the core concepts of promoting, educating, informing, and communicating (Steefel, 2010). Her strategy was to promote better health habits as essential care strategies relevant within nursing and health service professions (Selanders \& Crane, 2012). My study used these four core concepts to analyze how parents view their role with advocacy in becoming educated to influence better health outcomes (during their child's adolescent stage), and understand how parental ideas and what role they play in sleep health habits of adolescents. In Figure 3, I provided an illustration of how the main tenants of the AP were aligned with my second research question (RQ2) related to the knowledge parents obtain to promote better daily behaviors for sleep health habits in adolescents. To answer this question, four interview questions 
were formulated to explore knowledge (IQ5), routines (IQ6), recommendations (IQ7), and advocacy (IQ8).

With IQ5 aligned to RQ2, I investigated parental knowledge to promote better sleep health to adolescents. Parents reported the following top five results:

- gained knowledge from their parents then taught their kids the same (13 of 20 $[65 \%])$

- not aware of parent teacher association educating parents about sleep health (9 of $20[45 \%])$

- knowledge gained from balance judgement and parental instincts (8 of 20 [40\%]);

- not aware of schools providing sleep health education (7 of 20 [35\%]); and

- gained their knowledge from day-to-day experience with kids as well as tried trial and error strategies (5 of 20 [25\%]).

A complete listing of all common themes and clusters that emerged related to promoting better sleep health to adolescents was provided in Appendix $\mathbf{J}$ and significant parent quotes were listed in Appendix T.

With IQ6 aligned to RQ2, I gathered examples of daily routines that resulted from unhealthy adolescent sleep habits. Parents reported the following top five results:

- attitude become moody and cranky during daily routines (20 of 20 [100\%]);

- less productive in academic routines (10 of 20 [50\%]);

- yawning noted and eyes appear tired during daily routines(8 of 20 [40\%]);

- less productive with sports or extracurricular activities (7 of 20 [35\%]); and 
- less productive at part-time job, sleepy and slower with daily routines, usage of cell phones instead of sleeping, and taking more naps (6 of 20 [30\%]).

A complete listing of all common themes and clusters that emerged related to examples of daily routines that result from unhealthy adolescent sleep habits was provided in Appendix K and significant parent quotes were listed in Appendix T.

With IQ7 aligned to RQ2, I explored parental recommendations for promoting better adolescent sleep health. Parents reported the following top five results:

- $\quad$ schedule bed times (15 of 20 [75\%]);

- establish consistent daily routines (9 of 20 [45\%]);

- $\quad$ retain a sleep diary (8 of $20[40 \%])$;

- add sleep health courses in academic curriculum programs (7 of 20 [35\%]; and

- read bed time stories and plan for the morning commute schedules by bus or train (6 of $20[30 \%])$.

A complete listing of all common themes and clusters that emerged related to recommendations for promoting better adolescent sleep health was provided in Appendix L and significant parent quotes were listed in Appendix T.

With IQ8 aligned to RQ2, I inspected parental perspectives of AP toward sleep health specifically toward promoting, communicating, informing, and educating. For promoting (IQ8a), parents reported the following top five results:

- consistent bed times (15 of 20 [75\%]);

- consistent daily routines (9 of 20 [45\%]); 
- good sleep habits as parents (6 of 20 [30\%]);

- $\quad$ sleep affects sports and extracurricular performances (5 of 20 [25\%]); and

- $\quad$ proper nutrition for sleep habits (4 of 20 [20\%]).

For educating (IQ8b), parents reported the following top five results:

- not aware of schools educating students on sleep health (8 of 20 [40\%]);

- $\quad$ schools should add sleep health to the curriculum (6 of 20 [30\%]);

- $\quad$ read about sleep by Internet, magazines, or books (5 of 20 [25\%]);

- parents have a responsibility to educate kids (3 of 20 [15\%]); and

- $\quad$ parent teacher association meetings should educate parents about sleep health (1 of $20[5 \%])$.

For informing (IQ8c), parents reported the following top five results:

- $\quad$ tracking sleep with diaries (7 of $20[35 \%]$ );

- advising kids how sleep affects daily activities (5 of 20 [25\%]);

- $\quad$ reading about sleep by Internet, magazines, or books (3 of 20 [15\%]);

- informing kids about self-management strategies and organization (2 of 20 $[10 \%]) ;$ and

- inform kids of bed times and curfews and that teachers should inform parents when poor performances are noted (1 of 20 [5\%]).

For communicating (IQ8d), parents reported the following top five results:

- communicating no electronic devices at bed time (7 of 20 [35\%]); 
- have talks and discussions with kids to see how they feel and also to share personal experiences about lack of sleep (5 of 20 [25\%]);

- Read about sleep health in newspapers and journals (4 of 20 [20\%]); and

- discuss sleep articles from Internet, magazines, and books (3 of 20 [15\%]).

A complete listing of all common themes and clusters that emerged related to parental perspectives of AP toward adolescent sleep health specifically toward promoting, communicating, informing, and educating was provided in Appendix $\mathrm{M}$ and significant parent quotes were listed in Appendix T.

\section{Repair and Restoration Theory of Sleep (RRTS)}

Oswald's (1966) RRTS was imperative in fostering revitalization and restoration of the human body and brain for mental and physical functions. Adolescents require approximately 8-10 hours of daily sleep for this restoration to occur and to also maintain the required level of rest to achieve healthy lifestyles (Lee-Chiong, 2008). Oswald suggested the necessity for sleep stages and duration of hours (1966). In Figure 5, I illustrated the repair and restoration model that aligned with my third research question (RQ3) investigating conditions and behaviors parents consult health professionals for sleep problems in adolescents. To answer this question, four interview questions were formulated to investigate reasons to consult health professionals (IQ9), poor sleep (IQ10), outcomes from health professionals (IQ11), and repair and restoration (IQ12).

With IQ9 aligned to RQ3, I investigated reasons noted by parents to consult health professions. Parents reported the following top five results: 
- $\quad$ attitude changes (9 of 20 [45\%]);

- $\quad$ poor grades (7 of $20[35 \%])$;

- $\quad$ poor sports performance and short-tempered (5 of 20 [25\%]);

- $\quad$ snappy, insomnia, and not sleeping (4 of 20 [20\%]); and

- $\quad$ sleep talking, anxiety, panic, headaches, and medications (3 of 20 [15\%]).

A complete listing of all common themes and clusters that emerged related to reasons parents consult health professionals was provided in Appendix $\mathrm{N}$ and significant parent quotes were listed in Appendix U.

With IQ10 aligned to RQ3, I examined parental recognition of poor adolescent sleep health. Parents reported the following top five results:

- changes in routine, attitude, and personality (11 of 20 [55\%];

- $\quad$ cell phone, computers, Internet, and social media (10 of 20 [50\%]);

- $\quad$ tired or shut down (4 of 10 [20\%]);

- mischievous (3 of 20 [15\%]); and

- grouchy, poor grades, more naps, body pain, and snoring (2 of 20 [10\%]).

A complete listing of all common themes and clusters that emerged related to parental recognition of poor adolescent sleep health was provided in Appendix $\mathrm{O}$ and significant parent quotes were listed in Appendix U.

With IQ11 aligned to RQ3, I explored the outcomes from consulting with health professionals. Parents reported the following top five results: 
- health professionals helped to coach the importance of no electronic or television while sleeping (15 of 20 [75\%]);

- health professionals encouraged 8-10 hours of sleep per night for adolescents (13 of $15[65 \%])$;

- noticed less moodiness and attitude problems with adolescents after consulting better sleep habits with health professionals (12 of 20 [60\%]);

- health professionals enabled them to develop consistent sleep routines (11 of 20 [55\%]); and

- health professionals suggested sleep diaries to track and improve sleep patterns, to not drink caffeine after dinner, and to use melatonin or sleep aids (8 of 20 [40\%]). A complete listing of all common themes and clusters that emerged related to outcomes from consulting health professionals was provided in Appendix $\mathrm{P}$ and significant parent quotes were listed in Appendix U.

With IQ12 aligned to RQ3, I inspected parent viewpoints of repair and restoration from sleep habits related to overall health of adolescents. Parents reported the following top five results:

- adequate sleep helps adolescents do better in school and sports (6 of 20 [30\%]);

- doctors have advised them sleep prevents obesity, hypertension, and other health issues (5 of $20[25 \%])$;

- sleep makes adolescents friendlier and less moody as well as do better in sports (4 of $20[25 \%])$; 
- $\quad$ sleep seems to make adolescents more focused and able to make better decisions (3 of $20[15 \%]) ;$ and

- sleep helps adolescents when injured or sick (2 of 20 [10\%]).

A complete listing of all common themes and clusters that emerged related to parent viewpoints of repair and restoration for sleep habits related to overall health of adolescents was provided in Appendix Q and significant parent quotes were listed in Appendix U.

\section{Theory of Caring Science (TCS)}

Watson's (1979a) TCS suggested that values, beliefs, practices, healing techniques, and restoration measures are vital as a concession within childcare, health, education, and human service professions and related fields. The 10 core concepts important to the TCS model included: (a) embrace parental values; (b) honor family; (c) nurture practices; (d) foster trusting with parent-child relationships; (e) promote health; (f) use scientific strategies for caring; (g) teach adolescents in ways they understand; (h) promote restoration with respect to human dignity; (i) consider physical, mental, and spiritual needs for health care; and (j) allow the miracle of healing (Watson, 1979b). Each of these concepts were used to provide an understanding of how parents might consider their roles in adolescent sleep health. In Figure 2, I illustrated the purpose of how these 10 caring science core concepts from TCS provided the anchor for this descriptive phenomenological qualitative study and aligned with all three research questions. 
As reported above in the SLT, AP, and RRTS sections, I investigated caring science toward adolescent sleep health utilizing the first 12 interview questions aligned with RQ1, RQ2, and RQ3. To expand upon these results and further answer the three research questions, I used the thirteenth interview question (IQ13) to specifically examine the 10 concepts of caring science including value, honor, nurture, trust, health, care, teach, restore, needs, and heal with parental viewpoints toward adolescent sleep health.

With IQ13 aligned to RQ1, RQ2, and RQ3, I explored caring science and parental perspectives to promote adolescent sleep health. Parents reported the following top results:

- The value of sleep is critical for health and activities (15 of 20 [75\%]);

- We honor sleep within the family for rest for better health (13 of 20 [65\%]);

- We nurture our kids with pleasant sleep environment (10 of 20 [50\%]);

- We trust health professionals to guide our sleep health (11 of 20 [55\%]);

- Our overall health is affected by our sleep patterns (12 of 20 [60\%]);

- We care about sleep for school and sports performance (9 of 20 [45\%]);

- We teach adolescents daily consistent habits for sleep (8 of 20 [40\%]);

- Sleep restores us for routines and activities (12 of 20 [60\%]);

- Sleep is needed for better health and daily performance (10 of 20 [50\%]);

- Sleep helps our family heal mentally and physically (12 of 20 [60\%)]. 
A complete listing of all common themes and clusters that emerged related to caring science and parental perspectives to promote adolescent sleep health was provided in Appendix R and significant parent quotes were listed in Appendix V.

\section{Summary}

In summary, the purpose of this descriptive phenomenological qualitative research study was to investigate the problems of adolescent sleep health with focus from perspectives and views of parents among the Southeastern region of the United States. The research questions were designed to elicit how parents perceive and recognize conditions and behaviors among adolescents to promote better sleep habits or to consult with health professionals for better overall health.

Key findings included the value of sleep is critical for health and activities. For RQ1, I discovered social learning mechanisms reported by parents to perceive and recognize adolescents with potential unhealthy sleep habits related to attitude, breakfast, consistency, daily behaviors, electronic devices, family meetings, house rules, lights off, safety, schedule bed times, and transportation. For RQ2, I uncovered AP results related to academia, attitude, communication, consistency, daily behaviors, electronic devices, parental influence, scheduled bed times, sleep awareness, sleep diaries, and sleep education. For RQ3, I was able to track sleep health along with concerns parents reported for repair and restoration to consult health professionals related to academia, attitude, electronic devices, health impacts, routines, sports, and 8-10 hours of sleep. Lastly, I was able to overlap the findings with the TCS related to academia, better health, consistency, 
environment, activities, health professionals, mental activities, physical performance, routines, sports, and sleep patterns.

This Chapter 4 provided and overview of the key results of parental perspectives that led to the conclusions. In this chapter, I described the pilot study, research setting, demographics, data collection, data analysis, evidence of trustworthiness, and final results. The next Chapter 5 will provide discussion, interpretation, conclusions, and recommendations. 
Chapter 5: Discussion, Conclusions, and Recommendations

\section{Introduction}

The purpose of this study was to understand parental perspectives on adolescent sleep health using a descriptive, phenomenological, qualitative approach. The descriptive approach enabled me to obtain deep, rich, exhaustive details specific to the phenomenon of parental perspectives that relate to their adolescents' sleep habits as replicated by Shosha (2012). Prior researchers have predominately focused on the importance of sleep health to restore the human body and foster healing and bring about rejuvenation (LeeChiong, 2008). Few scholars, however, have examined the role that perceptions play in parental care and the advancement of positive sleep habits of adolescents. The goal of my study was to focus on perceptions held by parents and to further understand how their experiences as caregivers may influence positive sleep health of their adolescents. Various treatment options may be sought for sleep disorders to attain optimal health and wellness; therefore, parental perceptions could play a role in researchers attaining a better understanding of how to use intervention processes to help resolve these issues early (Orzech, 2013; Paiva \& Matos, 2011).

For the nature of the study, I developed a descriptive, phenomenological, qualitative research study using Colaizzi's strategy of methodology as a data analysis process. As a part of the data collection, I used semistructured, open-ended interview questions for data collection to understand the essence of parental perspectives to promote adolescent sleep health. These interview questions were used to obtain an 
exhaustive description of parents' lived experiences related to their role in influencing their adolescent's sleep habits. The rationale for this qualitative design was that I did not have measurable variables to quantify in effort to answer this study's research questions. Moreover, phenomenology is a philosophy and a research method for the exploration and understanding of shared perspectives and the core essence of a phenomenon experienced by a homogenous group of individuals as suggested by Shosha (2012).

Key findings discovered from this study pertained to the lived experiences from parents in the Southeast region of the United States to promote better sleep habits among adolescents. First, strategies parents use to recognize potential unhealthy sleep habits in adolescents (RQ1) related to attitude, breakfast, consistency, daily behaviors, electronic devices, family meetings, house rules, lights off, safety, schedule bed times, and transportation. Second, knowledge parents obtain to promote better daily behaviors for sleep health habits in adolescents (RQ2) related to academia, attitude, communication, consistency, daily behaviors, electronic devices, parental influence, scheduled bed times, sleep awareness, sleep diaries, and sleep education. Third, conditions and behaviors parents consult health professions for sleep problems in adolescents (RQ3) related to academia, attitude, electronic devices, health impacts, routines, sports, and 8-10 hours of sleep. Lastly, findings application for all three research questions (RQ1, RQ2, and RQ3) related to academia, better health, consistency, environment, activities, health professionals, mental activities, physical performance, routines, sports, and sleep patterns. 


\section{Interpretation of the Findings}

The findings from this descriptive, phenomenological, qualitative study might enable health professionals to better understand parental perspectives and to enhance treatments and strategies to improve adolescent sleep health. These findings provide significant examples and viewpoints from parents regarding their lived experiences with promoting better sleep habits among adolescents and extend upon information reported within the prominent themes in the literature reviewed in Chapter 2 pertaining to sleep health hygiene, understanding the importance of adolescent sleep health, parental perspectives, parental promoting and influence, parental recognition, knowledge and understanding, effects and consequences of inadequate sleep, and health professional influence.

For interpretation of findings, I condensed the results from the interviews reported in Chapter 4 into meaningful findings as outlined in Table 2 for the alignment of interview questions with research questions and theories. Graphs and charts allow researchers to condense large amounts of data into simpler formats that effectively communicate important points (Minter 2013). Bar graphs enable the researcher to present grouped data with rectangular bars with lengths proportional to the values which they represent (Smith, 2014). I used bar graphs to plot the top findings from the parental participants (X axis) versus the frequency reported by each of the 20 parental participants ( $\mathrm{Y}$ axis). 


\section{Social Learning Theory (SLT)}

Parent participants in this study reported that attitude, breakfast, consistency, daily behaviors, electronic devices, family meetings, house rules, lights off, safety, schedule bed times, and transportation are all related to social learning and promoting better sleep heath among adolescents. In Figure 9, I illustrated the top findings related to the SLT versus the frequency reported from the 20 parent participants. I used RQ1 to investigate the strategies that parents use to recognize potential unhealthy sleep habits in adolescents. To answer this question, I aligned the SLT and explored strategies (IQ1), difficulties (IQ2), behaviors (IQ3), interaction (IQ4a), observation (IQ4b), influence (IQ4c), and monitoring (IQ4d). Complete listings of these findings were listed in Appendix F, Appendix G, Appendix H, and Appendix I. Parent quotes related to the SLT are provided in Appendix S.

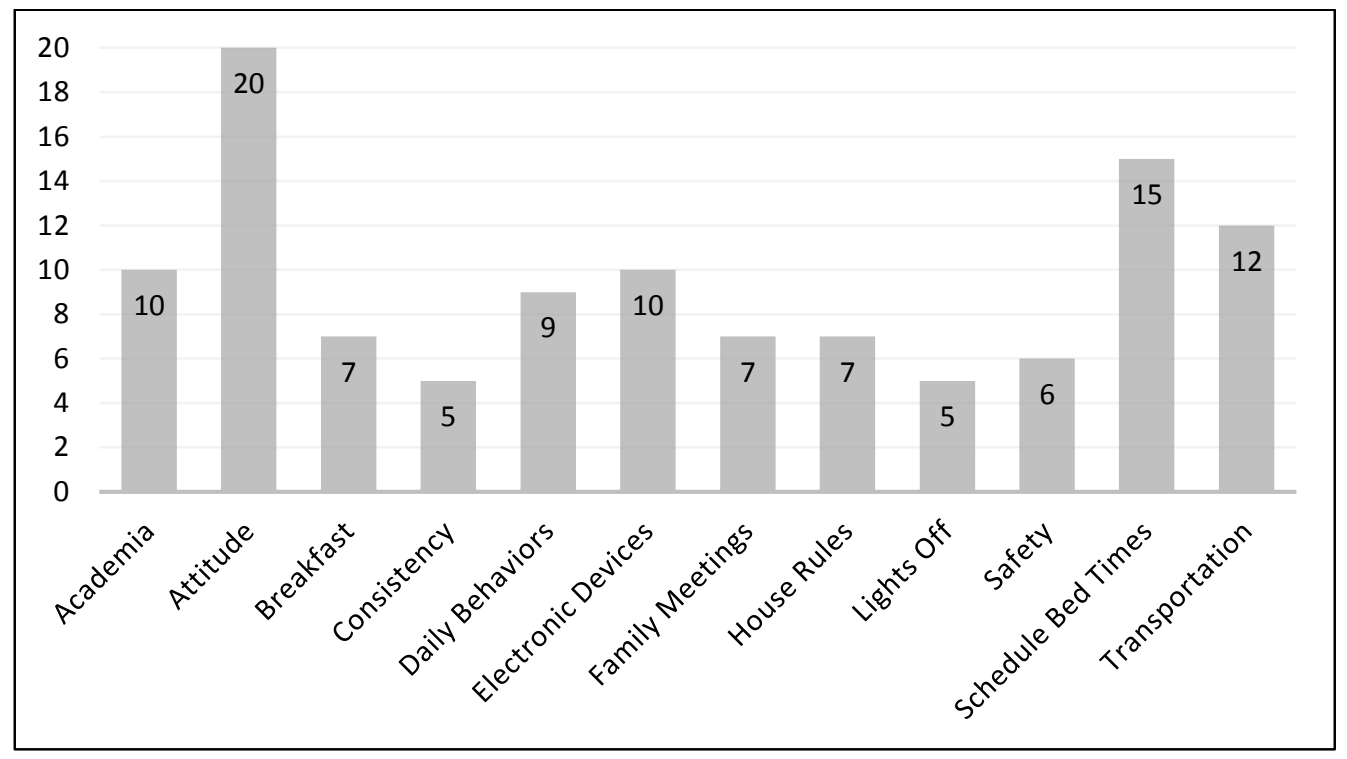

Figure 9. Findings related to SLT 
These findings expand upon Bandura's (1977) SLT and established that parents, teachers, and society positively influence children through social contexts of observation, learning, monitoring, and interacting. I expanded Bandura's seminal contexts interviewing parents in regard to their lived experiences and perspectives to promote better sleep habits for adolescents.

\section{Advocacy Paradigm (AP)}

Parent participants in this study reported that academia, attitude, communication, consistency, daily behaviors, electronic devices, parental influence, scheduled bed times, sleep awareness, sleep diaries, and sleep education are all related to AP and promoting better sleep habits for adolescents. In Figure 10, I illustrated the top findings related to AP versus the frequency reported from the 20 parent participants. I used the RQ2 to examine the knowledge parents obtain to promote better daily behaviors for sleep health habits in adolescents. To answer this question, I aligned AP and explored knowledge (IQ5), daily routines (IQ6), recommendations (IQ7), promoting (IQ8a), educating (IQ8b), informing (IQ8c), and communication (IQ8d). Complete listings of these findings were listed in Appendix J, Appendix K, Appendix L, and Appendix M. Parent quotes related to the SLT are provided in Appendix T. 


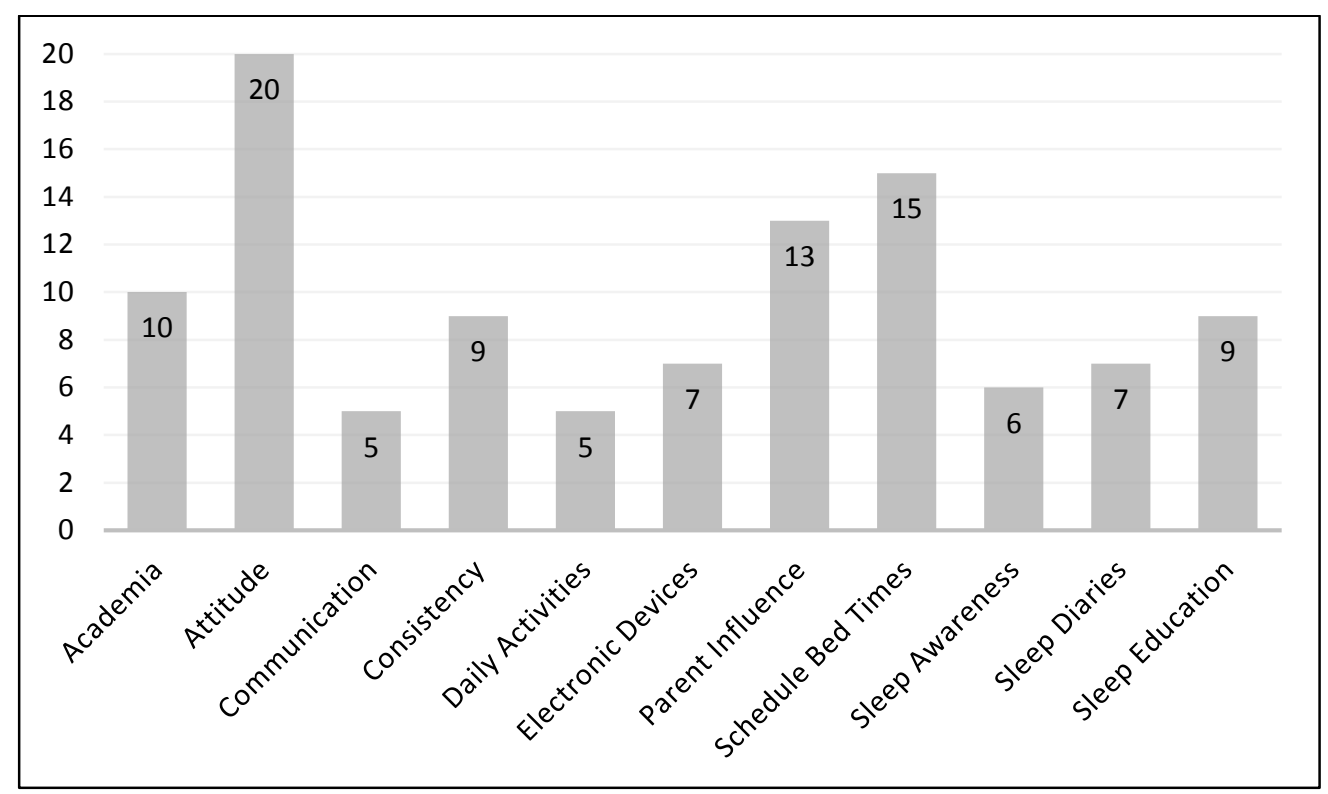

Figure 10. Findings related to AP

These findings expand upon Nightingale's (1893) AP which outlined core concepts of promoting, educating, informing, and communicating (as cited in Steefel, 2010). Nightingale's strategy was to promote better health habits as essential care strategies relevant within nursing and health service professions (as cited in Selanders \& Crane, 2012). I expanded on Nightingale's seminal contexts by interviewing parents in regard to their lived experiences and perspectives to promote better sleep habits for adolescents.

\section{Repair and Restoration Theory of Sleep (RRTS)}

Parent participants in this study reported that academia, attitude, electronic devices, health impacts, routines, sports, and 8-10 hours of sleep are all related to repair and restoration for adolescents. In Figure 11, I illustrated the top findings related to RRTS versus the frequency reported from the 20 parent participants. I used RQ3 to 
explore the conditions and behaviors that parents consult health professionals for sleep problems in adolescents. To answer this question, I aligned the RRTS and investigated reasons to consult health professionals (IQ9), poor sleep (IQ10), outcomes from health professionals (IQ11), and repair and restoration (IQ12). Complete listings of these findings were listed in Appendix N, Appendix O, Appendix P, and Appendix Q. Parent quotes related to the SLT are provided in Appendix U.

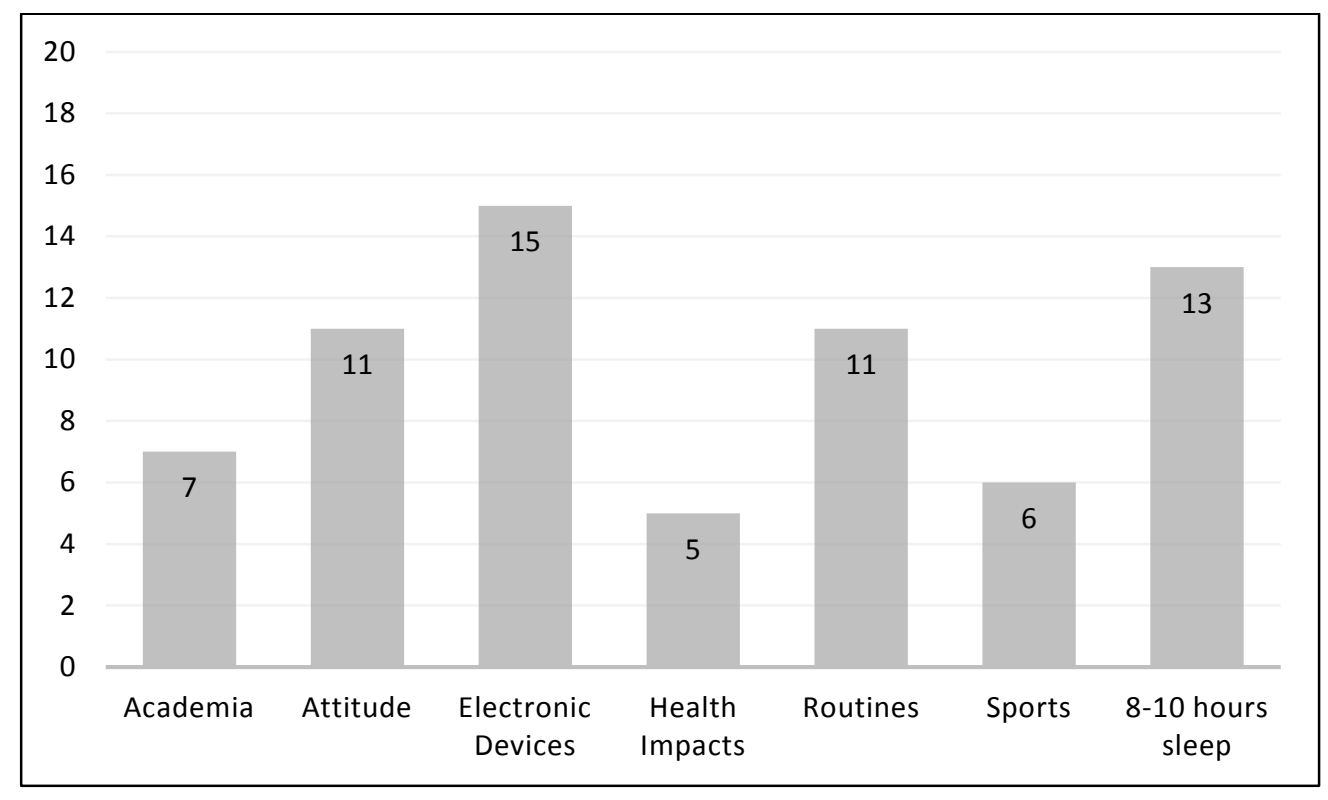

Figure 11. Findings related to RRTS

These findings expand upon Oswald's (1966) RRTS that sleep is imperative in fostering the revitalization and the restoration of the human body and brain for mental and physical functions. Adolescents require approximately 8-10 hours of daily sleep for this restoration to occur and to also maintain the required level of rest to achieve healthy lifestyles (Lee-Chiong, 2008). Oswald (1966) suggested the necessity for sleep stages and duration of hours. I expanded on Oswald's seminal contexts by interviewing parents in 
regard to their lived experiences and perspectives to promote better sleep habits for adolescents.

\section{Theory of Caring Science (TCS)}

Parent participants in this study reported that academia, better health, consistency, environment, activities, health professionals, mental activities, physical performance, routines, sports, and sleep patterns are all related to caring science and promoting better sleep habits among adolescents. In Figure 12, I illustrated the top findings related to the TCS versus the frequency reported from the 20 parent participants. I used RQ1 to investigate the strategies that parents use to recognize potential unhealthy sleep habits in adolescents. I used RQ2 to examine the knowledge that parents obtain to promote better daily behaviors for sleep health habits in adolescents. I used RQ3 to explore the conditions and behaviors that parents consult health professionals for sleep problems in adolescents. To answer these questions, I aligned the TCS and inspected the 10 concepts including value (IQ13a), honor (IQ13b), nurture (IQ13c), trust (IQ13d), health (IQ13e), caring (IQ13f), teach (IQ13g), restore (IQ13h), needs (IQ13i), and heal (IQ13j). Each of these concepts were used to provide an understanding of how parents might consider their roles in adolescent sleep health. Complete listings of these findings were listed in Appendix R. Parent quotes related to the TCS were provided in Appendix V. 


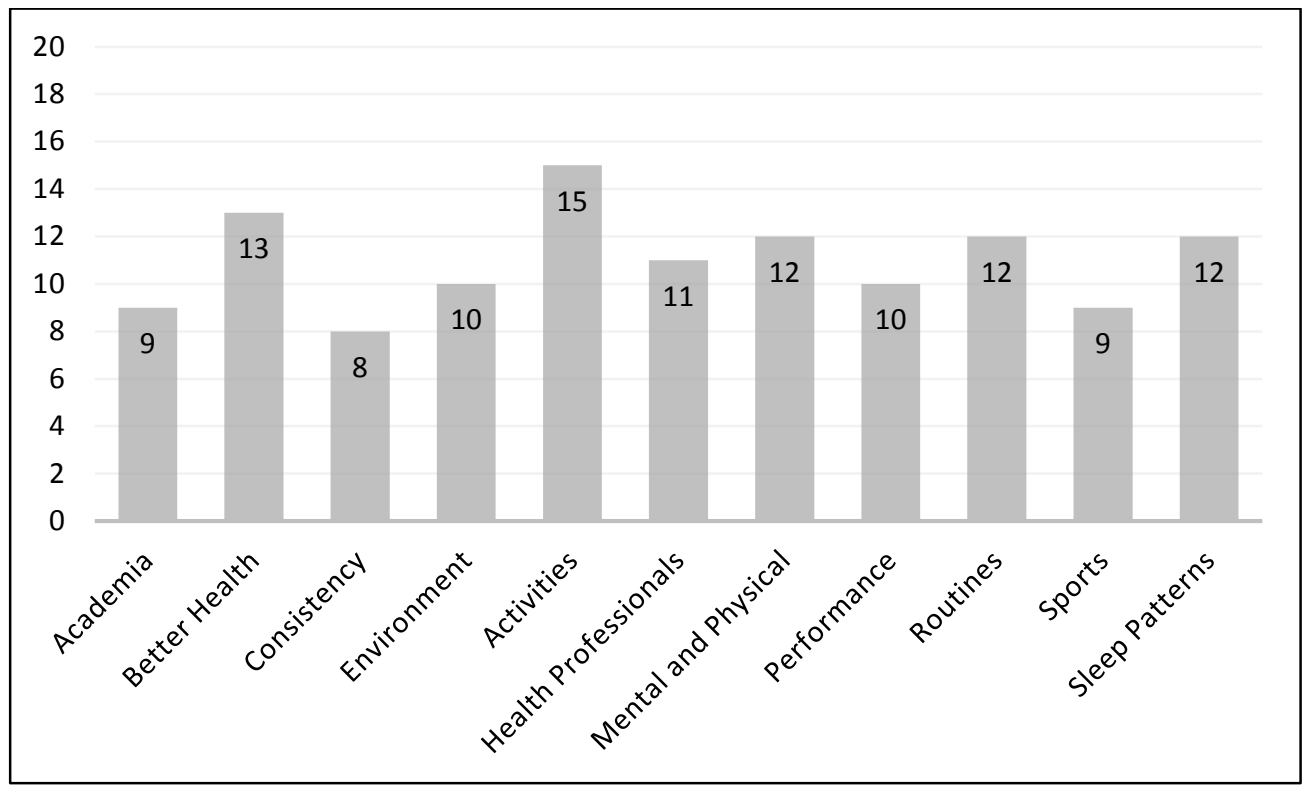

Figure 12. Findings related to TCS

These findings expand upon Watson's (1979a) TCS, which suggested that values, beliefs, practices, healing techniques, and restoration measures are vital as a concession within childcare, health, education, and human service professions and fields. I explored Watson's seminal contexts by interviewing parents in regard to their lived experiences and perspectives to promote better sleep habits for adolescents.

\section{Limitations of the Study}

Limitations pertaining to the design of this descriptive, phenomenological, qualitative study included time, financial resources, and administrative management for obtaining a representative population of parents with adolescents on various spectrums of sleep habits. In addition, the convenience-based sample of 20 parents may not consistently represent the broad spectrum of perception of parents globally. The possible 
drawback of convenience-based sampling was that the data collection may not represent the viewpoint of the entire particiapnt population (Mason, 2010). Phenonmenology studies, however, are specific to a group of individuals who have experienced the same phenomena of research inquiry. As the researcher, I recruited participants proportionally distributed among all of the states within the Southeastern region of the United States. More so, the outcomes and addressing the collection of data are subject to the bias of the researcher as asserted by Shosha (2012). For reasonable measures to address limitations, I adhered to the parameters identified within the scope of this study.

\section{Recommendations}

After investigating parental perspectives to promote better sleep habits for adolescents among the Southeastern region of the United States, I would recommend expanding this study to other regions throughout the United States and other countries in the world. Other recommendations would include exploring adolescent sleep health versus the common clusters, themes and trends noted from the data collected such as attitudes, behaviors, consistent schedules, academic scores, sports performance, and overall health.

In addition, a large portion of the parent participants mentioned school transportation and commutes as a possible issue for adolescents losing morning sleep. I would recommend scholars to investigate school bus schedules and transportation based upon some of the responses related to lengthy commutes. To support the recommendation for further investigation of school transportation schedules interfering with morning sleep 
schedules of adolescents, I provided quotes in Appendix W from parents related to possible reasons for infringement of adolescents loosing early morning sleep. I stopped reviewing here. Please go through the rest of your chapter and look for the patterns I pointed out to you. I will now look at your references.

\section{Implications}

The relevance of this study aligned with the goals of HHS and future goals and objectives for improving adolescent sleep health. The research focused on perceptions, attitudes, and knowledge of parents toward recognizing adolescent sleep problems for professional diagnosis and treatments. Potential implications for positive social change from these findings may provide information about parental care and perceptions of adolescent sleep habits to health care administrators to save money, reduce time, and expedite treatment techniques.

\section{Potential Impact for Positive Social Change}

Possible dissemination includes providing results summary to health services, health care administrators, parents, families, schools, pediatricians, and sleep medicine journals. This study might extend the literature by addressing the research gap through dissemination in peer-reviewed journals. The findings from this study may to better understand the views of parents toward the sleep habits of adolescents. Further, health professionals may advocate social change for healthier lifestyles of adolescents. The scope of this descriptive phenomenological qualitative study was targeted for potential transferability. 


\section{Methodological, Theoretical, and/or Empirical Implications}

The study did not have any methodological, theoretical, and/or empirical implications. The population identified for this study was parents among the Southeastern region of the United States with adolescents (ages 13-18). This population was justified and significant for delving into the missing gap in literature covered in Chapter 2 dealing with the views of parents toward the sleep habits of adolescents and may advocate social change for healthier lifestyles of adolescents.

\section{Recommendations for Practice}

Recommendations for practice of this descriptive phenomenological qualitative research study could possibly provide potential contributions to advance knowledge, practices, policies, and positive social change implications within health services, health care administration, and sleep medicine. Unfortunately, the general global population lacked awareness of sleep health standards (NSF, 2015). Parental perspectives of adolescent sleep health may enhance the understanding of past research involving adolescent health, puberty, growth, and development (Worcester, 2011) in addition to sleep disorder practices correlated with heart problems, lung diseases, neurology factors, obesity, high blood pressure, and various other health comorbidities and disparities (Costanzo \& Woody, 1984). 


\section{Conclusion}

The findings from this descriptive phenomenological qualitative study extend knowledge in the discipline of sleep medicine to possibly enable health professional to better understand parental perspectives to promote better sleep habits among adolescents.

Table 6

Key Findings From the Study

\begin{tabular}{lll}
\hline $\begin{array}{l}\text { Theoretical } \\
\text { foundation }\end{array}$ & $\begin{array}{l}\text { Research } \\
\text { question }\end{array}$ & $\begin{array}{l}\text { Key findings and concerns reported by parent participants } \\
\text { to promote better sleep health among adolescents }\end{array}$ \\
\hline SLT & RQ1 & $\begin{array}{l}\text { Attitude, breakfast, consistency, daily behaviors, electronic } \\
\text { devices, family meetings, house rules, lights off, safety, } \\
\text { schedule bed times, and transportation } \\
\text { Academia, attitude, communication, consistency, daily } \\
\text { behaviors, electronic devices, parental influence, scheduled } \\
\text { bed times, sleep awareness, sleep diaries, and sleep } \\
\text { education } \\
\text { Academia, attitude, electronic devices, health impacts, } \\
\text { routines, sports, and 8-10 hours of sleep } \\
\text { Academia, better health, consistency, environment, } \\
\text { RRTS }\end{array}$ \\
TCS & RQ2 & RQ1, \\
& RQ2, & $\begin{array}{l}\text { activities, health professionals, mental activities, physical } \\
\text { performance, routines, sports, and sleep patterns }\end{array}$ \\
\hline
\end{tabular}

These findings, as represented in Table 6, provide significant examples and viewpoints from parents. These lived experiences of parents may contribute to strategies to promote better sleep habits among adolescents. The results may contribute to mechanisms by which parents perceive and recognize adolescents with potential unhealthy sleep habits. The results may help increase the knowledge parents attain to promote better sleep health habits to adolescents and the effects on their daily behaviors. Finally, the results may add insight for conditions and behaviors parents perceive poor 
sleep habits as a health concern that requires exploration with health professionals to reduce adolescent health problems. A complete alignment matrix of findings is provided in Appendix X recapping the theories, research questions, interview questions, and findings of the study.

Key findings and concerns, as reported in Table 6, reflect results from the parent participants to promote better sleep health among adolescents were provided based upon alignment of theories and research questions. By understanding parental perspectives through these research findings, health professional may better understand adolescent sleep health and offer critical insight within the field of health services. These insights may contribute to the development of effective solutions to improve adolescent sleep health and influence health care administrators to maximize resources, control expense, decrease insurance billing, expedite treatment techniques, and encourage preventative measures for health care through adolescent sleep restoration. Given these possible benefits, understanding parental perspectives as it pertains to their experiences with adolescent sleep problems is an important contribution to this research domain. 


\section{References}

Albert, B. (2009). Needs and techniques for counseling parents of young children. Clinical Pediatrics, 9(10), 599-604. doi:10.1177/000992287000901011

Alekseeva, E. G., Krasnopolskaya, I. I., \& Skokova, Y. A. (2015). Introducing sexual education to Russian schools. Health Education. doi:10.1108/he-02-2014-0014

Andersen, M. N., Dore-Stites, D., Gleit, R., Lopez, M. J., \& Fredericks, E. M. (2014). A pilot study of the association between sleep disturbance in children with liver transplants and parent and family health-related quality of life perspectives. Journal of Pediatric Psychology, 39(7), 735-742. doi:10.1093/jpepsy/jsu037

Anfara, V. A. (2010). Theoretical frameworks in qualitative research. Thousand Oaks, CA: Sage Publications, Inc.

Anzman-Frasca, S., Newman, M. B., Angstrom, H. M., Sharma, S., Nelson, M. E., Dolan, P. R., \& Economos, C. D. (2014). Parent perspectives on nutrition and physical activity during out-of-school time. Journal of Nutrition Education and Behavior, 46(3), 156-163. doi:10.1016/j.jneb2013.09.011

Armour, M., Rivaux, S. L., \& Bell, H. (2009). Using context to build rigor: Application to two Hermeneutic phenomenological studies. Qualitative Social Work, 8, 101. doi: $10.1177 / 1473325008100424$

Arora, T., Broglia, E., Thomas, G. N., \& Taheri, S. (2014). Associations between specific technologies and adolescent sleep quantity, sleep quality, and parasomnias. Sleep Medicine, 15(2), 240-247. doi:10.1016/j.sleep.2013.08.799 
Bandura, A. J. (1977). Social learning theory. Englewood Cliffs, NJ: Prentice Hall.

Bartel, K., Gradisar, M., \& Williamson, P. (2014). Protective and risk factors for adolescent sleep: A meta-analytic review. Sleep Medicine Reviews. doi:10.1016./j.smrv.2014.08.002

Bayon, V., Leger, D., Gomez-Merino, D., Vecchierini, M. F., \& Chennaoui, M. (2014). Sleep debt and obesity. Annals of Medicine, 46(5), 264-272. doi: $10.3109 / 07853890.2014 .931103$

Beebe, D. W. (2011). Cognitive, behavioral, and functional consequences of inadequate sleep in children and adolescents. Pediatric Sleep Medicine Update, 58(3), 649665. doi:10.1016/j.pc1.2011.03.002

Berentzen, N. E., Smit, H. A., Bekkers, M., Brunekreef, B., Koppelman, G. H., Jongste, J. C., \& Wijga, A. H. (2014). Time in bed, sleep quality and associations with cardiometabolic makers in children: The prevention and incidence of asthma and mite allergy birth control cohort study. Journal of Sleep Research, 23(1), 3-12. doi:10.1111/jsr.12087

Berry, R. B., \& Wagner, M. H. (2014). Sleep medicine pearls (3rd ed.). Gainesville, FL: Elsevier Saunders.

Bleijenbergh, I., Korzilius, H., \& Verschuren, P. (2011). Methodological criteria for the internal validity and utility of practice oriented research. Quality and Quantity, 45(1), 145-156. doi: 10.1007/s11135-010-9361-5 
Branda, S., Grberb, M., Hatzingerc, M., Becka, J., \& Holsboer-Trachslera, E. (2009). Evidence for similarities between adolescents and parents in sleep patterns. Sleep Medicine, 1,124-1,131. doi:10.1016j.sleep.2009.12.013

Burns, R. B., \& Dobson, C. B. (1984). Introductory psychology: Repair and restoration theory of sleep (1st ed.). Springer, OH: Academic Press.

Burusic, J., \& Sakic, M. (2013). Parenal perceptions of adolescent health behaviors. Health Education Journal. doi:10.1177/0017896912471522

Centers for Disease Control and Prevention. (2013). Summary health statistics for United States children: National Health Interview Survey. Retrieved from http://www.cdc.gov/nchs/data/series/sr_10/sr10_258.pdf.

Chibber, K. S., Biggs, M. A., Roberts, S., \& Foster, D. G. (2014). The role of intimate partner's reasons for seeking abortion. Women's Health Issues, 24(1), 131-138. doi:10.1016/j.whi.2013.10.007

Cho, M., Quach, J., Anderson, P., Mensah, F., Wake, M., \& Roberts, G. (2015). Poor sleep and lower working memory in children: Cross sectional, population-based study. Academic Pediatrics, 15(1), 111-116. doi:10-1016/j.acap.2014.06.021

Clelland, T., Cushman, P., \& Hawkins, J. (2013). Challenges of parental involvement with a health promoting school framework in New Zealand. Education Research International, 1-8. doi:10.1155/2013/131636 I stopped reviewing here. Please go through the rest of your references and look for the patterns I pointed out to you. 
Costanzo, P. R., \& Woody, E. Z. (1984). Parental perspectives on health and obesity in children. Journal of Social and Clinical Psychology, 2(4), 305-313. doi:10.1521/jscp.1984.2.4.305

Crowley, S. J., Tarokh, L., \& Carskadon, M. A. (2007). Sleep, circadian rhythms, and delayed phase in adolescence. Sleep Medicine, 8(6), 602-612. doi:10.1016/j.sleep.2006.12.002

Delgado, S. V., Stawn, J. R., \& Pedapati, E. V. (2014). The neurodevelopment and neurfunctionality basis of intersubjectivity. Contemporary Psychodynamic Psychotherapy for Children and Adolescents, 185-206. doi:10.1007/978-3-64240520-4_7

Dement, W. C., \& Vaughan, C. (1999). The promise of sleep: A pioneer in sleep medicine explores the vital connection between health, happiness, and a good night's sleep. New York, NY: Delacorte Press. ISBN 0-385-32008-6

DePlantya, J. (2010). Perceptions of parent involvement in academic achievement. The Journal of Educational Research, 361-368. doi:10.3200/JOER.100.6.361.368

Dickinson, D. M., Hayes, K. A., Jackson, C., Ennett, S. T., \& Lawson, C. (2014). Promoting an alcohol-free childhood: A novel home-based parenting program. American Journal of Health Education, 45(2), 119-128. doi:10.1080/19325037.2013.875963

Dubik, M. (2010). Earlier parent-set bedtimes protect against adolescent depression. AAP Grand Rounds, 23(5), 59-60. doi:10.1542/gr.23-5-59 
Free, T. A. (1994). Promoting the health of adolescents: New directions for the twentyfirst century. Nurse Practitioner, 19(2). doi:10.1097/00006205-199402000-00023

Fulton, J., \& Hayes, C. (2012). Situational analysis-framing approaches to interpretive inquiry in health care research. International Journal of Therapy and Rehabilitation, 19(12), 662-669. doi:10.12968/ijtr.2012.19.12.662

Golafshani, N. (2003). Understanding reliability and validity in qualitative research. The Qualitative Report, 8(4), 597-606. Retrieved from http://www.nova.edu/ssss/QR/QR8-4/golafshani.pdf

Goldberg, A. E. and Allen, K. R. (2015), Communicating Qualitative Research: Some Practical Guideposts for Scholars. Journal of Marriage and Family, 77: 3-22. doi: 10.1111/jomf.12153

Hannon, T. S., Tu, W., Watson, S. E., Jalou, H., Chakrovorty, S., \& Arslanian, S. A. (2014). Morning blood pressure is associated with sleep quality in obese adolescents. Journal of Pediatrics, 164(2), 313-317. doi:10.1016/j.jpeds.2013.10.1011

Hart, K. H., Herriot, A., Bishop, J. A., \& Truby, H. (2013). Promoting healthy diet and exercise patterns amongst adolescents: A qualitative investigation of parental perspectives. Journal of Human Nutrition and Dietetics, 16, 89-96.

doi:10.1046/j.1365-277X.2003.00429.x 
Hoye, V. A., Fenton, S., Krommidas, C., Heuzé, J. P., Quested, E., Papaioannou, A., \& Duda, J. L. (2013). Physical activity and sedentary behaviours among grassroots football players: A comparison across three European countries. International Journal of Sport and Exercise Psychology, 11(4), 341-350. doi:10.1080/1612197x.2013.830432

Iglay Reger, H. B., Peterson, M. D., Liu, D., Parker, C. A., Woolford, S. J., Gafka, B. J., \& Gordon, P. M. (2014). Sleep predicts cardiometabolic risk in obese adolescents. Journal of Pediatrics, 164(5), 1085-1090. doi:10.1016/j.jpeds.2014.01.034

Jones, C. H., Pollard, T. M., Summerbell, C. D., \& Ball, H. (2014). Could parental rules play a role in the association between short sleep and obesity in young children? Journal of Biosocial Science, 46(3), 405-418. doi:10.1017.50021932013000291

Kabadayi, M. (2013). The effect of sleep, sports, and dietary habits on obesity in adolescents. IJAR, 5(4), 248-253. doi:10.7813/2075-4124.2013/5-4/a.35

Kallem, S., Renner, L., Ghebremichael, M., \& Paintsil, E. (2011). Prevalence and pattern of disclosure of HIV status in HIV-infected children in Ghana. AIDS Behavior, 15(6), 1121-1127. doi:10.1007/s10461-010-9741-9

Kennedy, D. P., Cowgill, B. O., Bogart, L. M., Corona, R., Ryan, G. W., Murphy, D. A., \& Schuster, M. A. (2010). Parents' disclosure of their HIV infection to their children in the context of family. AIDS and Behavior, 14(5), 1095-1105. doi:10.1007/s10461-010-9715-y 
Kryger, M., Dement, W. C., \& Roth, T. (2011). Principles and practice of sleep medicine. (5th, Ed.) Philadelphia, PA: Saunders/Elsevier. ISBN 978-1-4160$6645-3$

Lamberg, L. (2014). Why can't teenagers go to sleep earlier? Psychiatric News, 21(2), 110. doi:10.1176/appi.pn.2014.10a27

Lee-Chiong, T. (2008). Sleep medicine: Essentials and review. USA: Oxford University Press. ISBN: 9780195306590

Magee, C., Caputi, P., \& Iverson, D. (2014). Lack of sleep could increase obesity in children and too much television could be partly to blame. Acta Paediatrica, 103(1), e27-e31. doi:10.111/apa.12447

Malow, B. A., Adkins, K. W., Reynolds, A., Weiss, S. K., Loh, A., Fawkes, D., \& Clemons, T. (2013). Parent-based sleep education for children with autism spectrum disorders. Journal of Adolescent Development Disorders, 44(1), 216228. doi:10.1007/s10803-013-1866-Z

Manton, E., MacLean, S., Laslett, A. M., \& Room, R. (2014). Alcohol's harm to others: Using qualitative research to compliment survey findings. International Journal of Alcohol and Drug Research, 3(2), 143-148. doi:10.7895/ijadr.v3i2.178

Mantziki, K., Vassilopoulos, A., Radulian, G., Borys, J. M., Du Plessis, H., Gregorio, M. J., \& Seidell, J. C. (2014). Parental promoting health equity in European children: Design and methodology of the prospective. BMC Public Health, 14(1), 303-310. doi:10.1186/1471-2458-14-303 
Marshall, S. K., Nelson, M., Goessling, K., Chipman, J., \& Charles, G. (2015). Counseling adolescents for improved academia from an action theory perspective. Counseling and Action, 197-209. doi:10.1007/978-1-4939-0773

Mason, M. (2010). Sample Size and saturation in PhD studies using qualitative interviews. Forum: Qualitative Social Research, 11(3). Retrieved from http://nbnresolving.de/urn:nbn:de:0114-fqs100387

Maume, D. J. (2013). Social ties and adolescent sleep disruption. Journal of Health and Social Behavior, 54(4), 498-515. doi:10.1177/0022146513498512

McGarry, S., Elliott, C., McDonald, A., Valentine, J., Wood, F., \& Girdler, S. (2015). "This is not just a little accident": A qualitative understanding of paediatric burns from the perspective of parents. Disablity \& Rehabilitation, 37(1), 41-50. doi:10.3109/09638288.2014.892640

McKnight-Eilya, L. R., Eatonb, D. K., Lowryb, R., Crofta, J. B., Presley-Cantrella, L., \& Perrya, G. S. (2011). Relationships between hours of sleep and health-risk behaviors in US adolescent students. Preventative Medicine, 53(4-5), 271-273. doi:10.1016/j.ypmed.2011.06.020

Michalos, A. C. (2014). Adolescents personal well-being. Encyclopedia of Quality of Life and Well-Being Research. doi:10.1007/978-94-007-0753-5_100061

Michels, N., Sioen, I., Boone, L., Braet, C., Vanaelst, B., Huybrechts, I., \& De Henauw, S. (2015). Longitudinal association between child stress and lifestyle. Health Psychology, 40-50. doi:10.1037/hea0000108 
Miles, Huberman, \& Saldana. (2014). Qualitative Analysis: A methods sourcebook. CA: Thousand Oaks.

Minter, E., Michaud, M. Using Graphics to Report Evaluation Results. University of Wisconsin Cooperative Extension. 2013. Available at http://learningstore.uwex.edu/pdf/G3658-13.PDF

Moustakas, C. E. (1994). Phenomenological research methods. Thousand Oaks, CA: Sage Publications, Inc. ISBN 978-0-8039-578-5 ISBN 978-8039-5799-2

National Sleep Foundation. (2015). Sleep Health. Retrieved from http://sleepfoundation.org/sleep-health

Noland, H., Price, J. H., Dake, J., \& Telljohann, S. K. (2009). Adolescent sleep behaviors and perceptions of sleep. Journal of School Health, 79, 224-230. doi:10.1111/j.17461561.2009.00402.x

O'Dea, J. (2013). Why do kids eat healthful food? Healthy Eating, 103(4), 497-501. doi:10.1053/jada.203.50064

Okado, Y., Bierman, K. L., \& Welsh, J. A. (2014). Promoting school readiness in the context of socio-economic adversity: Associations with parental demoralization and support for learning. Child \& Youth Care Forum, 43(3), 353-371. doi:10.1007/s10566-013-9242-X

Orzech, K. M. (2013). A qualitative exploration of adolescent perceptions of healthy sleep in Tucson, Arizona, USA. Social Science \& Medicine, 79, 109-116. doi:10.1016/jimed.2012.05.001 
Orzech, K. M., Acebo, C., Seifer, R., Barker, D., \& Carskadon, M. A. (2014). Sleep patterns are associated with common illness in adolescents. Journal of Sleep Research, 23(2), 133-142. doi:10.1111/jsr.12096

Paiva, T., \& Matos, M. (2011). Sleep duration, quality of life, habits and academic success in adolescents. Sleep Medicine, 12, S93. doi:10.1016/s1389$9457(11) 70345-8$

Parsons, J. T., VanOra, J., Missildine, W., Purcell, D. W., \& Gomez, C. A. (2014). Positive and negative consequences of HIV disclosures among adolecents. AIDS Education and Prevention, 16(5), 459-475. doi:doi:10.1521/aeap.16.5.459.48741

Penev, P. D. (2014). Shortened sleep time and obesity. Treatment of the Obese Patient, 113-120. doi:10.1007/978-1-4939-2311-3_8

Penner, J. L., \& McClement, S. E. (2008). Using phenomenology to examine the experiences of family caregivers of patients with advanced head and neck cancer: Reflections of a novice researcher. International Journal of Qualitative Methods, 7(2), 92. Retrieved from http://connection.ebscohost.com/c/articles/33060497/using-phenomenologyexamine-experiences-family-caregivers-patients-advanced-head-neck-cancerreflections-novice-researcher

Persson, A., \& Richards, W. (2010). From closet to heterotopia: A conceptual exploration of disclosure and passing among hetersexuals living with HIV. Culture, Health, \& Society, 1095-1105. doi:10.1080/13691050701669048 
Pocock, M., Trivedi, D., Wills, W., Bunn, F., \& Magnusson, J. (2010). Parental perceptions regarding healthy behaviours for preventing overweight and obesity in young children: A systematic review of qualitative studies. Obesity Reviews, 11(5), 338-353. doi:10.1111/j.1467-789x.2009.00648.x

Pradhan, A. K., Li, K., Bingham, C. R., Simons-Morton, B. G., Ouimet, M. C., \& Shope, J. T. (2014). Influences on male drivers. Journal of Adolescent Health, 54(5), S42-S49. doi:10.1016/j.jadohealth.2014.01004

Resnick, M. D., Harris, L. J., \& Blum, R. W. (1993). The impace of caring and connectedness on adolescent health and well-being. Journal of Paediatrics and Child Health, 29(s1), S3-S9. doi:10.1111/j.1440-1754.1996.tb02257.x

Rice, R. C. (2014). Health care leaders' lived experiences regarding the implementation of electronic personal health records, (Order No. 3621069). Available from ProQuest Dissertations \& Theses Full Text. (1545690977). Retrieved from http://search.proquest.com/docview/1545690977? accountid=14872

Ross, S., Baird, A. S., \& Porter, C. C. (2014). Teenage pregnancy: strategies for prevention and parental perspectives. Obstetrics, Gynaecology \& Reproductive Medicine, 24(9), 266-273. doi:10.1016/j.ogrm.201406.002

Rubin, H. J., \& Rubin, I. S. (2005). Qualitative interviewing: The art of hearing data (2nd ed.). Thousand Oaks: Sage Publications, Inc. 
Rwemisisi, J., Wolff, B., Coutinho, A., Grosskurth, H., \& Whitworth, J. (2009). Delimmas of disclosing parental health status. Health Policy and Planning, 28, 3642. doi:10.1093/heapol/czm040

Santa Maria, D., Swartz, M. C., Markham, C., Chandra, J., McCurdy, S., \& BasenEngquist, K. (2014). Exploring parental factors related to weight management in survivors of childhood central nervous system tumors. Journal of Pediatric Oncology Nursing, 31(2), 84-94. doi:10.1177/1043454213518112

Selanders, L., \& Crane, P. (2012). The voice of Florence Nightengale on advocacy. The Online Journal of Issues in Nursing, 17(1). doi:10.3912/OJIN.Vol17No01Man01

Short, M. A., Gradisar, M., Wright, H., Lack, L. C., Dohnt, H., \& Carskadon, M. A. (2011). Time for bed: Parent-set bedtimes associated with improved sleep and daytime functioning in adolescents. Sleep, 34(6), 797-800. doi:10.5665/sleep.1052

Shosha, G. A. (2012). Employment of Colaizzi's strategy in descriptive phenomenology: A reflection of a researcher. European Scientific Journal, 8(24). Retrieved from http://eujournal.org/index.php/esj/article/view/588

Smith, James M. (2014). Meaningful graphs: Converting data into informative charts ( $1^{\text {st }}$ ed.). James Smith Publishing. 
Snyder, S. M., \& Smith, R. E. (2015). Do physical abuse, depression, and parental substance use influence patterns of substance use among child welfare involved youth? Substance Use Misuse, 50(2), 226-235. doi:10.3109/10826084.2014.966845

Speziale, H. S., \& Carpenter, D. R. (2007). Qualitative research in nursing. Philadelphia, PA: Lippincott Company.

Steefel, L. (2010). Through the eyes of the patient's nurse family member. Creative Nursing, 15(3), 148-150. doi:10.1891/1078-4535.15.3.148

Strunin, L., Diaz-Martinez, A., Diaz-Martinez, L. R., Kuranz, S., Hernández-Avila, C., \& Fernández-Varela, H. (2015). Changes in alcohol use among first year university students in Mexico. Substance Use \& Misuse, 50(1), 106-113. doi:10.3109/10826084.2014.960591

Taylor, C., \& Gibbs, G. R. (2010). How and what to code? Retrieved from http://onlineqda.hud.ac.uk/Intro_QDA/how_what_to_code.php

Taylor, D. J., \& Adam, B. (2010). Patterns and consequences of inadequate sleep in adolescents: substance use and motor vehicle accidents. Journal of Adolescent Health, 46(6). doi:10.1016/j.jadohealth.2009.12.010

Thind, H., Davies, S. L., Lewis, T., Pekmezi, D., Evans, R., \& Baskin, M. L. (2014). Does short sleep lead to obesity among children and adolescents? Current understanding and implications. American Journal of Lifestyle Medicine. doi: 1559827614533911 
Thoropy, M. J. (2011). History of sleep medicine. Sleep Disorders, 3-25. doi:10.1016/b978-0-444-52006-7.00001-0

Tripuraneni, M., Paruthi, S., Armbrecht, E. S., \& Mitchell, R. B. (2013). Obstructive sleep apnea in children. Laryngoscope, 123(5), 1289-1293. doi:10.1002/lary.23844

Turner III, D. W. (2010). Qualitative interview design: A practical guide for novice investigators. The qualitative report, 15(3), 754-760. Retrieved from http://nsuworks.nova.edu/tqr/vol15/iss3/19

van Manen, M. (2007). Phenomenology of practice. Phenomenology \& Practice, 1(1), 11-30. Retrieved from http://www.maxvanmanen.com/files/2011/04/2007Phenomenology-of-Practice.pdf

Watson, D. H., Adair, P., \& Humphris, G. (2012). Assessment of innovative behaviour change intervention for looked after young people through apply health psychology and public health. Lancet, S(33), 380. doi:10.1016/s01406736(13)60389-x

Watson, J. (1979a). Human caring science: A theory of nursing, human science and human care (2nd ed.). Sudbury, MA: Jones and Bartlett. ISBN-13: 9781449628109, IBSN-10: 1449628109

Watson, J. (1979b). Nursing: The philosophy and science of caring. Sadbury, MA: Jones and Bartlett. ISBN-13: 978-0870811548 ISBN-10: 0870811541 
Worcester, S. (2011). Healthy People 2020 adds goals for promoting sleep health. Family Practice News, 41(1). doi:10.1016/s0300-7073(11)70042-1

Zenobia, C. Y., Yeun-ling, F., \& Wai-tong, C. (2013). Bracketing in phenomenology: Only undertaken in the data collection and analysis process? The Qualitative Report, 18(59), 1-9. Retrieved from http://www.nova.edu/ssss/QR/QR18/chan59.pdf

Zhu, Y., Fu, A., Hoffman, A. E., Figueiro, M. G., Carskadon, M. A., Sharkey, K. M., \& Rea, M. S. (2013). Advanced sleep schedules affect circadian gene expression in young adults with delayed sleep schedules. Sleep Medicine, 14(5), 449-455. doi:10.1016/j.sleep.2012.12.006 


\section{Appendix A: Recruitment Flyer}

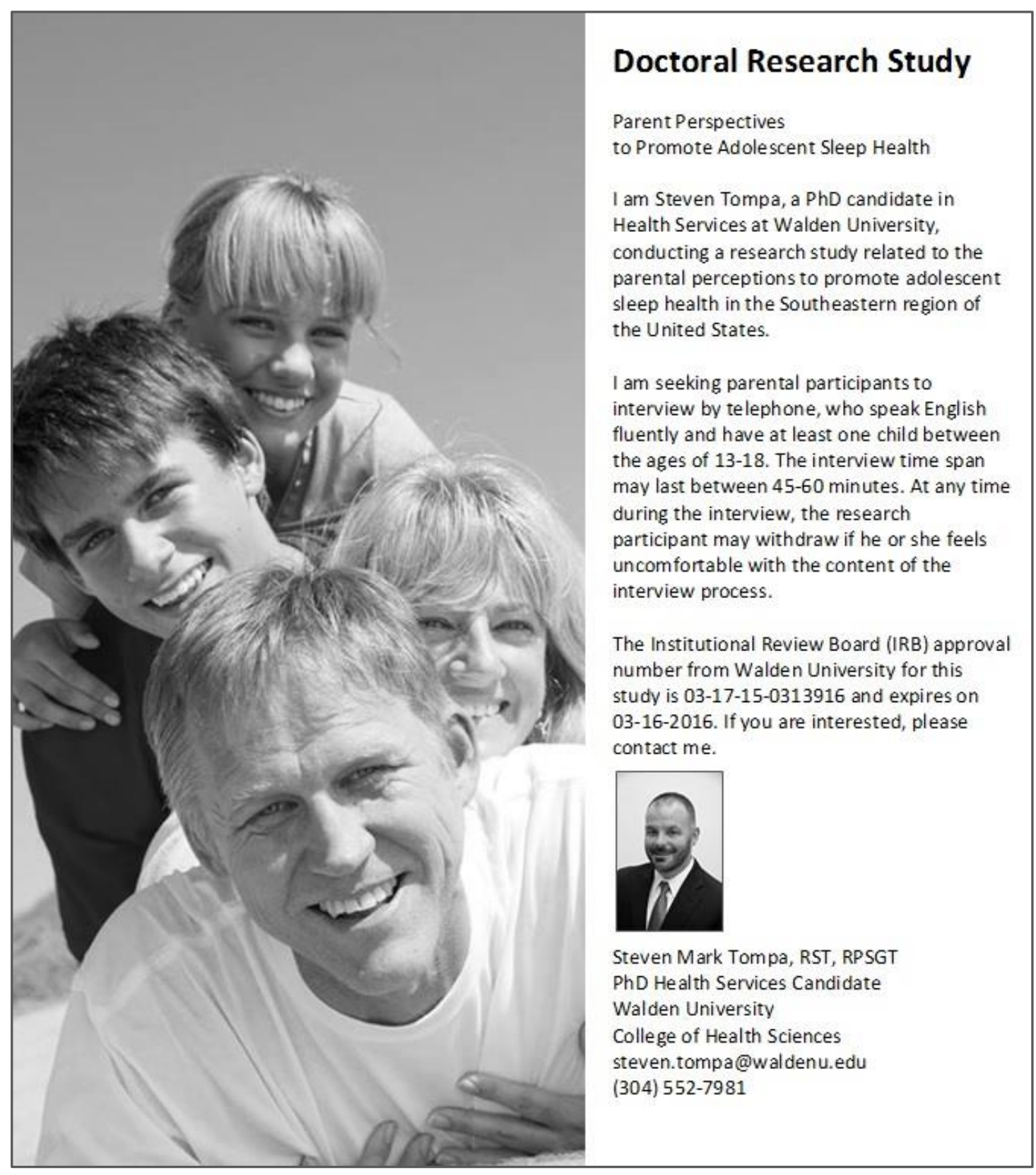

Note. Parental promotion photo reprinted with permission from iStock 


\section{Appendix B: Informed Consent Letter}

Date:

Dear Prospective Research Participant,

I am Steven Tompa, a PhD student in Health Services at Walden University, conducting a research study related to the parental perceptions to promote adolescent sleep health in the Southeastern region of the United States. The purpose of research is to focus on perceptions held by parents and to further understand how their experiences as caregivers may influence positive sleep habits of adolescents.

Participation in this research study is voluntary. Teddy bears valued at $\$ 1$ will be given or mailed with personalized thank you note for time and efforts to contribute to social change by promoting adolescent sleep health. If parent has more than one child, up to five sleep teddy bears will be given. Teddy bears will be given at the beginning and not withdrawn if participant cancels. Parental participants should be able to speak English fluently and have at least one child between the ages of 13-18. Participation in the interviews is voluntary and will last between 45-60 minutes by recorded Skype or telephone, and then transcribed into written report for review. The transcribed written report will be provided to the participant after the interview to ensure the accuracy of information collected with opportunity to provide corrections for any misunderstandings.

At any time during the interview, you may withdraw if you feel uncomfortable with the content of the interview process. The confidentiality of the research results will be assured as only I as the researcher and my Walden University dissertation supervisory committee will have complete access to the qualitative data. No associated risks are associated with participation in this study. The research results of this interview can be published after the completion of the research study. I am not affiliated with any organization except Walden University which is the school I am enrolled pursing my $\mathrm{PhD}$ degree in Health Services. A benefit for participation in this study includes contributing data that may improve the sleep quality and lifestyles for adolescents.

For your records, please feel free to retain a copy of this informed consent. If you have any questions, please feel free to contact me at (xxx) xxx-xxxx1. If you would like to know more about your rights as a research participant, you may contact Dr. Leilani Endicott at (612) 312-1210. The IRB approval number from Walden University for this study is 03-17-15-0313916 and expires on 03-16-2016. If you agree that you meet the criteria for this research study and would like to participate, please reply to this email with the words "I consent" to confirm that you are in agreement to participate in this study.

Sincerely, Steven Tompa, RST, RPSGT

$\mathrm{Ph}$.D. Health Services Candidate 


\section{Appendix C: Interview Tool}

Introduction: State name of researcher, title, research purpose, and IRB approval number. Obtain demographics including gender of parental participant, highest level of education completed, socio-economic income status, age of parental participant, and number of child(ren) along with gender and ages. Inform the participant the interview may last 4560 minutes. Administer ice breaker conversation, if needed.

Interview Questions (verbiage of some questions may need to be explained depending on the education level, socio-economic income status, or age of the parental participant):

1. What parental strategies have you used that you perceive to be the most effective, to related to your children's sleep habits?

2. What, if any difficulties have you experienced as a parent with your child(ren)'s sleep habits?

3. What, if any behaviors have you noticed with your child(ren) that may possibly be related to sleep habits?

4. Please elaborate upon how the following relate toward your perceptions of learning about better sleep habits for your child(ren): (a) Interaction, (b) Observation, (c) Influence, and (d) Monitoring

5. How, if at all did you develop knowledge as a parent about promoting better sleep health habits to your child(ren)?

6. Can you provide some examples of your child(ren)'s daily routine(s) that are a result of unhealthy sleep habits?

7. In your opinion, what do you believe are specific recommendations for promoting better sleep habits to your child(ren) and awareness of the effects on their daily activities?

8. Please elaborate upon how the following relate toward your perceptions of advocacy to promote better sleep habits for your child(ren): (a) Promote, (b) Communicate, (c) Inform, (d) Educate

9. Please provide some specific examples of conditions and behaviors of your child(ren) that you perceive as poor sleep health habits as a concern to explore with health professionals. 
10. What strategies would you recommend to recognize conditions or behaviors associated with poor sleep habits among your child(ren)?

11. What are the outcomes for repair and restoration when consulting with health professionals to reduce health problems of your child(ren)?

12. Please elaborate upon how the following relate toward your perceptions for the purpose of sleep for your child(ren): (a) Repair and (b) Restoration

13. Please elaborate upon how the following relate toward your viewpoint of caring about the sleep habits of your child(ren): (a) Value, (b) Honor, (c) Nurture, (d) Trust, (e) Health, (f) Care, (g) Teach, (h) Restore, (i) Needs, and (j) Heal

Conclusion: Thank the participant for their time as a research participant. As thank you to the participants of this study, the researcher will give teddy bears (valued at \$1) to the parent participants to give to their child with personalized note thanking the parents for their time and efforts to contribute to social change by promoting adolescent sleep health.

Debrief: Provide the participants with a description of what happens next and how they will be contacted for follow-up and verification. Also explain how their data will be protected. 
Appendix D: NIH Certification

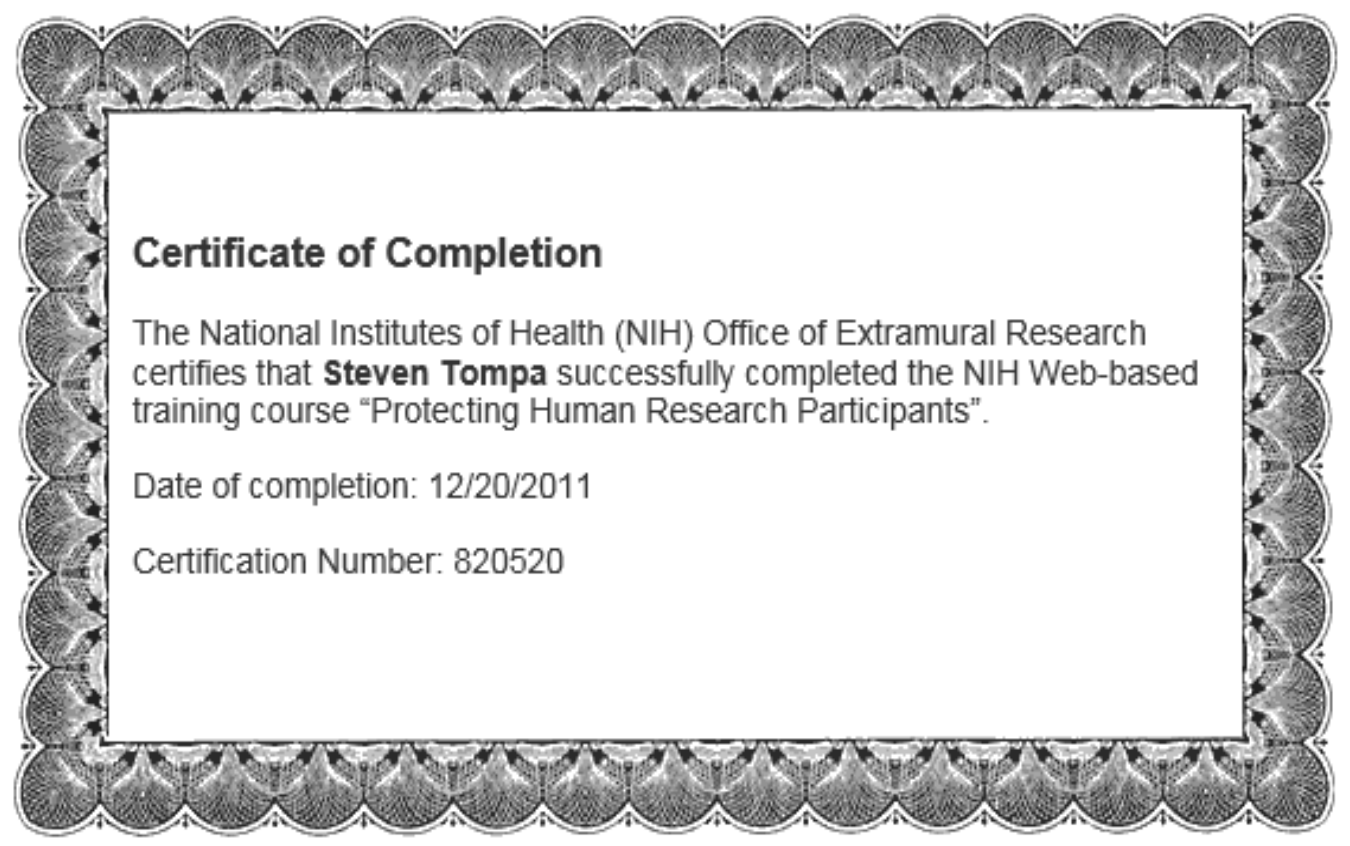


Appendix E: Free Parental Counseling Resource List

Child Parent Counseling

224 Mayo Road Suite E

Edgewater, MD 21037

Phone: (410) 848-4292

Fax: (410) 649-5256

Website: http://www.childparentcounseling.com/

The Parenting Center

2828 West Fifth Street

Forth Worth, TX 76107

Phone: (817) 332-6348

Fax: (817) 332-6489

Website: http://theparentingcenter.org/

Parent Hotline

Phone: 1-800-840-6537

Website: http://parenthotline.net/

Parent Help 123

Phone: 1-800-322-2588

Website: http://www.parenthelp123.org

Parent Counseling and Wellness Center

936 Market Street

Parkersburg, WV 26101

Phone: 1-800-841-7876

Website: http://www.counselingandwellnesscenter.com

Health Care Service International

Free Health and Welfare Clinic

400 West Olney Road

Norfolk, VA 23507

Phone: (757) 622-8688

Federal Bureau of Prisons Counseling

320 First St., NW

Washington, DC 20534

Phone: (202) 307-3198

Website: http://www.bop.gov/contact/ 
Counseling Services for Older Adults

P.O. Box 3120

Oakland, CA 94609

24 Hour Crisis Hotline: 1-800-273-8255

Website: http://www.crisissupport.org/senior_counseling

Note: In the event any parental participant experiences emotional issues from the interviews as a result of feeling neglect for adolescent sleep health, this reference list provides source for free parental counseling. 
Appendix F: IQ1/Parental Strategies Most Effective for Adolescent Sleep Health

\begin{tabular}{clc}
\hline$\#$ & Common themes and clusters reported by parents & Frequency \\
\hline 1 & Schedule bed times & 15 \\
2 & Establish consistent daily routines & 9 \\
3 & Exercise, exhaust, wear out, or wind down before bed & 8 \\
4 & Plan for bus, train, ferry, metro, or other commutes & 7 \\
5 & Read bed time stories for younger kids & 6 \\
6 & Brush teeth before bed time and when wake & 5 \\
7 & Take warm, soothing shower to relax before bed time & 5 \\
8 & Set curfew for older kids & 4 \\
9 & Turn off electronic devices, televisions, cell phones, etc. & 4 \\
10 & Monitor kids to assure sleeping and not using electronic devices & 3 \\
11 & Sleep later on weekends & 3 \\
12 & Complete homework and school projects after dinner & 3 \\
13 & Set alarm clocks or help kids wake in the morning & 3 \\
14 & Eat dinner around 6pm and avoid caffeinated drinks afterwards & 3 \\
15 & Turn lights off and sleep in dark & 3 \\
16 & Complete chores after dinner and before bed time & 2 \\
17 & Monitor times for melatonin and other medications & 2 \\
18 & Follow doctor advice for children with sleep disorders & 2 \\
19 & Teach kids self-management strategies & 2 \\
20 & Take naps as necessary & 2 \\
21 & Say prayers before bed & 1 \\
22 & Hugs before bed & 1 \\
23 & Snack couple hours before bed & 1 \\
24 & Walk younger kids to sleep & 1 \\
25 & Pat younger kids to sleep & 1 \\
26 & Sing lullaby to younger kids & 1 \\
27 & Listen to music to relax while trying to fall asleep & 1 \\
28 & Organize for next day before bed time & 1 \\
29 & Eat breakfast when first wake & 1 \\
30 & Lower house temperature to cool environment & 1 \\
31 & Stop video games and other hyperactivity 1-2 hours before bed & 1 \\
32 & Enforce schedules even when kids do not want to adhere & 1 \\
33 & Spouse reinforce same bed rules and household act as a team & 1 \\
34 & Everyone in household follow same bedtime schedules & 1 \\
35 & Negotiate to get kid to bed at decent hour & 1 \\
36 & Sacrifice activities for sleep time & 1 \\
\hline & & \\
\hline
\end{tabular}


Appendix G: IQ2/Parental Difficulties for Adolescent Sleep Health

\begin{tabular}{clc}
\hline$\#$ & Common themes and clusters reported by parents & Frequency \\
\hline 1 & Transportation schedules to school by bus, metro, train, ferry, etc. & 12 \\
2 & Electronic devices (cell phones, Internet, television, etc.) & 10 \\
3 & Consistent bed times & 9 \\
4 & Stress, emotions, fear, or anxiety & 8 \\
5 & Fall asleep at school or not focused & 7 \\
6 & Lack of exercise or physical activity & 6 \\
7 & Teeth grinding & 5 \\
8 & Time for hygiene, brushing teeth, getting dressed & 5 \\
9 & Negotiate or enforce bed time rules & 5 \\
10 & Lights & 4 \\
11 & Naps & 4 \\
12 & Finding proper dosage of melatonin to use & 4 \\
13 & Caffeine keeps kids awake & 4 \\
14 & Menstrual issues with girls & 4 \\
15 & Sleep cycle variance with kids with ADHD, Asperger's, cancer, & \\
& etc. & 4 \\
16 & Stress, emotions, anxiety, and panic attacks & 4 \\
17 & Nutrition and diet & 4 \\
18 & Need background noise of music, radio, or television & 3 \\
19 & Scary movies & 3 \\
20 & Sharing bedrooms & 3 \\
21 & Muscle aches & 3 \\
22 & Mood swings & 3 \\
23 & Medications alter sleep, sometimes more and sometimes less & 2 \\
24 & Sleep walking & 2 \\
25 & Sleep talking & 2 \\
26 & Homework & 2 \\
27 & Insomnia and can't sleep at night & 2 \\
28 & Need background noise with televisions or music & 1 \\
29 & Bad dreams, nightmares, or night terrors & 1 \\
30 & Kids pretending to sleep but awake & 1 \\
31 & Tuck in younger kids to feel secure & 1 \\
32 & Temperature of bed room and house & 1 \\
33 & Alarm clocks and waking up & 1 \\
34 & Extracurricular Activities & 1 \\
\hline & & \\
\hline
\end{tabular}


Appendix H: IQ3/Adolescent Behaviors Related to Sleep Health

\begin{tabular}{|c|c|c|}
\hline \# & Common themes and clusters reported by parents & Frequency \\
\hline 1 & Attitude changes & 20 \\
\hline 2 & Poor performance at school with grades or homework & 10 \\
\hline 3 & Snappy, agitated, short-tempered, crabby, cranky, and moody & 9 \\
\hline 4 & Poor performances with sports and extracurricular activities & 7 \\
\hline 5 & Watch television or use electronic devices instead of sleep & 6 \\
\hline 6 & Daytime sleepiness and naps & 6 \\
\hline 7 & Intolerable and irritable & 5 \\
\hline 8 & Not focused & 5 \\
\hline 9 & Less energy and tired & 5 \\
\hline 10 & Grouchy and grumpy & 4 \\
\hline 11 & Hard to wake up in morning if not enough sleep & 4 \\
\hline 12 & Dental issues from grinding teeth during sleep & 4 \\
\hline 13 & Talk and communicate less & 4 \\
\hline 14 & Take more medications or melatonin & 4 \\
\hline 15 & Aggressive, high anxiety & 3 \\
\hline 16 & Drag feet next day, seem sluggish & 3 \\
\hline 17 & Yawn frequently next day & 3 \\
\hline 18 & Fatigue & 3 \\
\hline 19 & Takes longer to get dressed & 2 \\
\hline 20 & Less responsive & 2 \\
\hline 21 & Doesn't listen or obey rules well & 2 \\
\hline 22 & Body pain and headaches & 2 \\
\hline 23 & Snoring & 2 \\
\hline 24 & Whiney & 1 \\
\hline 25 & Emotional & 1 \\
\hline 26 & Antsy and hyper & 1 \\
\hline 27 & Texting in sleep & 1 \\
\hline 28 & Accident prone & 1 \\
\hline 29 & Sore muscles & 1 \\
\hline 30 & Appetite less when sleep less & 1 \\
\hline 31 & Heavy breathing & 1 \\
\hline 32 & Sleep walk & 1 \\
\hline 33 & Use CPAP & 1 \\
\hline 34 & Menstrual issues & 1 \\
\hline 35 & Not pay attention as well when driving vehicle & 1 \\
\hline 36 & Miss School bus to school & 1 \\
\hline
\end{tabular}


Appendix I: IQ4/Parental Perceptions of Social Learning and Adolescent Sleep

Common themes and clusters reported by parents

Frequency

Interaction

Family time/meetings $\quad 7$

Breakfast discussions $\quad 7$

Dinner discussions $\quad 6$

Family drives $\quad 6$

Homework and chores $\quad 5$

Holidays 4

Weekends $\quad 4$

Text messages $\quad 3$

Interact with school teachers, counselors, PTA meetings 2

Grocery store trips $\quad 2$

Afternoons, after school $\quad 1$

Sports and extracurricular activities $\quad 1$

Observation

Observe daily behaviors, attitude, fatigue, etc. 9

Observe that kids are sleeping and cooperating with house rules $\quad 7$

Observe sleep habits more when sick 6

Observe when kids need medication (melatonin, Zoloft, etc.) 4

Observe kids to be alert and not sleepy at day 3

Observe kids yawning or pulling ears when sleepy 2

Observe kids are awake in morning, getting ready for school 1

Influence

Set sleep routines, schedules, and habits when young $\quad 10$

Set guidelines for daily habits $\quad 5$

Set example, practice same sleep habits as kids 4

Enforce no electronic devices or television 3

Engage with kids to teach health habits overall $\quad 2$

Influence kids that sleep is to rejuvenate 1

Monitoring

Assure kids following bedtime schedule $\quad 10$

Check kids are safe $\quad 6$

Check kids are sleeping, not pretending 5

Compare sleep pattern versus school and sports performance 3

Check that lights are off and doors shut 3

Listen for noises $\quad 3$

Check younger kids are breathing without snoring issues 2

Assure temperature of house comfortable for sleeping 2 
Appendix J: IQ5/Parental Knowledge to Promote Better Adolescent Sleep

\begin{tabular}{|c|c|c|}
\hline \# & Common themes and clusters reported by parents & Frequency \\
\hline 1 & Gained knowledge from my parents then taught kids the same & 13 \\
\hline 2 & Not aware of PTA educating parents about sleep health & 9 \\
\hline 3 & $\begin{array}{l}\text { Knowledge gained from balance judgement and parental } \\
\text { instincts }\end{array}$ & 8 \\
\hline 4 & Not aware of schools providing sleep health education & 7 \\
\hline 5 & Gained knowledge from day-to-day experience with kids & 5 \\
\hline 6 & Trial and error strategies helped me learn & 5 \\
\hline 7 & Never thought much about sleep, it's just something we do & 4 \\
\hline 8 & Gained knowledge in college courses, specifically psychology & 4 \\
\hline 9 & Sleep is important for everything in life & 3 \\
\hline 10 & $\begin{array}{l}\text { Asked health professionals questions when kids had sleep } \\
\text { problems }\end{array}$ & 3 \\
\hline 11 & $\begin{array}{l}\text { Ask pharmacists and health professionals about sleep } \\
\text { medications }\end{array}$ & 3 \\
\hline 12 & Television commercials & 3 \\
\hline 13 & $\begin{array}{l}\text { Parent knowledge about sleep impacts kids academic } \\
\text { performance }\end{array}$ & 2 \\
\hline 14 & Parent knowledge about sleep impacts kids physical activity & 2 \\
\hline 15 & Knowledge about the basics of sleep in school & 2 \\
\hline 16 & Explored Internet when kids had sleep problems & 2 \\
\hline 17 & Military taught me sleep habits and strict discipline & 2 \\
\hline 18 & Knowledge is power and sleep gives kids strength & 2 \\
\hline 19 & Magazine articles and ads & 2 \\
\hline 20 & Newspaper stories & 2 \\
\hline 21 & Medical pamphlets/brochures at doctor's office & 2 \\
\hline 22 & Friends and family with sleep problems increased my & \\
\hline & knowledge & 1 \\
\hline 23 & $\begin{array}{l}\text { Teachers call or email when kids sleep in school or are not } \\
\text { focused }\end{array}$ & 1 \\
\hline 24 & My own sleep problems helped me increase knowledge & 1 \\
\hline 25 & $\begin{array}{l}\text { Pediatricians helped me know large tonsils cause snore and } \\
\text { apnea }\end{array}$ & 1 \\
\hline 26 & Watch attitudes of kids to learn better strategies for sleep health & 1 \\
\hline 27 & $\begin{array}{l}\text { Gained knowledge from coaches sleep improves sports } \\
\text { performances }\end{array}$ & 1 \\
\hline
\end{tabular}


Appendix K: IQ6/Daily Routines Resulted From Unhealthy Adolescent Sleep

\begin{tabular}{clc}
\hline$\#$ & Common themes and clusters reported by parents & Frequency \\
\hline 1 & Attitude becomes moody and cranky during daily routines & 20 \\
2 & Less productive in academic routines & 10 \\
3 & Yawn and eyes appear tired during daily routines & 8 \\
4 & Less productive with sports or extracurricular routines & 7 \\
5 & Less productive at part-time job & 6 \\
6 & Slower with daily routines and sleepiness noted & 6 \\
7 & Using cell phones instead of sleeping & 6 \\
8 & Take more naps & 6 \\
9 & Less focused with daily routines & 5 \\
10 & Morning routine delayed, oversleep & 4 \\
11 & Daily routines includes medication (melatonin, sleep aids, etc.) & 4 \\
12 & Sleep marathons to catch up on sleep & 2 \\
13 & Miss or late for morning school bus routine & 2 \\
14 & Emotionally fragile during daily routines & 1 \\
15 & Not as sharp with daily routines & 1 \\
16 & Less engaged in conversations & 1 \\
17 & Driving routines are more reckless & 1 \\
\hline
\end{tabular}


Appendix L: IQ7/Parental Recommendations to Promote Adolescent Sleep

\begin{tabular}{|c|c|c|}
\hline \# & Common themes and clusters reported by parents & Frequency \\
\hline 1 & Schedule bed times & 15 \\
\hline 2 & Establish consistent daily routines & 9 \\
\hline 3 & Retain sleep diary & 8 \\
\hline 4 & $\begin{array}{l}\text { Add sleep health courses to the school academic curriculum } \\
\text { programs }\end{array}$ & 7 \\
\hline 5 & Read bed time stories & 6 \\
\hline 6 & Plan for bus, train, or commute schedules & 6 \\
\hline 7 & $\begin{array}{l}\text { Reinforce the importance of sleep and how affects daily } \\
\text { activities }\end{array}$ & 5 \\
\hline 8 & Set example with good sleep habits & 5 \\
\hline 9 & Warm bath/shower and brush teeth before bed & 5 \\
\hline 10 & Exercise, exhaust, wear out, or wind down before bed & 5 \\
\hline 11 & Encourage healthy nutrition & 4 \\
\hline 12 & Monitor sports and extracurricular performances & 4 \\
\hline 13 & Set curfew for older kids & 4 \\
\hline 14 & Turn off electronic devices, televisions, cell phones, etc. & 4 \\
\hline 15 & Educate parents and kids about sleep by Internet, books, etc. & 3 \\
\hline 16 & Monitor academic performance performances & 3 \\
\hline 17 & Have talks and discussions with kids to see how they feel & 3 \\
\hline 18 & Monitor kids to assure sleeping and no electronic devices in use & 3 \\
\hline 19 & Sleep later on weekends & 3 \\
\hline 20 & Complete homework and school projects after dinner & 3 \\
\hline 21 & Set alarm clocks or wake kids & 3 \\
\hline 22 & No foods or caffeinated drinks after $6 \mathrm{pm}$ & 3 \\
\hline 23 & Turn lights off and sleep in dark & 3 \\
\hline 24 & Assure kids achieve adequate hours of sleep each night & 2 \\
\hline 25 & Share personal experiences about lack of sleep & 2 \\
\hline 26 & Complete chores after dinner and before bed time & 2 \\
\hline 27 & Take medications before bed and when first wake up & 2 \\
\hline 28 & Follow doctor advice for children with sleep disorders & 2 \\
\hline 29 & Exercise before bed & 2 \\
\hline 30 & Teach kids self-management strategies and organization & 2 \\
\hline 31 & Lower house temperature to cool environment & 1 \\
\hline 32 & Stop video games and other hyperactivity $1-2$ hours before bed & 1 \\
\hline 33 & Enforce schedules even when kids do not want to adhere & 1 \\
\hline 34 & Spouse reinforce same bed rules and household act as a team & 1 \\
\hline 35 & Everyone in household follow same bedtime schedules & 1 \\
\hline 36 & Melatonin or herbal sleep medications & 1 \\
\hline
\end{tabular}


Appendix M: IQ8/Parental Recommendations to Advocate Adolescent Sleep

\begin{tabular}{lc}
\hline Common themes and clusters reported by parents & Frequency \\
\hline Promote & 15 \\
Promote consistent bed times & 9 \\
Promote consistent daily routines & 6 \\
Promote good sleep habits as parents & 5 \\
Promote sleep affects sports and extracurricular performances & 4 \\
Promote proper nutrition for better sleep habits & 3 \\
Promote sleep affects academic performance performances & \\
Educate & 8 \\
Not aware of schools educating students on sleep health & 6 \\
Schools should add sleep health to the curriculum & 5 \\
Read about sleep by Internet, magazines, books, etc. & 3 \\
Parents have responsibility to educate kids & 1 \\
PTA meetings should educate parents about sleep health & \\
Inform & 7 \\
Tracking sleep with diaries & 5 \\
Advise kids how sleep affects daily activities & 3 \\
Read about sleep by Internet, magazines, books, etc. & 2 \\
Inform kids about self-management strategies and organization & 1 \\
Inform kids of bed times and curfews & 1 \\
Teachers inform parents when poor performances noted & \\
Communicate & 7 \\
Communicate no electronic devices at bed time & 5 \\
Have talks and discussions with kids to see how they feel & 5 \\
Share personal experiences about lack of sleep & 4 \\
Read about sleep articles in newspapers and journals & 3 \\
Discuss sleep articles from Internet, magazines, books, etc. &
\end{tabular}


Appendix N: IQ9/Reasons Noted by Parents to Consult Health Professionals

\begin{tabular}{clc}
\hline$\#$ & Common themes and clusters reported by parents & Frequency \\
\hline 1 & Attitude or mannerisms changes & 9 \\
2 & Poor grades & 7 \\
3 & Poor sports performance & 5 \\
4 & Short-tempered & 5 \\
5 & Snappy & 4 \\
6 & Insomnia or not sleeping & 4 \\
7 & Sleep talking & 3 \\
8 & Anxiety or panic & 3 \\
9 & Headaches & 3 \\
10 & Medications & 3 \\
11 & Argumentative & 2 \\
12 & Waking up through the night & 2 \\
13 & Stop breathing & 2 \\
14 & Sleep walking & 2 \\
15 & Bed wetting & 2 \\
16 & Teeth grinding & 2 \\
17 & Fall asleep everywhere, in public, in the car & 2 \\
18 & More injuries or accidents & 2 \\
19 & Sniffles & 2 \\
20 & Irritable & Respiratory disorders \\
21 & Excessive snoring & 1 \\
23 & Look tired & 1 \\
24 & Misbehaving & Tonsils causing snoring and blocking airway \\
26 & Weight gain and obesity & 1 \\
27 & Wellness programs or physicals & 1 \\
\hline & & 1 \\
\hline
\end{tabular}


Appendix O: IQ10/Parental Recognition of Poor Adolescent Sleep

\begin{tabular}{clc}
\hline$\#$ & Common themes and clusters reported by parents & Frequency \\
\hline 1 & Changes in Routine & 11 \\
2 & Attitude and personality changes & 11 \\
3 & Cell phone & 10 \\
4 & Computers, Internet, social medial & 10 \\
5 & Tired or shut down & 4 \\
6 & Mischievous & 3 \\
7 & Grouchy & 2 \\
8 & Poor grades & 2 \\
9 & More naps & 2 \\
10 & Body pain & 2 \\
11 & Snore & 2 \\
12 & Irritability & 1 \\
13 & Moody & 1 \\
14 & Mean or misbehaving & 1 \\
15 & Parental instinct & 1 \\
16 & Eating habits change & 1 \\
17 & Poor sports performance & 1 \\
18 & Whiney & 1 \\
19 & Wants extra affection and cuddle time & 1 \\
20 & High anxiety or panic & 1 \\
21 & Bed wetting & 1 \\
22 & Sleep marathons & 1 \\
23 & Loss of time recognition & 1 \\
24 & Don't listen or pay attention & 1 \\
25 & Difficulty sleeping & 1 \\
26 & Not wanting to wake in the morning & 1 \\
27 & Poor sports performance & 1 \\
28 & Lazy with house chores & 1 \\
29 & Not wanting to shower or bath & 1 \\
30 & Longer to wind down & 1 \\
31 & Stop breathing in sleep & 1 \\
\hline & & 1 \\
\hline
\end{tabular}


Appendix P: IQ11/Outcomes From Health Professionals

\begin{tabular}{clc}
\hline$\#$ & Common themes and clusters reported by parents & Frequency \\
\hline 1 & No electronic devices or television while sleeping & 15 \\
2 & Encourage 8-10 hours of sleep per night & 13 \\
3 & Noticed less moodiness and attitude problems & 12 \\
4 & Develop consistent sleep routine & 11 \\
5 & Encourage exercise for better health and sleep & 8 \\
6 & Sleep diaries to track and improve sleep habits & 8 \\
7 & No caffeine after dinner & 8 \\
8 & Melatonin and other sleep aids were recommended & 7 \\
9 & Turn off lights at night & 7 \\
10 & Reduce noise at night & 6 \\
11 & Reduce naps during the day to save sleep for night & 5 \\
12 & Keep temperature cooler for more comfort and better sleep & 5 \\
13 & Oral appliance prescribed to protect teeth from grinding in & \\
& sleep & 4 \\
14 & CPAP was prescribed for sleep apnea & 4 \\
15 & Actigraphy was suggested to monitor sleep and movements & 2 \\
\hline
\end{tabular}


Appendix Q: IQ12/Parental Views of Adolescent Sleep Repair and Restoration

\begin{tabular}{llc}
\hline$\#$ & Common themes and clusters reported by parents & Frequency \\
\hline 1 & Sleep helps my kids do better in school and sports & 6 \\
2 & Sleep helps with obesity, hypertension, and other health issues. & 5 \\
3 & Sleep makes my kids friendlier and less moody & 4 \\
4 & Sleep helps my kids do better in sports & 4 \\
5 & Sleep helps and make better decisions & 3 \\
6 & Sleep helps my kids when they are injured or sick & 2 \\
7 & Sleep helps my kids recharge their minds & 2 \\
8 & Sleep helps my kids be more active at day & 2 \\
9 & The doctors tell me sleep helps with growth & 1 \\
10 & CPAP stops apnea and allows my child to get all sleep stages & 1 \\
11 & Sleep helps my child be more alert while driving & 1 \\
\hline
\end{tabular}


Appendix R: IQ13/Parental Views for Caring and Adolescent Sleep

\begin{tabular}{llc}
\hline Construct & Most popular themes and clusters reported by parents & Frequency \\
\hline Value & The value of sleep is critical for health and activities. & 15 \\
Honor & We honor sleep within our family for rest for better & 13 \\
& health. & 10 \\
Nurture & We nurture our kids with pleasant sleep environment. & 11 \\
Trust & We trust health professionals to guide our sleep health. & 12 \\
Health & Our overall health is affected by our sleep patterns. & 9 \\
Care & We care about sleep for school and sports performance. & 8 \\
Teach & We teach adolescents daily consistent habits for sleep. & 12 \\
Restore & Sleep restores us for routines and activities. & 10 \\
Needs & Sleep is needed for better health and daily performance. & 12 \\
Heal & Sleep helps our family heal mentally and physically. & \\
\hline
\end{tabular}


Appendix S: Parent Quotes Related to SLT

\begin{tabular}{|c|c|c|}
\hline IQ, concept & Parent & Parent quote \\
\hline $\begin{array}{l}\text { IQ1, } \\
\text { Strategies }\end{array}$ & Azmitha & $\begin{array}{l}\text { I purposely set consistent bedtimes at an early age. I } \\
\text { sang or read to them, 'Nightie night, nightie night, } \\
\text { Momma looks to you in the morning light'. And so } \\
\text { their habit would be stories, and then it was time for } \\
\text { them to go to sleep. And those strategies seemed to } \\
\text { work to establish consistency and habit for bedtime. }\end{array}$ \\
\hline $\begin{array}{l}\text { IQ2, } \\
\text { Strategies }\end{array}$ & Shashni & $\begin{array}{l}\text { Well, when Lanx and Sirius were younger, we } \\
\text { developed a consistent routine for dinner, snacks, } \\
\text { brushing our teeth, reading a book, hugs, lights out, } \\
\text { and bed time. Now that they are teenagers, they } \\
\text { follow this schedule like clockwork. It's all about } \\
\text { learning consistency when they are young to create } \\
\text { habit. }\end{array}$ \\
\hline $\begin{array}{l}\text { IQ1, } \\
\text { Strategies }\end{array}$ & Ashwin & $\begin{array}{l}\text { Consistency within our household seems important } \\
\text { to learning healthy sleep habits. Beid and Kuma } \\
\text { seemed to learn and follow better sleep habit } \\
\text { routines when everyone in the house followed the } \\
\text { same sleep schedules with lights out at the same } \\
\text { time. It helped further when my partner reinforced } \\
\text { these rules too. }\end{array}$ \\
\hline $\begin{array}{l}\text { IQ2, } \\
\text { Difficulties }\end{array}$ & Kirithiga & $\begin{array}{l}\text { Seems children are losing early morning hours of } \\
\text { sleep due to school bus schedules with school } \\
\text { consolidations to save money. }\end{array}$ \\
\hline $\begin{array}{l}\text { IQ2, } \\
\text { Difficulties }\end{array}$ & Mughilsri & $\begin{array}{l}\text { The difficulty with electronic devices was so severe } \\
\text { in our household that we removed the bedroom } \\
\text { doors to assure our kids were sleeping rather than } \\
\text { texting. }\end{array}$ \\
\hline $\begin{array}{l}\text { IQ2, } \\
\text { Difficulties }\end{array}$ & Shashvina & $\begin{array}{l}\text { Consistency with bed time schedules has been } \\
\text { instrumental in helping Kastra and Lucida with } \\
\text { improved sleep. }\end{array}$ \\
\hline $\begin{array}{l}\text { IQ3, } \\
\text { Behaviors }\end{array}$ & Andromeda & $\begin{array}{l}\text { Without sufficient sleep, Ksora and Markif have } \\
\text { intolerable attitudes. You would not want to be } \\
\text { around them. Lack of sleep makes them moody. }\end{array}$ \\
\hline
\end{tabular}


IQ3, Talitha When Jomam, Nava, and Asterion do not get enough

Behaviors sleep, and we notice a pattern with behavior in school. They focus less and their grades are less than.

IQ3, Mrudani Zaniah drags his feet or he'll, you know, yawn and Behaviors stretch a lot when he has less sleep and can be snappy and crabby.

IQ4a, Mugana

We try to establish routines to begin our day talking Interaction over breakfast and dinner, and then at the end of the day recap things that went well before calling it a day to lay down to sleep.

IQ4b, Latrell

We notice attitudes changing and fatigue when our Observation kids are not getting enough sleep. Jhydrobius is our star athlete and is not as focused with basketball.

IQ4c, Denebola We encouraged set routines for bed time. We told Influence them we would remove their bedroom doors if we found them on their phones or computers during the night instead of sleeping.

IQ4d, Lyra Monitoring

I normally check to see Jegor, Menchib, and Diadem are in bed safely about nine and all the lights are off then I try to go to bed and spot check if needed. 
Appendix T: Parent Quotes Related to AP

\begin{tabular}{|c|c|c|}
\hline IQ, concept & Parent & Parent quote \\
\hline $\begin{array}{l}\text { IQ5, } \\
\text { Knowledge }\end{array}$ & Kawkab & $\begin{array}{l}\text { The topic for sleep education is not popular in any of } \\
\text { the schools that I am aware. The teachers usually } \\
\text { send a letter home to us to remind us when Electra } \\
\text { and Hamal have the annual standardized tests to } \\
\text { make sure they get good night sleep and good meal, } \\
\text { but that's all I recall being told about sleep. }\end{array}$ \\
\hline $\begin{array}{l}\text { IQ5, } \\
\text { Knowledge }\end{array}$ & Belros & $\begin{array}{l}\text { In elementary school, they recommended eight hours } \\
\text { of sleep but the topic of sleep was never mentioned } \\
\text { any other times. I am not aware of sleep even being } \\
\text { discussed in parent teacher association (PTA) } \\
\text { meetings. }\end{array}$ \\
\hline $\begin{array}{l}\text { IQ5, } \\
\text { Knowledge }\end{array}$ & Deneb & $\begin{array}{l}\text { I think my knowledge for sleep habits for Matar and } \\
\text { Scheat came from balance judgment and parental } \\
\text { instinct. If they did well in school and sports, I knew } \\
\text { things were right. When their performance dropped, } \\
\text { I knew to look into their habits. }\end{array}$ \\
\hline $\begin{array}{l}\text { IQ6, } \\
\text { Routines }\end{array}$ & Kirithiga & $\begin{array}{l}\text { When Jcynosura and Gacrux don't get enough sleep, } \\
\text { I have noticed a trend with lower scores on math } \\
\text { exams and they are run down when they play hockey } \\
\text { and participate in other sports or physical activities. }\end{array}$ \\
\hline $\begin{array}{l}\text { IQ6, } \\
\text { Routines }\end{array}$ & Denebola & $\begin{array}{l}\text { Dnoces appears moody and cranky when she doesn't } \\
\text { get enough sleep at night. She looks tired the next } \\
\text { day and doesn't usually have a good day. When this } \\
\text { happens, the pattern is that she usually doesn't do } \\
\text { well at soccer practice and just wants to come home } \\
\text { and nap. }\end{array}$ \\
\hline $\begin{array}{l}\text { IQ6, } \\
\text { Routines }\end{array}$ & Ashwin & $\begin{array}{l}\text { I have received calls from my son Kuma's teachers } \\
\text { on several instances that he has not been focused or } \\
\text { has fallen asleep in class. Those are usually the } \\
\text { times he has not had a good night's sleep with at } \\
\text { least eight hours. }\end{array}$ \\
\hline $\begin{array}{l}\text { IQ7, } \\
\text { Recommend }\end{array}$ & Shashni & $\begin{array}{l}\text { I am an advocate to promote consistency in all } \\
\text { aspects for the routines for my children. Consistency }\end{array}$ \\
\hline
\end{tabular}




IQ7,
Recommend

IQ7,

Recommend

IQ7,

Recommend

IQ8a,

Promote

IQ8b,

Educate

Kirithiga

Azmitha seems to be the best parental strategy for me for better outcome for my children with school, sports, nutrition, exercise, and sleep habits.

As a parent, I advocate standard bed times for my children. The pediatrician advised us that children require more sleep during the tender growing years, especially during puberty. As they grew older, I extended the time for chores, homework, hygiene, and unwind. Menkent seems to perform better with football when well rested.

Talitha I am an advocate of diaries and journals to track sleep times and compare what is the best routine. Even though we try to keep consistent, our routines may have to deviate from time to time, because things come up. You should stick to a routine.

As a parent advocate, I would suggest the school systems look into the bus schedules and transportation routines so that children all over the United States will have more sleep time in the mornings to obtain 8-9 hours to be well rested.

Brochures and pamphlets are a good source for promoting the importance of sleep for overall health. This could help by offering more awareness to students in health class or even at the doctor offices by brochures, in additional training, parent training that the school system offers to parents, and letters, and just during meetings, themselves. I have heard how important it is that the students come to school having had a good night sleep and proper nutrition.

I would advocate more education to be offered about the importance of sleep for children as well as teaching parents. I think the rest would help them emotionally and mentally, be able to stay focused the next day. I had an incident that happened with my daughter Scheat about a month ago. Scheat had an accident because she fell asleep driving to work. If education placed more emphasis on teaching us about the importance of sleep, perhaps we would 
IQ8c, Mugana Informing

IQ8d, Izar

Communicate have known better and my daughter Scheat would not have been driving drowsy.

Um, I think, um, informing children about the importance of sleep and how it affects their performance is important. My kids have a really good health program and they talk about it in their, um, classes and I think, um, I think my kids had coaches informing them to keep journals of their activities and, like, they're supposed to track their activities. They have stressed the importance of good nutrition and, you know, good sleep patterns and stuff like that. Through retaining daily dairies, it has helped them cut back on sodas and other unhealthy food. Also helps them to track to foods before bed. They no longer drink caffeine after $6 \mathrm{pm}$. They seem more informed from their coaches in sports than their teachers. Overall, they keep themselves better informed when they take selfresponsibility and track their habits with diaries or journals.

I would advocate parents look for ways to include sleep habits in their communication with their kids. Sleep is part of our morning conversation. You know, "did you sleep well last night?" "What did you dream about?" That's actually a standard question each morning at the breakfast table. They tell me the reasons they can't sleep well and we talk about it. 
Appendix U: Parent Quotes Related to RRTS

\begin{tabular}{|c|c|c|}
\hline IQ, concept & Parent & Parent quote \\
\hline $\begin{array}{l}\text { IQ9, } \\
\text { Consult } \\
\text { Health } \\
\text { Professionals }\end{array}$ & Andromeda & $\begin{array}{l}\text { Well, I believe a health professional should be } \\
\text { consulted if issues are noted affecting my kids } \\
\text { daily routines, for example, if their grades are } \\
\text { constantly slipping ... um... also if their behaviors } \\
\text { or attitude towards people in general is very ... } \\
\text { you know, snappy, very short-tempered, you } \\
\text { know... day dreaming, }\end{array}$ \\
\hline $\begin{array}{l}\text { IQ9, } \\
\text { Consult } \\
\text { Health } \\
\text { Professionals }\end{array}$ & Talitha & $\begin{array}{l}\text { Um, I would call a health professional, first and } \\
\text { foremost, if there's a noticeable change in } \\
\text { mannerism and attitude. My daughters Nava and } \\
\text { Asterion went through some stages of insomnia. } \\
\text { They were irritable and cranky during the day so } \\
\text { the pediatrician recommended we try melatonin. } \\
\text { Once they started sleeping better, their mannerism } \\
\text { and attitude was better. }\end{array}$ \\
\hline $\begin{array}{l}\text { IQ9, } \\
\text { Consult } \\
\text { Health } \\
\text { Professionals }\end{array}$ & Mughilsri & $\begin{array}{l}\text { I found it time to consult help from a health } \\
\text { professional because my son Lasuperba would get } \\
\text { night terrors. He was admitted to a } \\
\text { psychologist. My daughter Lrumium was grinding } \\
\text { her teeth in her sleep. The pediatrician referred her } \\
\text { to the dentist for night guard to wear to protect her } \\
\text { teeth from the grinding. }\end{array}$ \\
\hline $\begin{array}{l}\text { IQ9, } \\
\text { Consult } \\
\text { Health } \\
\text { Professionals }\end{array}$ & Izar & $\begin{array}{l}\text { There was a concern with my kids' sleep walking } \\
\text { and talking. Even more severe, I had a concern for } \\
\text { my daughter Diadem as far as breathing because of } \\
\text { her tonsils. She was snoring heavily. She was } \\
\text { monitored for a little while and once we got her } \\
\text { tonsils removed then she was able to breathe } \\
\text { better. }\end{array}$ \\
\hline $\begin{array}{l}\text { IQ9, } \\
\text { Consult } \\
\text { Health } \\
\text { Professionals }\end{array}$ & Denebola & $\begin{array}{l}\text { Well, when my son is not getting enough sleep, he } \\
\text { is aggressive at school. He would be very defiant, } \\
\text { and he would cry, and then he would fight. And } \\
\text { he'd be really sensitive. When he's having normal } \\
\text { interactions with other kids, things that normally } \\
\text { might bother him and he'd be irritated and walk }\end{array}$ \\
\hline
\end{tabular}




IQ10, Alya
Poor Sleep

IQ10, Poor Sleep

IQ10, Poor Sleep

IQ11, Health Professional Outcomes

IQ11,

Health

Professional

Outcomes

IQ11, Health Professional Outcomes away. Well, we took him to the doctor and he was diagnosed with sleep apnea. He now uses CPAP. Now that he gets all of his sleep stages and cycles, his school and social interactions are much better. The best way I recognize that my children are not getting proper sleep is their mood and personality. Their mood is awful when they do not get enough sleep. They just do not have their normal happy attitude and pleasant disposition.

Jabbah If I recognize changes affecting my daughters' routines with volleyball, dancing, debate club, etc., then I know they probably aren't getting enough sleep. That's when my wife and I know we need to look more closely into their schedules.

Belros If I recognize texting activity on the phone bill during the wee hours of the night, I discuss with them the importance to turn off phones at night because I want them to sleep to be focused and refreshed at school and in their daily routines.

Latrell After our doctor told us how cell phones, iPads, lap tops, television, and other electronic devices affect sleep at night, we enforced house rules for Decrux, Jhydrobius, Baham, and Iwezn that they must leave cell phones and lap tops in the living room at night. It's not that we don't trust our children but the temptation to use the devices was too strong when the devices were in their bedrooms. We just want the best for our children.

After the pediatrician told me adolescents require 8-10 hours of sleep per night, we started to enforce a consistent schedule so Diadem, Jegor, and Menchib would be better rested for their overall daily activities.

Shashvina

We noticed our children to do better with so many things after taking sleep hygiene advice from the doctor with consistent sleep routine, exercise, sleep diaries, and no caffeine after dinner. This 
IQ12,

Repair and

Restoration

IQ12,

Repair and

Restoration

IQ12, Repair and Restoration advice helped to improve all aspects of their daily plans.

Andromeda I feel sleep helps Ksora and Marfik recharge and obtain the repair and restoration that their body needs both mentally and physically to do better in all aspects for their daily routines. They are even less moody, cranky, tired, and sad.

Kiriya

When Gacrux or Edasich are sick or injured, the more they sleep the quicker their body heals.

Seems sleep is essential for repair and restoration to the human body for them to be better rested and healthier, especially during the young growing years of life.

Ashwin Seems sleep is nature's way of giving our children and their body the repair and restoration to help improve the overall health of us all to prevent obesity, high blood pressure, heart issues, and just overall give us better health in general. 


\section{Appendix V: Parent Quotes Related to TCS}

\begin{tabular}{|c|c|c|}
\hline IQ, concept & Parent & Parent quote \\
\hline $\begin{array}{l}\text { IQ13a, } \\
\text { Value }\end{array}$ & Mrudani & $\begin{array}{l}\text { In our household, we truly value the importance } \\
\text { of our rest and sleep to assure we will be } \\
\text { productive the next day. We realize we must care } \\
\text { about our children to assure they are rested for the } \\
\text { next day. Sleep is God's way to heal our bodies } \\
\text { and keep us healthy. }\end{array}$ \\
\hline $\begin{array}{l}\text { IQ13b, } \\
\text { Honor }\end{array}$ & Shashni & $\begin{array}{l}\text { My husband and I honor sleep. We both have } \\
\text { very hectic jobs - me as a social worker and him } \\
\text { as a graphic artist. We have to be rested to do our } \\
\text { jobs well so we honor sleep and encourage the } \\
\text { same of our sons Lanx and Sirius. We want our } \\
\text { sons to do well in school and in their part-time } \\
\text { jobs. }\end{array}$ \\
\hline $\begin{array}{l}\text { IQ13c, } \\
\text { Nurture }\end{array}$ & Shashvina & $\begin{array}{l}\text { Just like we nurture Kastra, Lucida, Menkent, and } \\
\text { Canopus with shelter, clothes, and meals - we all } \\
\text { nurture them so they will have good sleep habits. } \\
\text { To nurture the, we make sure they have a pleasant } \\
\text { sleep environment and atmosphere with a cool } \\
\text { and comfortable room temperature, warm } \\
\text { blankets and bed linen, nice pajamas, and quiet } \\
\text { room. }\end{array}$ \\
\hline $\begin{array}{l}\text { IQ13d, } \\
\text { Trust }\end{array}$ & Denebola & $\begin{array}{l}\text { We trust our health professionals advice for sleep } \\
\text { hygiene to not let our children use cell phones, } \\
\text { iPads, televisions, and electronic devices while } \\
\text { they sleep. We trust sleep will keep our children } \\
\text { better restored mentally and physically for better } \\
\text { performance in school and sports. }\end{array}$ \\
\hline $\begin{array}{l}\text { IQ13e, } \\
\text { Health }\end{array}$ & Jabbah & $\begin{array}{l}\text { My wife and I love our children Taygeta and } \\
\text { Capella with all our hearts. We help them with } \\
\text { their sleep habits because our family doctor } \\
\text { mentions proper sleep habits help deter chances } \\
\text { of heart disease and diabetes. We want them to be } \\
\text { happy and healthy. }\end{array}$ \\
\hline
\end{tabular}




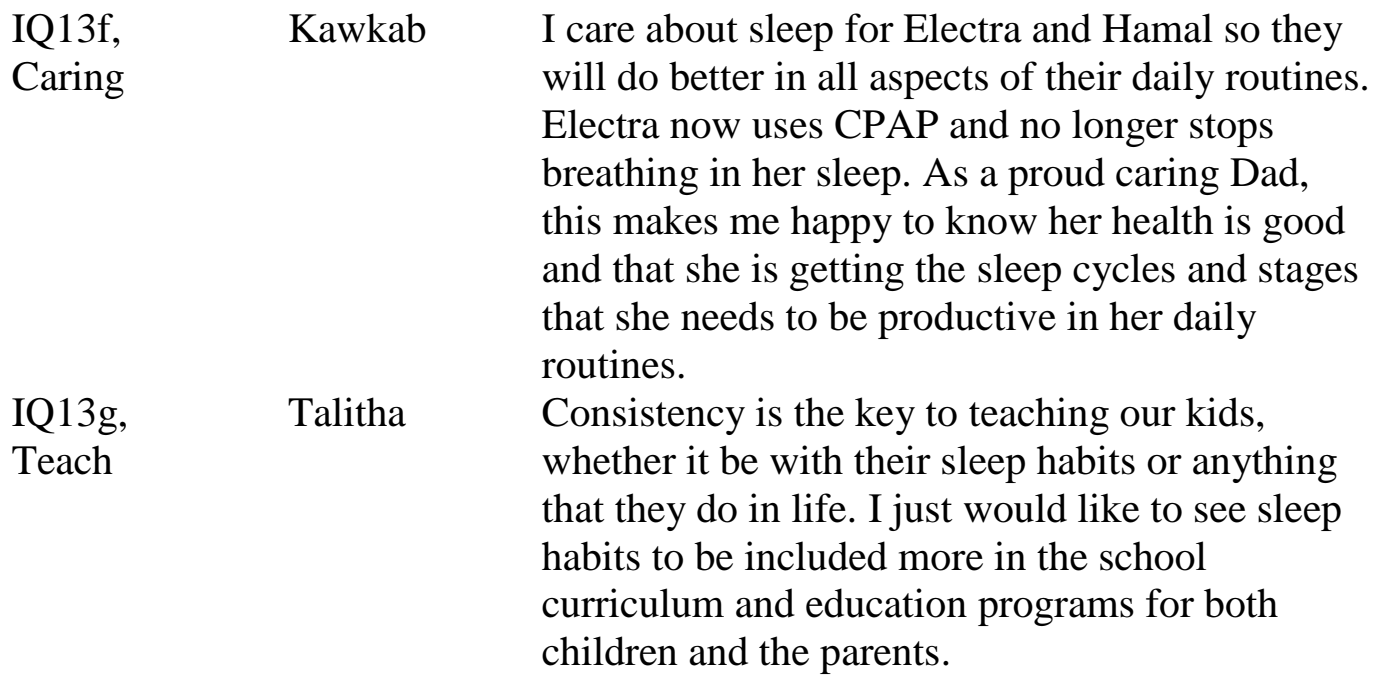

IQ13h, Belros Sleep helps my children restore themselves. Restore Pleione has an amazing singing voice and Iwast is great with sports. I have noticed when they attain proper sleep, Pleione keeps her voice restored so she sings better in church and Iwast continues to do well in sports.

IQ13i, Lyra We follow recommendations from our doctor that Needs our children need 8-10 hours of sleep per night. When we make sure their sleep needs are met, we have noticed that Muscida and Magrez seem to be more mentally and physically focused and do better in school and sports.

IQ13j, Izar I truly believe sleep is nature's way to help assure Healing our bodies heal from illness and injuries. When Magrez and Muscida are feeling sick, sleep seems to help their bodies heal. When they have had an accident, fallen and bruised themselves, or even cut themselves - sleep seems to help their bodies heal faster. 
Appendix W: Parent Quotes Related to School Transportation

\begin{tabular}{|c|c|c|}
\hline State & Parent & Parent quote \\
\hline Alabama & Denebola & $\begin{array}{l}\text { Our children do not have option for school bus } \\
\text { here in Birmingham, Alabama. The school district } \\
\text { chose to cut their cost with transportation. As } \\
\text { parents, we are responsible for the transportation } \\
\text { of our children. Because of our work schedules, } \\
\text { our children have to wake much earlier. This } \\
\text { causes them to loose early hours of sleep. }\end{array}$ \\
\hline Kentucky & Kiriya & $\begin{array}{l}\text { We reside in Kentucky. So that our children do not } \\
\text { have to catch the school bus, my husband and I } \\
\text { drive them. Our work schedules, however, } \\
\text { interfere and cause our children to arrive to school } \\
\text { early and miss morning sleep time. }\end{array}$ \\
\hline Maryland & Jabbah & $\begin{array}{l}\text { We reside in Maryland and my oldest daughter } \\
\text { Taygeta has a two hour commute by public bus } \\
\text { then metro to nursing vocational school and his } \\
\text { youngest daughter Capella has an hour van } \\
\text { commute from her private school in the evenings. } \\
\text { Both miss early morning sleep time. }\end{array}$ \\
\hline North Carolina & Shashvina & $\begin{array}{l}\text { We reside in North Carolina and my children } \\
\text { Kastra and Lucida have a two hour commute } \\
\text { involving both a bus and a ferry. This is stressful } \\
\text { on kids to travel so far back and forth to school as } \\
\text { well as miss early morning hours of sleep. }\end{array}$ \\
\hline Virginia & Alya & $\begin{array}{l}\text { My daughter Vindemiatrix has a two hour bus } \\
\text { commute to her special performing arts school as } \\
\text { there is only one bus offered for children in } \\
\text { multiple regions here in Virginia who attend this } \\
\text { school. She has to wake up extra early for school. }\end{array}$ \\
\hline West Virginia & Kirithiga & $\begin{array}{l}\text { Schools in West Virginia have consolidated and } \\
\text { kids are having to commute as much as two hours } \\
\text { through the mountains from their home to the } \\
\text { consolidated school. Even though the school } \\
\text { systems are saving money, the long bus commutes } \\
\text { seem to take away from morning sleep for kids. }\end{array}$ \\
\hline
\end{tabular}


Appendix X: Alignment Matrix of Findings

\begin{tabular}{|c|c|c|c|}
\hline Theory & $\begin{array}{l}\text { Research } \\
\text { questions }\end{array}$ & Interview questions & Key findings \\
\hline SLT & $\begin{array}{l}\text { RQ1: } \\
\text { What } \\
\text { strategies do } \\
\text { parents use to } \\
\text { recognize } \\
\text { potential } \\
\text { unhealthy } \\
\text { sleep habits in } \\
\text { adolescents? }\end{array}$ & $\begin{array}{l}\text { - IQ1: What parental strategies have } \\
\text { you used that you perceive to be the } \\
\text { most effective, related to your } \\
\text { children's sleep habits? } \\
\text { - IQ2: What, if any difficulties have } \\
\text { you experienced as a parent with your } \\
\text { child(ren)'s sleep habits? } \\
\text { - IQ3: What, if any behaviors have you } \\
\text { noticed with your child(ren) that may } \\
\text { possibly be related to sleep habits? } \\
\text { - IQ4: Please elaborate upon how the } \\
\text { following relate toward your } \\
\text { perceptions of learning about better } \\
\text { sleep habits for your child(ren): (a) } \\
\text { Interaction, (b) Observation, (c) } \\
\text { Influence, and (d) Monitoring }\end{array}$ & $\begin{array}{l}\text { - Attitude } \\
\text { - Breakfast } \\
\text { - Consistency } \\
\text { - Daily behaviors } \\
\text { - Electronic } \\
\text { devices } \\
\text { - Family meetings } \\
\text { - House rules } \\
\text { - Lights off } \\
\text { - Safety } \\
\text { - Schedule bed } \\
\text { times } \\
\text { - Transportation }\end{array}$ \\
\hline AP & $\begin{array}{l}\text { RQ2: What } \\
\text { knowledge do } \\
\text { parents obtain } \\
\text { to promote } \\
\text { better daily } \\
\text { behaviors for } \\
\text { sleep health } \\
\text { habits in } \\
\text { adolescents? }\end{array}$ & $\begin{array}{l}\text { - IQ5: How, if at all did you develop } \\
\text { knowledge as a parent about promoting } \\
\text { better sleep health habits to your } \\
\text { child(ren)? } \\
\text { - IQ6: Can you provide some examples } \\
\text { of your child(ren)'s daily routine(s) that } \\
\text { are a result of unhealthy sleep habits? } \\
\text { - IQ7: In your opinion, what do you } \\
\text { believe are specific recommendations } \\
\text { for promoting better sleep habits to your } \\
\text { child(ren) and awareness of the effects } \\
\text { on their daily activities? } \\
\text { - IQ8: Please elaborate upon how the } \\
\text { following relate toward your } \\
\text { perceptions of advocacy to promote } \\
\text { better sleep habits for your child(ren): } \\
\text { (a) Promote, (b) Communicate, (c) } \\
\text { Inform, (d) Educate }\end{array}$ & $\begin{array}{l}\text { - Academia } \\
\text { - Attitude } \\
\text { - Communication } \\
\text { - Consistency } \\
\text { - Daily Behaviors } \\
\text { - Electronic } \\
\text { devices } \\
\text { - Parental } \\
\text { influence } \\
\text { - Schedule bed } \\
\text { times } \\
\text { - Sleep awareness } \\
\text { - Sleep diaries } \\
\text { - Sleep education }\end{array}$ \\
\hline RRTS & $\begin{array}{l}\text { RQ3: Which } \\
\text { conditions and } \\
\text { behaviors do } \\
\text { parents } \\
\text { consult health } \\
\text { professionals } \\
\text { for sleep }\end{array}$ & $\begin{array}{l}\text { - IQ9: Please provide some specific } \\
\text { examples of conditions and behaviors of } \\
\text { your child(ren) that you perceive as } \\
\text { poor sleep health habits as a concern to } \\
\text { explore with health professionals. } \\
\text { - IQ10: What strategies would you } \\
\text { recommend to recognize conditions or }\end{array}$ & $\begin{array}{l}\text { - Academia } \\
\text { - Attitude } \\
\text { - Electronic } \\
\text { devices } \\
\text { - Health impacts } \\
\text { - Routines } \\
\text { - Sports }\end{array}$ \\
\hline
\end{tabular}




\begin{tabular}{|c|c|c|}
\hline $\begin{array}{l}\text { problems in } \\
\text { adolescents? }\end{array}$ & $\begin{array}{l}\text { behaviors associated with poor sleep } \\
\text { habits among your child(ren)? } \\
\text { - IQ11: What are the outcomes for } \\
\text { repair and restoration when consulting } \\
\text { with health professionals to reduce } \\
\text { health problems of your child(ren)? } \\
\text {-IQ12: Please elaborate upon how the } \\
\text { following relate toward your } \\
\text { perceptions for the purpose of sleep for } \\
\text { your child(ren): (a) Repair and (b) } \\
\text { Restoration }\end{array}$ & - 8-10 hours sleep \\
\hline $\begin{array}{l}\text { RQ1, RQ2, } \\
\text { and RQ3 }\end{array}$ & $\begin{array}{l}\text { - IQ13: Please elaborate upon how the } \\
\text { following relate toward your viewpoint } \\
\text { of caring about the sleep habits of your } \\
\text { child(ren): (a) Value, (b) Honor, (c) } \\
\text { Nurture, (d) Trust, (e) Health, (f) Care, } \\
\text { (g) Teach, (h) Restore, (i) Needs, and (j) } \\
\text { Heal }\end{array}$ & $\begin{array}{l}\text { - Academia } \\
\text { - Activities } \\
\text { - Better health } \\
\text { - Consistency } \\
\text { - Environment } \\
\text { - Health } \\
\text { professionals } \\
\text { - Mental activities } \\
\text { - Physical } \\
\text { performance } \\
\text { - Routines } \\
\text { - Sports } \\
\text { - Sleep patterns }\end{array}$ \\
\hline
\end{tabular}

